NBER WORKING PAPER SERIES

WHEN IS MARKET INCOMPLETENESS IRRELEVANT FOR THE PRICE OF AGGREGATE RISK (AND WHEN IS IT NOT)?

\author{
Dirk Krueger \\ Hanno Lustig \\ Working Paper 12634 \\ http://www.nber.org/papers/w12634
NATIONAL BUREAU OF ECONOMIC RESEARCH
1050 Massachusetts Avenue
Cambridge, MA 02138
October 2006

We would like to thank Andy Atkeson, John Campbell, Nicolae Garleanu, John Heaton, Francis Longstaff, Narayana Kocherlakota, Per Krusell, Victor Rios-Rull, Kjetil Storesletten, Dimitry Vayanos, the Wharton and UCLA macro lunch participants and seminar participants at UCLA Anderson, Duke University, UC Irvine, NYU Stern, Princeton, the University of Wisconsin, SUNY Stonybrook, the UC Santa Barbara Conference on Risk Sharing and the AP sessions of the NBER Summer Institute for comments and the NSF for financial support. The editor, Christian Hellwig, and two referees, as well as Dave Backus, Hal Cole, Stijn Van Nieuwerburgh, Pierre-Olivier Weill and Stan Zin provided exceptionally detailed and helpful comments. All remaining errors are our own.

(C) 2006 by Dirk Krueger and Hanno Lustig. All rights reserved. Short sections of text, not to exceed two paragraphs, may be quoted without explicit permission provided that full credit, including (C notice, is given to the source. 
When is Market Incompleteness Irrelevant for the Price of Aggregate Risk (and when is it not)?

Dirk Krueger and Hanno Lustig

NBER Working Paper No. 12634

October 2006, Revised July 2009

JEL No. E21,E44,G0

\begin{abstract}
In a standard incomplete markets model with a continuum of households that have constant relative risk aversion (CRRA) preferences, the absence of insurance markets for idiosyncratic labor income risk has no effect on the premium for aggregate risk if the distribution of idiosyncratic risk is independent of aggregate shocks and aggregate consumption growth is independent over time. In the equilibrium, which features trade and binding solvency constraints, as opposed to Constantinides and Duffie (1996), households only use the stock market to smooth consumption; the bond market is inoperative. Furthermore we show that the cross-sectional wealth and consumption distributions are not affected by aggregate shocks. These results hold regardless of the persistence of idiosyncratic shocks, and arise even when households face tight solvency constraints, but only a weaker irrelevance result survives when we allow for predictability in aggregate consumption growth.
\end{abstract}

\author{
Dirk Krueger \\ Department of Economics \\ University of Pennsylvania \\ 3718 Locust Walk \\ Philadelphia, PA 19104 \\ and NBER \\ dkrueger@econ.upenn.edu \\ Hanno Lustig \\ UCLA Anderson School of Management \\ 110 Westwood Plaza, Suite C413 \\ Los Angeles, CA 90095-1481 \\ and NBER \\ hlustig@anderson.ucla.edu
}




\title{
When is Market Incompleteness Irrelevant for the Price of Aggregate Risk (and when is it not)? *
}

\author{
Dirk Krueger ${ }^{\dagger}$ \\ University of Pennsylvania, CEPR and NBER \\ Hanno Lustig $\ddagger$ \\ UCLA Anderson and NBER \\ July 15, 2009
}

\begin{abstract}
In a standard incomplete markets model with a continuum of households that have constant relative risk aversion (CRRA) preferences, the absence of insurance markets for idiosyncratic labor income risk has no effect on the premium for aggregate risk if the distribution of idiosyncratic risk is independent of aggregate shocks and aggregate consumption growth is independent over time. In the equilibrium, which features trade and binding solvency constraints, as opposed to Constantinides and Duffie (1996), households only use the stock market to smooth consumption; the bond market is inoperative. Furthermore we show that the cross-sectional wealth and consumption distributions are not affected by aggregate shocks. These results hold regardless of the persistence of idiosyncratic shocks, and arise even when households face tight solvency constraints, but only a weaker irrelevance result survives when we allow for predictability in aggregate consumption growth.
\end{abstract}

\section{Introduction}

This paper provides general conditions under which closing down insurance markets for idiosyncratic risk (our definition of market incompleteness) does not increase the risk premium that stocks

${ }^{*}$ We would like to thank Andy Atkeson, John Campbell, Nicolae Garleanu, John Heaton, Francis Longstaff, Narayana Kocherlakota, Per Krusell, Victor Rios-Rull, Kjetil Storesletten, Dimitry Vayanos, the Wharton and UCLA macro lunch participants and seminar participants at UCLA Anderson, Duke University, UC Irvine, NYU Stern, Princeton, the University of Wisconsin, SUNY Stonybrook, the UC Santa Barbara Conference on Risk Sharing and the AP sessions of the NBER Summer Institute for comments and the NSF for financial support. The editor, Christian Hellwig, and two referees, as well as Dave Backus, Hal Cole, Stijn Van Nieuwerburgh, Pierre-Olivier Weill and Stan Zin provided exceptionally detailed and helpful comments. All remaining errors are our own.

†email address: dkrueger@econ.upenn.edu.

$\ddagger$ email address: hlustig@anderson.ucla.edu 
command over bonds. We study a standard incomplete markets endowment economy populated by a continuum of agents who have CRRA preferences and who can trade a risk-free bond and a stock, subject to potentially binding solvency constraints. In the benchmark version of our model the growth rate of the aggregate endowment is uncorrelated over time, that is, the logarithm of aggregate income is a random walk. Under these assumptions, the presence of uninsurable idiosyncratic risk is shown to lower the equilibrium risk-free rate, but it has no effect on the price of aggregate risk in equilibrium if the distribution of idiosyncratic shocks is statistically independent of aggregate shocks. Consequently, in this class of models, the representative agent ConsumptionCAPM (CCAPM) developed by Rubinstein (1974), Breeden (1979) and Lucas (1978) prices the excess returns on the stock correctly. Therefore, as long as idiosyncratic shocks are distributed independently of aggregate shocks, the extent to which households manage to insure against idiosyncratic income risk as well as the tightness of the borrowing constraints they face are irrelevant for risk premia. These results deepen the equity premium puzzle, because we show that Mehra and Prescott's (1985) statement of the puzzle applies to a much larger class of incomplete market models 1 We also show that uninsurable income risk does not contribute to any variation in the conditional market price of risk.

While earlier work exploring autarchic equilibria by Constantinides and Duffie (1996) is suggestive of the irrelevance of idiosyncratic (consumption) risk, our work derives the exact conditions for irrelevance in non-autarchic equilibria for economies with standard labor income processes while allowing for binding borrowing constraints. We show that these conditions depend critically on the properties of aggregate consumption growth once trade of financial assets occurs in equilibrium.

The asset pricing implications of our model follow from a crucial result about equilibrium consumption and portfolio allocations. We show that in this class of incomplete market models with idiosyncratic and aggregate risk, the equilibrium allocations and prices can be obtained from the allocations and interest rates of an equilibrium in a stationary model with only idiosyncratic risk (as in Bewley (1986), Huggett (1993) or Aiyagari (1994)). Specifically, we demonstrate that scaling up the consumption allocation of the Bewley equilibrium by the aggregate endowment delivers an equilibrium for the model with aggregate risk. In this equilibrium, there is no trade in bond markets, only in stock markets. This result is the key to why the history of aggregate shocks has no bearing on equilibrium allocations and prices. Households in equilibrium only trade the stock (i.e. the market portfolio), regardless of their history of idiosyncratic shocks, even in the presence of binding solvency constraints. This invariance of the household's portfolio composition directly implies the irrelevance of the history of aggregate shocks for equilibrium prices and allocations.

This finding has several important consequences beyond the asset pricing irrelevance result. First, it implies that the wealth and consumption distribution in the model with aggregate risk

\footnotetext{
${ }^{1}$ Weil's (1989) statement of the risk-free rate puzzle, on the contrary, does not.
} 
(normalized by the aggregate endowment) coincides with the stationary wealth distribution of the Bewley equilibrium. Aggregate shocks therefore have no impact on these equilibrium distributions 2

In the Bewley model, due to the absence of aggregate risk, a bond and a stock have exactly the same return characteristics in equilibrium and thus one asset is redundant. Households need not use the bond to smooth consumption. This portfolio implication carries over to the model with aggregate risk: at equilibrium prices households do not need to trade the uncontingent bond and only use the stock, i.e. a claim to aggregate consumption, to transfer resources over time and to self-insure against idiosyncratic labor earnings risk. In equilibrium, all households bear the same share of aggregate risk and they all hold the same portfolio, regardless of their history of idiosyncratic shocks and the implied financial wealth holdings. Hence, this class of models does not generate any demand for bonds at the equilibrium interest rate, if bonds are in zero net supply 3

To interpret our portfolio result it is important to note that in the model, what we refer to as the stock is a claim to aggregate consumption. We show this is the only security households trade. However, if we take equity to be a levered claim to aggregate consumption, then households in our model effectively hold a fixed portfolio of corporate bonds and stocks. As is easy to verify, the proportion of corporate bonds in the portfolio is $2 / 3$ when corporate leverage is 2 . The remaining $1 / 3$ is in equities. A key implication of the equilibrium we derive is that all households choose not to deviate from these fixed proportions.

We also show that making markets more complete does not always lead to more consumption smoothing in equilibrium. In the benchmark model with i.i.d. aggregate endowment growth, allowing agents to trade claims on payoffs that are contingent on aggregate shocks, in addition to the risk-free bond and the stock, leaves their equilibrium consumption allocations unaltered. Agents still only trade the stock, and there are no effects of introducing these additional state contingent claims on interest rates and asset prices.

In our benchmark model, aggregate consumption growth is not predictable (that is, the growth rate of the aggregate endowment is i.i.d.). This is a standard assumption in the asset pricing literature (e.g. Campbell and Cochrane (1999)), because the empirical evidence for predictability is rather weak (see e.g. Heaton and Lucas (1996)). It is also a natural benchmark, because in this case all the dynamics in the conditional market price of risk, if any, comes from the model itself

\footnotetext{
${ }^{2}$ Since stationary equilibria in Bewley models are relatively straightforward to compute, our result implies an algorithm for computing equilibria in this class of models which appears to be simpler than the auctioneer algorithm devised by Lucas (1994) and its extension to economies with a continuum of agents. There is also no need for computing a law of motion for the aggregate wealth distribution, or approximating it by a finite number of moments, as in Krusell and Smith $(1997,1998)$. This result also implies the existence of a recursive competitive equilibrium with only asset holdings in the state space. Kubler and Schmedders (2002) establish the existence of such an equilibrium in more general models, but only under very strong conditions. Miao (2005) relaxes these conditions, but he includes continuation utilities in the state space.

${ }^{3}$ Of course, excluding some households from the stock market would force them to trade bonds for consumption smoothing purposes, invalidating the irrelevance result.
} 
rather than the exogenously specified aggregate consumption growth process. However, if there is predictability in aggregate income growth in our model, we show that agents want to hedge their portfolio against interest rate shocks, creating a role for trade in a richer menu of assets than just the stock. The risk premium irrelevance result, however, still applies as long as households can trade a full set of aggregate state-contingent claims, provided that solvency constraints do not bind in equilibrium. Therefore only a weaker form of our result survives when predictability in aggregate consumption growth is allowed for. In contrast, in the autarchic equilibria examined by Constantinides and Duffie (1996), their irrelevance result does not depend on the properties of aggregate consumption growth.

The key assumptions underlying our irrelevance result are (i) a continuum of agents, (ii) CRRA utility, (iii) idiosyncratic labor income risk that is independent of aggregate risk, (iv) a constant capital share of income and (v) solvency constraints or borrowing constraints on total financial wealth that are proportional to aggregate income. We now discuss each of these assumptions in detail to highlight and explain the differences with existing papers in the literature.

First, we require the economy to be populated by a continuum of agents. As forcefully pointed out by Denhaan (2001), in an economy with a finite number of agents, each idiosyncratic shock is by construction an aggregate shock because it changes the wealth distribution and, through these wealth effects, asset prices.

Second, our results rely on the homogeneity property of the CRRA utility function. Third, in our model labor income grows with the aggregate endowment, as is standard in this literature 4 In addition, for our results to go through, idiosyncratic income shocks must be distributed independently of aggregate shocks. This explicitly rules out that the variance of idiosyncratic shocks is higher in recessions (henceforth we refer to this type of correlation as countercyclical cross-sectional variance of labor income shocks, or $\mathrm{CCV}$ ).

Fourth, we require the assumption that the capital share of income is independent of the aggregate state of the economy. This assumption is standard in macroeconomics, and it is not obviously at odds with the data (see e.g. Cooley and Prescott (1995)).

Finally, in the main section of the paper, households face either constraints on total net wealth today or state-by-state solvency constraints on the value of their portfolio in each state tomorrow. These solvency constraints have to be proportional to aggregate income. If this were not the case, the tightness of the constraints would depend on the aggregate history of shocks, invalidating our map from equilibria of the Bewley model into equilibria of the model with stochastic aggregate endowment growth 5 Apart from the proportionality condition the solvency constraints we can

\footnotetext{
${ }^{4}$ By contrast, Weil (1992) derives a positive effect of background risk on the risk premium in a two-period model in which labor income is not proportional to the aggregate endowment. This non-homotheticity invalidates our mapping from the growing to the stationary economy.

${ }^{5}$ This assumption is less restrictive than it appears. Constraints arising from limited commitment, as e.g. in Alvarez and Jermann (2000) satisfy this restriction, as do the tight borrowing constraints used by Krusell and Smith
} 
permit are very general. Also note that in the case in which aggregate consumption growth is uncorrelated over time, we can allow for arbitrary separate constraints on the household bond positions, e.g. a short-sale constraint for bonds only. In the i.i.d. aggregate consumption growth case households choose only to trade the stock to smooth their consumption. Therefore, in this benchmark case, our result is also robust to the introduction of transaction costs in the bond market (but not to such costs in the stock market).

Our irrelevance result is robust along many empirically important dimensions. It does not hinge on mean-reversion in labor income as it also goes through in the case of permanent idiosyncratic shocks. If the idiosyncratic part of household income follows a logarithmic random walk, equilibria still feature trade in general. In fact, it is easy to show that in this case autarchy is an equilibrium if and only if all assets are in zero net supply, that is if and only if there is no net wealth in the economy. Constantinides and Duffie (henceforth CD) (1996) also consider an environment in which agents face only permanent idiosyncratic income shocks and in which they can trade stocks and bonds. They choose a (somewhat non-standard) stochastic household income process where household labor income depends on aggregate dividends that delivers an autarchic equilibrium even in the case of positive net wealth. CD's results also imply that if the cross-sectional variance of consumption growth is orthogonal to returns, then the equilibrium risk premium is equal to the one in the representative agent model. We show that this characterization of the household consumption process is indeed the correct one in equilibrium in a large class of incomplete market models with standard household labor income processes, including those with permanent idiosyncratic shocks 6 Relative to CD, our paper adds potentially binding solvency or borrowing constraints. Moreover, our equilibrium does feature trade in financial markets, and we do not make any assumptions about the distribution of the underlying idiosyncratic shocks. The consumption growth distribution across households in our model is the endogenous, equilibrium outcome of these trades, but we can still fully characterize equilibrium asset prices 7

However, we also show that only a weaker irrelevance result survives when we allow for predictability (serial correlation) in aggregate consumption growth, because different households have different hedging demands to insure against interest rate shocks and the hedging demands give rise to trade in the contingent bond markets. In CD's autarchic equilibrium, idiosyncratic risk is not priced regardless of the properties of aggregate consumption growth. So, introducing equilibrium trade does matter. This is also means that contingent (on aggregate shocks) claims markets

\footnotetext{
(1997) and may others.

${ }^{6}$ Krebs (2006) derives the same result in a production economy with human capital accumulation.

${ }^{7}$ In a separate class of continuous-time diffusion models, Grossman and Shiller (1982) have demonstrated that idiosyncratic risk has no effect on risk premia, simply because the cross-sectional variance of consumption growth is locally deterministic. Our irrelevance result is obtained in a different class of discrete-time incomplete market models in which uninsurable idiosyncratic background risk does potentially matter, as shown by Mankiw (1986), CD (1996) and others.
} 
are needed and borrowing constraints cannot bind in order to obtain aggregation in models with long-run risk, like the one considered by Bansal and Yaron (2004).

Finally, the irrelevance result survives cyclicality in the aggregate capital share and preference heterogeneity, but only in special cases. In the case of stochastic variation in the capital share households can keep their consumption in line with aggregate consumption by taking positions in the contingent bond market, but only if the variation in the aggregate labor income share does not lead to variation in the distribution of idiosyncratic labor income shocks and activate the CCV mechanism. If this condition is satisfied, the irrelevance result survives. In the case of preference heterogeneity, a weaker version of the irrelevance result remains valid if less risk averse households have labor income that is more exposed to aggregate risk. In both cases, trade in a richer menu of assets that include aggregate state-contingent claims is required.

We characterize equilibria in the model with aggregate risk that are derived from Bewley equilibria 8 by scaling allocations by the aggregate endowment. While we cannot formally rule out the existence of other types of equilibria, we conjecture that the equilibria that we characterize are the only ones. Moreover, since we have derived at least one class of equilibria in which market incompleteness has no bearing on risk premia, it seems hard to argue that this class of models robustly generates larger risk premia than the representative agent model. Finally, we also demonstrate that the irrelevance result continues to hold even when we allow for endogenous labor supply decisions and production.

Related Literature In the quest towards the resolution of the equity premium puzzle identified by Hansen and Singleton (1983) and Mehra and Prescott (1985), uninsurable idiosyncratic income risk has been introduced into standard dynamic general equilibrium models 9 Incomplete insurance of household consumption against idiosyncratic income risk was introduced into quantitative asset pricing models by Telmer (1993), Lucas (1994), Heaton and Lucas (1996), Marcet and Singleton (1999) and others. Their main result, derived numerically for various parameterizations, can be summarized as suggesting that the impact of uninsurable labor income risk per se has only small effects on the equity premium. The main contribution of our paper is to establish theoretically that, under a set of fairly general conditions spelled out above and further discussed below 10 , adding uninsurable idiosyncratic income risk to the standard consumption based asset pricing model does not alter the asset pricing implications of the model with respect to excess returns at

\footnotetext{
${ }^{8}$ For our equivalence and asset pricing results there is no need to assume or show that the Bewley equilibrium is unique. Thus our results imply that there is at least one equilibrium in the incomplete markets model with idiosyncratic and aggregate risk that has the same market price of risk as the standard representative agent model.

${ }^{9}$ For examples, see the work of Ayiagari and Gertler (1991), Telmer (1993), Lucas (1994), Heaton and Lucas (1996), Krusell and Smith (1998), and Marcet and Singleton (1999). Also see Kocherlakota (1996) for an overview of this literature.

${ }^{10}$ Evidently in all quantitative papers cited above at least one of the assumptions we make is relaxed.
} 
all. Our theoretical result holds regardless of how tight the solvency constraints are, how persistent the income process is and how much agents discount the future. It is therefore independent of the degree of consumption smoothing that can be achieved by households that face idiosyncratic income shocks. In equilibrium, all households bear the same amount of aggregate risk, and accordingly, they are only compensated in equilibrium for the aggregate consumption growth risk they take on by investing in stocks.

Most of the work on incomplete markets and risk premia focuses on the moments of modelgenerated data for particular calibrations of the model, but there are few general theoretical results. Levine and Zame (2002) show that in economies populated by agents with infinite horizons, the equilibrium allocations converge in the limit, as their discount factors approach one, to the complete markets allocations. Consequently, the pricing implications of the incomplete markets model converge to that of the representative agent model as households become perfectly patient. We provide a qualitatively similar equivalence result that applies only to the risk premium. Our result, however, does not depend on the time discount factor of households. For households with CARA utility, closed form solutions of the individual decision problem in incomplete markets models with idiosyncratic risk are sometimes available, as Willen (1999) shows 11 In contrast to Willen, we employ CRRA preferences, and we obtain an unambiguous (and negative) result for the impact of uninsurable income risk for the equity premium in case the distribution of individual income shocks is independent of aggregate shocks.

There is a large empirical literature that documents a strong correlation in the data between financial wealth and equity holdings (see e.g. Campbell (2006)). We show analytically that the history of a household's idiosyncratic shocks and hence their financial wealth has no bearing on their portfolio choice in a large class of incomplete markets models.

The result of our paper that equilibria in the model with aggregate risk can be obtained from equilibria of the stationary Bewley model also makes contact with the literature on aggregation. Constantinides (1982), building on work by Negishi (1960) and Wilson (1968), derives an aggregation result for heterogenous agents in complete market models, implying that assets can be priced off the intertemporal marginal rate of substitution of an agent who consumes the aggregate endowment. Rubinstein (1974) obtains an aggregation result without assuming complete markets, but he does not allow for non-traded assets such as risky labor income. Our findings extend these aggregation results to a large class of incomplete market models with idiosyncratic income shocks, but the result only applies to excess returns. Alvarez and Jermann (2000, 2001) derive a similar result, but they consider a different trading arrangement; in the AJ-model, agents trade a complete menu of assets subject to binding solvency constraints. Instead, the focus of our paper is on what happens when exactly these markets for idiosyncratic risk are shut down.

\footnotetext{
${ }^{11}$ CARA utility eliminates wealth effects which crucially simplifies the analysis. Angeletos and Calvet (2006) examine the private equity premium in an environment with idiosyncratic risk and agents with CARA utility.
} 
Roadmap The paper is structured as follows. In section 2, we lay out the physical environment of our model. Before analyzing the infinite horizon economy, section 3 considers a two-period example, to develop some intuition for our main results in a version of the model that permits a full analytical solution. Section 4 then analyzes the general infinite horizon model. This section demonstrates how to transform a model where aggregate income grows stochastically into a stationary model with a constant aggregate endowment. In subsection 4.1 we study this stationary model, called the Bewley model henceforth. The next section, subsection 4.2, introduces the Arrow model, a model with aggregate uncertainty and a full set of Arrow securities whose payoffs are contingent on the realization of the aggregate shock. We show that any equilibrium of the Bewley model can be mapped into an equilibrium of the Arrow model just by scaling up allocations by the aggregate endowment. In subsection 4.3 we derive the same result for a model where only a one-period risk-free bond and the stock can be traded. We call this the Bond model. Section 5 shows that risk premia in the representative agent Breeden-Lucas $(B L)$ model and the Arrow model (and by implication, in the Bond model) coincide. Section 6 investigates the robustness of our results with respect to the assumptions about the underlying stochastic income process, and shows in particular that most of our results can be extended to the case in which the aggregate shocks are correlated over time and to the case of permanent household income shocks. We also explains how cyclicality in the capital income share weakens our result. Finally, section 7 concludes; all proofs are contained in the appendix.

\section{Environment}

Our exchange economy is populated by a continuum of individuals of measure 1 . There is a single nonstorable consumption good. The aggregate endowment of this good is stochastic. Each individual's endowment depends, in addition to the aggregate shock, also on the realization of an idiosyncratic shock. Thus, the model we study is identical to the one described by Lucas (1994), except that ours is populated by a continuum of agents (as in Bewley (1986), Aiyagari and Gertler (1991), Huggett (1993) and Aiyagari (1994)), instead of just two agents.

\section{$2.1 \quad$ Representation of Uncertainty}

We denote the current aggregate shock by $z_{t} \in Z$ and the current idiosyncratic shock by $y_{t} \in Y$. For simplicity, both $Z$ and $Y$ are assumed to be finite. Furthermore, let $z^{t}=\left(z_{0}, \ldots, z_{t}\right)$ and $y^{t}=\left(y_{0}, \ldots, y_{t}\right)$ denote the history of aggregate and idiosyncratic shocks. As shorthand notation, we use $s_{t}=\left(y_{t}, z_{t}\right)$ and $s^{t}=\left(y^{t}, z^{t}\right)$. We let the economy start at an initial aggregate node $z_{0}$. Conditional on an idiosyncratic shock $y_{0}$ and thus $s_{0}=\left(y_{0}, z_{0}\right)$, the probability of a history $s^{t}$ is given by $\pi_{t}\left(s^{t} \mid s_{0}\right)$. We assume that shocks follow a first order Markov process with transition 
probabilities given by $\pi\left(s^{\prime} \mid s\right)$.

\subsection{Preferences and Endowments}

Consumers rank stochastic consumption streams $\left\{c_{t}\left(s^{t}\right)\right\}$ according to the following homothetic utility function:

$$
U(c)\left(s_{0}\right)=\sum_{t=0}^{\infty} \sum_{s^{t} \geq s^{0}} \beta^{t} \pi\left(s^{t} \mid s_{0}\right){\frac{c_{t}\left(s^{t}\right)}{1-\gamma}}^{1-\gamma},
$$

where $\gamma>0$ is the coefficient of relative risk aversion and $\beta \in(0,1)$ is the constant time discount factor. We define $U(c)\left(s^{t}\right)$ to be the continuation expected lifetime utility from a consumption allocation $c=\left\{c_{t}\left(s^{t}\right)\right\}$ in node $s^{t}$. This utility can be constructed recursively as follows:

$$
U(c)\left(s^{t}\right)=u\left(c_{t}\left(s^{t}\right)\right)+\beta \sum_{s_{t+1}} \pi\left(s_{t+1} \mid s_{t}\right) U(c)\left(s^{t}, s_{t+1}\right)
$$

where we made use of the Markov property the underlying stochastic processes. The economy's aggregate endowment process $\left\{e_{t}\right\}$ depends only on the aggregate event history; we let $e_{t}\left(z^{t}\right)$ denote the aggregate endowment at node $z^{t}$. Each agent draws a 'labor income' share $\eta\left(y_{t}, z_{t}\right)$, as a fraction of the aggregate endowment in each period. Her labor income share only depends on the current individual and aggregate event. We denote the resulting individual labor income process by $\left\{\eta_{t}\right\}$, with

$$
\eta_{t}\left(s^{t}\right)=\left(1-\alpha\left(z_{t}\right)\right) \eta\left(y_{t}, z_{t}\right) e_{t}\left(z^{t}\right)
$$

where $s^{t}=\left(s^{t-1}, y_{t}, z_{t}\right)$. We assume that $\eta\left(y_{t}, z_{t}\right)>0$ in all states of the world. The stochastic growth rate of the endowment of the economy is denoted by $\lambda\left(z^{t+1}\right)=e_{t+1}\left(z^{t+1}\right) / e_{t}\left(z^{t}\right)$. We assume that aggregate endowment growth only depends on the current aggregate state.

Condition 2.1. Aggregate endowment growth is a function of the current aggregate shock only:

$$
\lambda\left(z^{t+1}\right)=\lambda\left(z_{t+1}\right)
$$

Furthermore, we assume that a Law of Large Numbers hold 12 , so that $\pi\left(s^{t} \mid s_{0}\right)$ is not only a household's individual probability of receiving income $\eta_{t}\left(s^{t}\right)$, but also the fraction of the population receiving that income.

In addition to labor income, there is a Lucas tree that yields a share $\alpha(z)$ of the total aggregate endowment as capital income, so that the total dividends of the tree are given by $\alpha\left(z_{t}\right) e_{t}\left(z^{t}\right)$ in each period. The remaining fraction of the total endowment accrues to individuals as labor income, so

\footnotetext{
${ }^{12}$ See e.g. Hammond and Sun (2003) for conditions under which a LLN holds with a continuum of random variables.
} 
that $1-\alpha(z)$ denotes the labor income share. Therefore, by construction, the labor shares sum to one:

$$
\sum_{y_{t} \in Y} \Pi_{z_{t}}\left(y_{t}\right) \eta\left(y_{t}, z_{t}\right)=1
$$

for all $z_{t}$, where $\Pi_{z_{t}}\left(y_{t}\right)$ represents the cross-sectional distribution of idiosyncratic shocks $y_{t}$, conditional on the aggregate shock $z_{t}$. By the law of large numbers, the fraction of agents who draw

$y$ in state $z$ only depends on $z 13$ At time 0 , the agents are endowed with initial wealth $\theta_{0}$. This wealth represents the value of an agent's share of the Lucas tree producing the dividend flow in units of time 0 consumption, as well as the value of her labor endowment at date 0 . We use $\Theta_{0}$ to denote the initial joint distribution of wealth and idiosyncratic shocks $\left(\theta_{0}, y_{0}\right)$.

This concludes our description of the physical environment. We start our analysis by studying a two-period example of our model in which prices and allocations can be characterized analytically to develop some intuition for the irrelevance result, when it holds and when it breaks down. We use the model to illustrate the importance of the conditions that we have listed as sufficient for our result: (i) a continuum of agents, (ii) CRRA utility, (iii) idiosyncratic labor income risk that is independent of aggregate risk, (iv) a constant capital share of income and (v) solvency constraints or borrowing constraints on total financial wealth that are proportional to aggregate income.

\section{A Two Period Example}

We consider a simple example in which the economy only lasts for two periods, $t=0,1$, and there are only two possible realizations of the aggregate state. In the first period, there is no uncertainty and the initial aggregate state of the economy is fixed at $z_{0} \in Z=\left\{z_{l}, z_{h}\right\}$. There is no heterogeneity in initial endowments or income realizations among agents in period 0 . In the second period, an aggregate shock is realized $z_{1} \in Z=\left\{z_{l}, z_{h}\right\}$ with $z_{1} \sim \phi\left(z_{1} \mid z_{0}\right)$, as well as an idiosyncratic shock $y_{1} \in Y$, with $y_{1} \sim \pi\left(y_{1} \mid z_{1}\right)$. We use the following notation: $z^{1}=\left(z_{0}, z_{1}\right)$ and $s^{1}=\left(s_{0}, s_{1}\right)$ with $s_{0}=z_{1}$ and $s_{1}=\left(y_{1}, z_{1}\right)$. Initial shares in the Lucas tree are given by $\sigma_{-1}=1$ for all households; initial financial assets excluding shares in the Lucas tree are given by $a_{-1}=0$.

The aggregate endowment in period $0, e_{0}\left(z_{0}\right)$, is not subject to randomness, but the aggregate endowment in period 1 depends on the realization of the aggregate shock: $e_{1}\left(z^{1}\right)=e_{0}\left(z_{0}\right) \lambda\left(z_{1}\right)$. In period 1 , the Lucas tree yields a fraction $\alpha\left(z_{1}\right)$ of the aggregate endowment in the form of dividends, the remainder, $1-\alpha\left(z_{1}\right)$ consists of labor income. The individual labor endowments in

\footnotetext{
${ }^{13}$ Our setup nests the baseline model of Heaton and Lucas (1996), except for the fact that they allow for the capital share $\alpha$ to depend on $z$.
} 
the first and second period are given by:

$$
\begin{aligned}
& \eta_{0}\left(s_{0}\right)=\left(1-\alpha\left(z_{0}\right)\right) e_{0}\left(z_{0}\right) \\
& \eta_{1}\left(s^{1}\right)=\left(1-\alpha\left(z_{1}\right)\right) \eta\left(y_{1}, z_{1}\right) e_{0}\left(z_{0}\right) \lambda\left(z_{1}\right) .
\end{aligned}
$$

Household Problem In our baseline model (we will refer to this as the Arrow model), households trade two different contingent bonds with payoffs contingent on the two aggregate shocks as well as shares in the Lucas tree. Here, households trade a full set of Arrow securities against aggregate risk, but not against idiosyncratic risk. We use $a_{0}\left(s_{0}, z_{1}\right)$ to denote the holdings of bond that pays off one unit of consumption if $z_{1}$ is realized and we use $q_{0}\left(z_{0}, z_{1}\right)$ to denote the price of this security. We refer to these as Arrow prices. The household chooses a consumption allocation $\left\{c_{0}\left(\theta_{0}, s_{0}\right), c_{1}\left(\theta_{0}, s^{1}\right)\right\}$, contingent bond positions $\left\{a_{0}\left(\theta_{0}, s_{0}, z_{1}=z_{l}\right), a_{0}\left(\theta_{0}, s_{0}, z_{1}=z_{h}\right)\right\}$ and shares in the Lucas tree $\sigma_{0}$ to maximize its expected utility (where for simplicity we have abstracted from time discounting):

$$
\max \left\{u\left(c_{0}\left(\theta_{0}, s_{0}\right)\right)+\sum_{z_{1} \in Z} \sum_{y_{1} \in Y} \pi\left(y_{1} \mid z_{1}\right) \phi\left(z_{1} \mid z_{0}\right) u\left(\theta_{0}, c_{1}\left(s^{1}\right)\right)\right\}
$$

subject to the budget constraint in period 0 :

$$
c_{0}\left(\theta_{0}, s_{0}\right)+\sum_{z_{1}} a_{0}\left(\theta_{0}, s_{0}, z_{1}\right) q_{0}\left(z_{0}, z_{1}\right)+\sigma_{0}\left(\theta_{0}, s_{0}\right) v_{0}\left(z_{0}\right)=\theta_{0}\left(s_{0}\right)
$$

and the budget constraint in period 1 :

$$
c_{1}\left(\theta_{0}, s^{1}\right) \equiv \eta\left(s^{1}\right)+a_{0}\left(\theta_{0}, s_{0}, z_{1}\right)+\sigma_{0}\left(\theta_{0}, s_{0}\right) \alpha e_{1}\left(z^{1}\right) .
$$

The market clearing conditions for stock markets, contingent bond markets and goods markets are straightforward:

$$
\begin{aligned}
\int \sigma_{0}\left(\theta_{0}, s_{0}\right) d \Theta_{0} & =1 \\
\int a_{0}\left(\theta_{0}, s_{0}, z_{1}\right) d \Theta_{0} & =0 \text { for all } z_{1} \\
\int c_{0}\left(\theta_{0}, s_{0}\right) d \Theta_{0} & =e_{0}\left(z_{0}\right) \\
\int \sum_{y_{1} \in Y} c_{1}\left(\theta_{0}, s^{1}\right) \pi\left(y_{1} \mid z_{1}\right) d \Theta_{0} & =e_{1}\left(z_{1}\right) \text { for all } z_{1}
\end{aligned}
$$


In the remainder, we leave out the obvious dependence on initial wealth $\theta_{0}$, which is trivial in this example since there is no heterogeneity across households in $\theta_{0}$.

\subsection{Irrelevance Result}

In this example the equilibrium features no trade, as in Constantinides and Duffie (1996); note that this will not be the case in our general model in the remainder of the paper. In equilibrium all households simply hold on to their initial shares in the Lucas tree $\left(\sigma_{0}\left(s_{0}\right)=1\right)$, and contingent bond markets are inoperative $\left(a_{0}\left(s_{0}, z_{1}\right)=0\right.$ for all $\left.z_{1}\right)$. In the first period, households consume the average endowment $c_{0}\left(s_{0}\right)=e_{0}\left(z_{0}\right)$, and in the second period they consume $c_{1}\left(s^{1}\right)=\left[\left(1-\alpha\left(z_{1}\right)\right) \eta\left(y_{1}, z_{1}\right)+\alpha\left(z_{1}\right)\right] e_{1}\left(z^{1}\right)$ for all $z_{1}$.

In this no-trade equilibrium, we can analytically characterize the ratio of the Arrow prices $\frac{q_{0}\left(z_{0}, z_{h}\right)}{q_{0}\left(z_{0}, z_{l}\right)}$ in the two different aggregate states. We use $m\left(c_{1}\left(s^{1}\right), c_{0}\left(s_{0}\right)\right)=\frac{u^{\prime}\left(c_{1}\left(s^{1}\right)\right)}{u^{\prime}\left(c_{0}\left(s_{0}\right)\right)}$ to denote the household's intertemporal marginal rate of substitution (MRS henceforth) as a function of consumption in the first and second period.

Proposition 3.1. There exists a no-trade equilibrium of the two-period economy without trade in the contingent bond and stock markets. The ratio of the prices of the Arrow securities in the two aggregate states in period 1 is given by:

$$
\frac{q_{0}\left(z_{0}, z_{h}\right)}{q_{0}\left(z_{0}, z_{l}\right)}=\frac{\phi\left(z_{h} \mid z_{0}\right)}{\phi\left(z_{l} \mid z_{0}\right)} * \frac{\sum_{y_{1}} \pi\left(y_{1} \mid z_{h}\right) m\left(\left[\left(1-\alpha\left(z_{h}\right)\right) \eta\left(y_{1}, z_{h}\right)+\alpha\left(z_{h}\right)\right] \lambda\left(z_{h}\right) e_{0}\left(z_{0}\right), e_{0}\left(z_{0}\right)\right)}{\sum_{y_{1}} \pi\left(y_{1} \mid z_{l}\right) m\left(\left[\left(1-\alpha\left(z_{l}\right)\right) \eta\left(y_{1}, z_{l}\right)+\alpha\left(z_{l}\right)\right] \lambda\left(z_{l}\right) e_{0}\left(z_{0}\right), e_{0}\left(z_{0}\right)\right)}
$$

In this equilibrium, all households choose the same exposure to aggregate consumption growth risk by holding one share in the Lucas tree and no contingent bonds. The key to the irrelevance result that idiosyncratic risk does not affect risk premia is that the ratio of Arrow prices in the two aggregate states is the same in the representative agent model and the model with idiosyncratic risk. This being the case, market incompleteness only raises the price of a unit of consumption by the same amount in the good and the bad aggregate state, but it does not change the premium for bearing aggregate risk. In the representative agent model the ratio of state prices is given by:

$$
\frac{q_{0}^{R E}\left(z_{0}, z_{h}\right)}{q_{0}^{R E}\left(z_{0}, z_{l}\right)}=\frac{\phi\left(z_{h} \mid z_{0}\right)}{\phi\left(z_{l} \mid z_{0}\right)} * \frac{m\left(\lambda\left(z_{h}\right) e_{0}\left(z_{0}\right), e_{0}\left(z_{0}\right)\right)}{m\left(\lambda\left(z_{l}\right) e_{0}\left(z_{0}\right), e_{0}\left(z_{0}\right)\right)}
$$

Hence, by comparing this expression with the incomplete markets analogue in equation (4), it becomes apparent that the necessary and sufficient condition for irrelevance is given by:

$$
\frac{m\left(\lambda\left(z_{h}\right) e_{0}\left(z_{0}\right), e_{0}\left(z_{0}\right)\right)}{m\left(\lambda\left(z_{l}\right) e_{0}\left(z_{0}\right), e_{0}\left(z_{0}\right)\right)}=\frac{\sum_{y_{1}} \pi\left(y_{1} \mid z_{h}\right) m\left(\left[\left(1-\alpha\left(z_{h}\right)\right) \eta\left(y_{1}, z_{h}\right)+\alpha\left(z_{h}\right)\right] \lambda\left(z_{h}\right) e_{0}\left(z_{0}\right), e_{0}\left(z_{0}\right)\right)}{\sum_{y_{1}} \pi\left(y_{1} \mid z_{l}\right) m\left(\left[\left(1-\alpha\left(z_{l}\right)\right) \eta\left(y_{1}, z_{l}\right)+\alpha\left(z_{l}\right)\right] \lambda\left(z_{l}\right) e_{0}\left(z_{0}\right), e_{0}\left(z_{0}\right)\right)} .
$$


Three conditions need to be satisfied in order to enforce this equality :

1. homogeneity of the period utility function: the CRRA utility function is homogeneous of degree $1-\gamma$

2. independence of idiosyncratic shocks and aggregate shocks: this rules out CCV (counter-cyclical cross-sectional variance of income shocks)

3. constant capital income share

When independence (condition 2) is satisfied and when the capital income share is constant (condition 3), household consumption in the second period is proportional to the aggregate endowment $\left(c_{1}\left(s^{1}\right)=\left[(1-\alpha) \eta\left(y_{1}\right)+\alpha\right] e_{1}\left(z^{1}\right)\right)$, and the constant of proportionality does not depend on the aggregate shock, only the idiosyncratic shock. As a result, the ratio of state prices in the incomplete markets economy simplifies to:

$$
\frac{\sum_{y_{1}} \pi\left(y_{1}\right) m\left(\left[(1-\alpha) \eta\left(y_{1}\right)+\alpha\right] \lambda\left(z_{h}\right) e_{0}\left(z_{0}\right), e_{0}\left(z_{0}\right)\right)}{\sum_{y_{1}} \pi\left(y_{1}\right) m\left(\left[(1-\alpha) \eta\left(y_{1}\right)+\alpha\right] \lambda\left(z_{l}\right) e_{0}\left(z_{0}\right), e_{0}\left(z_{0}\right)\right)}
$$

but we still cannot separate the idiosyncratic shocks $y_{1}$ from the aggregate shocks $z_{1} \in\left\{z_{l}, z_{h}\right\}$. To do that, we need homogeneity of the utility function (condition 1). Since $u$ is homogeneous of degree $1-\gamma$, it follows that the lifetime utility function is homogeneous of degree $1-\gamma$ and therefore also homothetic 14 Furthermore it follows that marginal utility $u^{\prime}$ is homogeneous of degree $-\gamma$.

From the homotheticity of the lifetime utility function and the homogeneity of degree $-\gamma$ of the marginal utility function it follows that the ratio of state prices in the representative agent economy, the left hand side of equation (5) can be written as

$$
\frac{m\left(\lambda\left(z_{h}\right) e_{0}\left(z_{0}\right), e_{0}\left(z_{0}\right)\right)}{m\left(\lambda\left(z_{l}\right) e_{0}\left(z_{0}\right), e_{0}\left(z_{0}\right)\right)}=\frac{m\left(\lambda\left(z_{h}\right), 1\right)}{m\left(\lambda\left(z_{l}\right), 1\right)}=\left(\frac{\lambda\left(z_{h}\right)}{\lambda\left(z_{l}\right)}\right)^{-\gamma}
$$

Similarly, given the same properties, the ratio of state prices in the incomplete markets economy simplifies to:

$$
\begin{aligned}
& \frac{\sum_{y_{1}} \pi\left(y_{1}\right) m\left(\left[(1-\alpha) \eta\left(y_{1}\right)+\alpha\right] \lambda\left(z_{h}\right) e_{0}\left(z_{0}\right), e_{0}\left(z_{0}\right)\right)}{\sum_{y_{1}} \pi\left(y_{1}\right) m\left(\left[(1-\alpha) \eta\left(y_{1}\right)+\alpha\right] \lambda\left(z_{l}\right) e_{0}\left(z_{0}\right), e_{0}\left(z_{0}\right)\right)} \\
= & \frac{\lambda\left(z_{h}\right)^{-\gamma} \sum_{y_{1}} \pi\left(y_{1}\right) m\left(\left[(1-\alpha) \eta\left(y_{1}\right)+\alpha\right], 1\right)}{\lambda\left(z_{l}\right)^{-\gamma} \sum_{y_{1}} \pi\left(y_{1}\right) m\left(\left[(1-\alpha) \eta\left(y_{1}\right)+\alpha\right], 1\right)}=\left(\frac{\lambda\left(z_{h}\right)}{\lambda\left(z_{l}\right)}\right)^{-\gamma}
\end{aligned}
$$

Thus, the ratio of Arrow prices is the same in the representative agent model and the model with idiosyncratic risk. To derive this result, we used the homogeneity of the lifetime utility function,

\footnotetext{
${ }^{14}$ The degree of homogeneity is of course irrelevant, all we need is that $u$ is homogeneous of some degree, which reduces the class of utility functions we can handle to the CRRA class.
} 
not the time-separability. This suggests that the irrelevance results carries over to Epstein-Zin recursive preferences. We demonstrate in appendix C.3 that this is indeed the case.

The proportionality of household consumption to the aggregate endowment, combined with the homogeneity assumption on preferences, are key for the asset pricing irrelevance result: market incompleteness raises the price of a unit of consumption by the same amount in the good and in the bad aggregate state, but leaves their ratio unchanged. These results carry over exactly to the general model in which there is trade in equilibrium.

Market Structure To demonstrate our results in the general model we proceed as in the simple example, by first arguing that the equilibrium consumption allocation of households can be decomposed into an idiosyncratic part and an aggregate part that is proportional to the aggregate endowment, and then showing that this characterization of allocations implies the asset pricing results. In order to do so, we use four models, whose main characteristics are summarized in table 1. The first three models are endowment models with aggregate shocks. The models differ along two dimensions, namely whether agents can trade a full set of Arrow securities against aggregate shocks, and whether agents face idiosyncratic risk, in addition to aggregate risk. Idiosyncratic risk, if there is any, is never directly insurable.

Our primary goal is to understand asset prices in the first model in the table, the Bond model. This model has idiosyncratic and aggregate risk, as well as incomplete markets (against idiosyncratic and aggregate shocks). Agents can only insure against idiosyncratic and aggregate risk by trading a single bond and a stock. The second model, the Arrow model, differs from the bond model only in the availability of a full set of aggregate state-contingent claims. We analyzed a two-period version of the Arrow model to derive the irrelevance result above, but we found that there is no trade in the contingent bond markets. This implies that our irrelevance results for the two-period economy immediately carries over to two-period Bond economy, in which agents can only trade a stock and a non-contingent bond 15 Because of the result that idiosyncratic household consumption is proportional to aggregate consumption, excess returns in the Bond and Arrow model are priced as in the standard representative agent complete markets Breeden (1979)-Lucas (1978)

$$
(B L) \text { model, which does not have idiosyncratic risk. }
$$

\footnotetext{
${ }^{15}$ With two shocks a bond and a stock complete the markets, so restricting the number of aggregate shocks to two automatically generates the equivalence between the Arrow model and the Bond model. In the general model aggregate shocks can take an abritrary (finite) number of values, and thus the two models do not trivally deliver the same results.
} 


\begin{tabular}{|c|c|c|c|c|}
\hline & Environment & & Trading & \\
\hline Model & Idiosyncr. Shocks & Aggregate Shocks & Arrow Securities & Bond and Stock \\
\hline Bond & Yes & Yes & No & Yes \\
\hline Arrow & Yes & Yes & Yes & Yes \\
\hline$B L$ & No & Yes & Yes & Yes \\
\hline Bewley & Yes & No & $\mathrm{N} / \mathrm{A}$ & Yes \\
\hline
\end{tabular}

These results carry over to the infinite horizon economy. However, in the two-period economy, the equilibrium allocations are autarchic. They are not in the infinite horizon economy. The fundamental result underlying our asset pricing findings is that equilibrium allocations in both the Bond and the Arrow model can be found by first determining equilibria in a model with only idiosyncratic risk (the Bewley model henceforth, the fourth row in the table) and then by simply scaling consumption allocations in that model by the stochastic aggregate endowment. As in the simple model, household consumption is therefore proportional to aggregate consumption, and the asset pricing results immediately follow.

\subsection{Robustness}

We briefly consider the robustness of this irrelevance result in the two-period economy to solvency constraints, cyclicality in the labor income share and preference heterogeneity. Basically, as long as households can keep their consumption proportional to aggregate consumption (or a levered version thereof), the irrelevance result goes through.

Solvency Constraints The households face solvency constraints in the second period that put a lower bound on net wealth in each state $z_{1}$ :

$$
a_{0}\left(s_{0}, z_{1}\right)+\sigma_{0}\left(s_{0}\right) \alpha e_{1}\left(z^{1}\right) \geq K_{1}\left(z_{1}\right)
$$

If we assume that the lower bound is proportional to the aggregate endowment, $K_{1}\left(z_{1}\right)=\widehat{K}_{1} e_{1}\left(z^{1}\right)$, then the solvency constraint simplifies to:

$$
\frac{a_{0}\left(s_{0}, z_{1}\right)}{e_{1}\left(z^{1}\right)}+\sigma_{0}\left(s_{0}\right) \alpha \geq \widehat{K}_{1}
$$

Since the right hand side of the constraint does not depend on the aggregate shock realization, households can still choose $a_{0}\left(s_{0}, z_{1}\right)=0$ in equilibrium, as before. Thus, the irrelevance result survives solvency constraints that are proportional to the aggregate endowment. However, if 
$\widehat{K}_{1}\left(z_{1}\right)$ depends on the realization of the aggregate shock, this no-trade equilibrium may not be implementable without violating the solvency constraints in some aggregate state.

Counter-cyclical Labor Income Share If the capital share $\alpha$ depends on $z_{1}$, then the notrade equilibrium still obtains but the ratio of state prices in the representative agent and the Arrow models are not identical, as can be seen from equation 4, simply because second period consumption is no longer simply proportional to the aggregate endowment; the fraction of the aggregate endowment consumed by households depends on the realization of the aggregate shock 16 There is one important exception. Suppose the individual labor endowments are given by the following additive specification:

$$
\begin{aligned}
& \eta_{0}\left(s_{0}\right)=(1-\alpha) e_{0}\left(z_{0}\right)+\left(\alpha-\alpha\left(z_{0}\right)\right) e_{0}\left(z_{0}\right) \\
& \eta_{1}\left(s^{1}\right)=(1-\alpha) \eta\left(y_{1}, z_{1}\right) e_{0}\left(z_{0}\right) \lambda\left(z_{1}\right)+\left(\alpha-\alpha\left(z_{1}\right)\right) e_{0}\left(z_{0}\right) \lambda\left(z_{1}\right)
\end{aligned}
$$

In this case, the realization of the aggregate shock does not affect the ratio of state prices and we obtain the same equality of the ratios in the representative agent economy and the economy with idiosyncratic risk, because the labor income and capital income share effect offset each other if the households all hold the same amount of shares in the Lucas tree. A less trivial version of this result carries over to the infinite horizon economy, but it requires households to trade in the contingent bond market to offset the labor income fluctuations induced by the term $\alpha\left(z_{0}\right) e_{0}\left(z_{0}\right)$. The crucial feature of this additive specification is that the cross-sectional distribution of labor income shares remains independent of the aggregate shocks, as can easily be verified. If idiosyncratic labor income would affected multiplicatively by the aggregate shock to the labor income share, the cross-sectional distribution of labor income and its risk is affected by the aggregate shock, in effect violating assumption 2 ,

Preference Heterogeneity Finally, we explore what happens if households have different risk attitudes. Suppose there are two classes of agents. The first type is less risk averse than the second type. Then the first type of agents will seek more exposure to aggregate risk in equilibrium than the second type. In order for the irrelevance result to hold we need to assume that the less risk averse group of agents has labor income processes that are more exposed to aggregate risk:

$$
\begin{aligned}
& \eta_{1}^{1}\left(s^{1}\right)=(1-\alpha) \eta\left(y_{1}, z_{1}\right) \chi_{1}\left(z^{1}\right)\left(z_{1}\right) \text { and } \\
& \eta_{1}^{2}\left(s^{1}\right)=(1-\alpha) \eta\left(y_{1}, z_{1}\right)\left(1-\chi_{1}\left(z^{1}\right)\right)\left(z_{1}\right)
\end{aligned}
$$

\footnotetext{
${ }^{16}$ Households cannot fully hedge against these aggregate shocks to their labor income share because the contingent bond payoff has to depend on both the idiosyncratic shock $y$ and the aggregate shock $z$ to neutralize the effect of the shock to the aggregate labor income share $z$.
} 
where the properties of $\chi_{1}\left(z^{1}\right)$ will be discussed below. Schulhofer-Wohl (2008) shows that, empirically, risk-tolerant workers hold jobs whose earnings carry more aggregate risk. This is plausible because their shadow valuations of these earnings is higher. In the first period labor income for both groups is given by $\eta_{0}^{1}\left(s_{0}\right)=\chi_{0}\left(z_{0}\right) e_{0}\left(z_{0}\right)$ and $\eta_{0}^{2}\left(s_{0}\right)=\left(1-\chi_{0}\left(z_{0}\right)\right) e_{0}\left(z_{0}\right)$.

With this income process the equilibrium consumption allocations in the first period are given by

$$
c_{0}^{1}\left(s_{0}\right)=\chi_{0}\left(z_{0}\right) e_{0}\left(z_{0}\right)
$$

and in the second period

$$
c_{1}^{1}\left(s^{1}\right) \equiv\left[(1-\alpha) \eta\left(y_{1}, z_{1}\right)+\alpha\left(z_{1}\right)\right] \chi_{1}\left(z^{1}\right) e_{1}\left(z^{1}\right)
$$

where $\chi_{1}\left(z_{0}, z_{l}\right)<1<\chi_{1}\left(z_{0}, z_{h}\right)$ is chosen such that the MRS of the stand-in agent who consumes the group consumption lines up with that of the other group:

$$
\left(\lambda\left(z_{1}\right) \frac{\chi_{1}\left(z^{1}\right)}{\chi_{0}\left(z_{0}\right)}\right)^{-\gamma_{1}}=\left(\lambda\left(z_{1}\right) \frac{1-\chi_{1}\left(z^{1}\right)}{1-\chi_{0}\left(z_{0}\right)}\right)^{-\gamma_{2}}
$$

in each aggregate history $z^{1}$. While household consumption for the less risk averse group is not proportional to the aggregate endowment, it is proportional to a levered up version thereof. Hence, the ratio of state prices in the economy without idiosyncratic risk (and thus a representative agent in each household group) simplifies to:

$$
\frac{m^{1}\left(\chi_{1}\left(z_{0}, z_{h}\right) \lambda\left(z_{h}\right) e_{0}\left(z_{0}\right), \chi_{0}\left(z_{0}\right) e_{0}\left(z_{0}\right)\right)}{m^{1}\left(\chi_{1}\left(z_{0}, z_{l}\right) \lambda\left(z_{l}\right) e_{0}\left(z_{0}\right), \chi_{0}\left(z_{0}\right) e_{0}\left(z_{0}\right)\right)}=\left(\frac{\lambda\left(z_{h}\right) \chi_{1}\left(z_{0}, z_{h}\right)}{\lambda\left(z_{l}\right) \chi_{1}\left(z_{0}, z_{l}\right)}\right)^{-\gamma_{1}}
$$

for agents of type 1. Similarly, the ratio of state prices in the incomplete markets economy with idiosyncratic risk simplifies to:

$$
\frac{\sum_{y_{1}} \pi\left(y_{1}\right) m^{1}\left(\left[(1-\alpha) \eta\left(y_{1}\right)+\alpha\right] \chi_{1}\left(z_{0}, z_{h}\right) \lambda\left(z_{h}\right) e_{0}\left(z_{0}\right), \chi_{0}\left(z_{0}\right) e_{0}\left(z_{0}\right)\right)}{\sum_{y_{1}} \pi\left(y_{1}\right) m^{1}\left(\left[(1-\alpha) \eta\left(y_{1}\right)+\alpha\right] \chi_{1}\left(z_{0}, z_{l}\right) \lambda\left(z_{l}\right) e_{0}\left(z_{0}\right), \chi_{0}\left(z_{0}\right) e_{0}\left(z_{0}\right)\right)}=\left(\frac{\lambda\left(z_{h}\right) \chi_{1}\left(z_{0}, z_{h}\right)}{\lambda\left(z_{l}\right) \chi_{1}\left(z_{0}, z_{l}\right)}\right)^{-\gamma_{1}}
$$

for agents of type 1 , and thus the ratio of state prices $\frac{q_{0}\left(z_{0}, z_{h}\right)}{q_{0}\left(z_{0}, z_{l}\right)}$ is the same in the model without and the model with idiosyncratic risk. This does not mean that preference heterogeneity leaves risk premia unaffected; but it implies that it affects risk premia in the same way in both the model with idiosyncratic risk and the model with a representative agent per household group, as first analyzed by Dumas (1989) 17

We conjecture that the same results go through in the infinite horizon economy, as long we can

\footnotetext{
${ }^{17}$ Recent papers that explore preference heterogeneity as a vehicle for time variation in risk premia include Chan and Kogan (2002) and Garleanu and Panageas (2007).
} 
tune the aggregate risk exposure of the labor income processes for each group of households in the same way as in the two period example. Under these conditions, the least risk averse households as a group are more exposed to aggregate risk than the most risk averse households, but the within group wealth dynamics are invariant with respect to the history of aggregate shocks 18

Summary This simple model conveys the main intuition. In spite of the idiosyncratic shocks, households simply want to keep their individual consumption lined up with aggregate consumption, and if conditions 1 and 2 are satisfied, they can do so. If condition 3 holds as well, this also implies that risk premia are unaffected.

What is missing in the two-period model? In the no-trade equilibrium of the two-period version of our economy, securities markets are inoperative, and the allocations are autarchic. However, we will show that the basic irrelevance result carries over to equilibria which do feature equilibrium trade in an infinite horizon version of this economy: The zero (contingent) bond trade result, which holds by construction in this simple economy, turns out to carry over to the infinite horizon economy, if aggregate shocks are i.i.d., but the zero stock trade result does not, in that households in the general model will trade the stock for consumption-smoothing purposes. As a result, in the infinite horizon version of this economy, we need to solve a Bewley model to compute the equilibrium allocations (and the risk-free rate).

In addition, the simple two-period model with its autarchic equilibrium by construction does not display cross-sectional dispersion or variation in the wealth distribution. Therefore this model is silent about what is needed for the cross-sectional distribution of wealth and consumption to be nonstochastic and how wealth dispersion affects asset prices. In the general model a continuum of agents is needed to obtain an equilibrium with a wealth distribution that is nonstochastic, which is key for the asset pricing irrelevance result since prices depend on the wealth distribution. In the two-period example the irrelevance result can be established even with a finite number of agents, whereas in the general model with finitely many households household-specific shocks move the wealth distribution and thus asset prices. Second, when aggregate shocks are non-i.i.d., interest rates are stochastic. Households in the infinite horizon economy want to hedge against this risk. Different households have different hedging demands depending on their net financial wealth position. This wealth heterogeneity creates trade in the contingent bond markets. In contrast, the two period model cannot capture these inter-temporal hedging motives, and the importance the wealth distribution has for these motives.

We therefore now turn to the theoretical analysis of the general model.

\footnotetext{
${ }^{18}$ This being the case, the excess returns on any asset can be priced off the consumption of each group.
} 


\section{General Results in the Infinite Horizon Economy}

Most of our results for the infinite horizon economy are derived in a de-trended version of our model. This de-trended model features a constant aggregate endowment and a growth-adjusted transition probability matrix. The agents in this de-trended model, discussed now, have stochastic time discount factors.

Transformation of the Growth Model into a Stationary Model We transform our growing model into a stationary model with a stochastic time discount rate and a growth-adjusted probability matrix, following Alvarez and Jermann (2001). First, we define growth deflated consumption allocations (or consumption shares) as

$$
\hat{c}_{t}\left(s^{t}\right)=\frac{c_{t}\left(s^{t}\right)}{e_{t}\left(z^{t}\right)} \text { for all } s^{t}
$$

Next, we define growth-adjusted probabilities and the growth-adjusted discount factor as:

$$
\hat{\pi}\left(s_{t+1} \mid s_{t}\right)=\frac{\pi\left(s_{t+1} \mid s_{t}\right) \lambda\left(z_{t+1}\right)^{1-\gamma}}{\sum_{s_{t+1}} \pi\left(s_{t+1} \mid s_{t}\right) \lambda\left(z_{t+1}\right)^{1-\gamma}} \text { and } \hat{\beta}\left(s_{t}\right)=\beta \sum_{s_{t+1}} \pi\left(s_{t+1} \mid s_{t}\right) \lambda\left(z_{t+1}\right)^{1-\gamma} \text {. }
$$

Note that $\hat{\pi}$ is a well-defined Markov matrix in that $\sum_{s_{t+1}} \hat{\pi}\left(s_{t+1} \mid s_{t}\right)=1$ for all $s_{t}$ and that $\hat{\beta}\left(s_{t}\right)$ is stochastic as long as the original Markov process is not iid over time. For future reference, we also define the time zero discount factor applied to utils at time $t$ :

$$
\hat{\beta}\left(s^{t}\right)=\hat{\beta}\left(s_{0}\right) \cdot \ldots \cdot \hat{\beta}\left(s_{t}\right)
$$

and we note that $\frac{\hat{\beta}\left(s^{t}\right)}{\hat{\beta}\left(s^{t-1}\right)}=\hat{\beta}\left(s_{t}\right)$. Finally, we let $\hat{U}(\hat{c})\left(s^{t}\right)$ denote the lifetime expected continuation utility in node $s^{t}$, under the new transition probabilities and discount factor, defined over consumption shares $\left\{\hat{c}_{t}\left(s^{t}\right)\right\}$

$$
\hat{U}(\hat{c})\left(s^{t}\right)=u\left(\hat{c}_{t}\left(s^{t}\right)\right)+\hat{\beta}\left(s_{t}\right) \sum_{s_{t+1}} \hat{\pi}\left(s_{t+1} \mid s_{t}\right) \hat{U}(\hat{c})\left(s^{t}, s_{t+1}\right) .
$$

In the appendix we prove that this transformation does not alter the agents' ranking of different consumption streams.

Proposition 4.1. Households rank consumption share allocations in the de-trended model in exactly the same way as they rank the corresponding consumption allocations in the original model with growth: for any $s^{t}$ and any two consumption allocations $c, c^{\prime}$

$$
U(c)\left(s^{t}\right) \geq U\left(c^{\prime}\right)\left(s^{t}\right) \Longleftrightarrow \hat{U}(\hat{c})\left(s^{t}\right) \geq \hat{U}\left(\hat{c}^{\prime}\right)\left(s^{t}\right)
$$


where the transformation of consumption into consumption shares is given by (6) .

This result is crucial for demonstrating that equilibrium allocations $c$ for the stochastically growing model can be found by solving for equilibrium allocations $\hat{c}$ in the transformed model.

To derive the irrelevance result in the infinite horizon economy, we need to impose more structure on the environment, specifically on the interaction between aggregate and idiosyncratic risk.

Independence of Idiosyncratic Shocks from Aggregate Conditions We assume that idiosyncratic shocks are independent of the aggregate shocks. This assumption is crucial for most of the results in this paper.

Condition 4.1. Individual endowment shares $\eta\left(y_{t}, z_{t}\right)$ are functions of the current idiosyncratic state $y_{t}$ only, that is $\eta\left(y_{t}, z_{t}\right)=\eta\left(y_{t}\right)$. Also, transition probabilities of the shocks can be decomposed as

$$
\pi\left(z_{t+1}, y_{t+1} \mid z_{t}, y_{t}\right)=\varphi\left(y_{t+1} \mid y_{t}\right) \phi\left(z_{t+1} \mid z_{t}\right)
$$

That is, individual endowment shares and the transition probabilities of the idiosyncratic shocks are independent of the aggregate state of the economy $z$. In this case, the growth-adjusted probability matrix $\hat{\pi}$ and the re-scaled discount factor is obtained by adjusting only the transition probabilities for the aggregate shock, $\phi$, but not the transition probabilities for the idiosyncratic shocks:

$$
\hat{\pi}\left(s_{t+1} \mid s_{t}\right)=\varphi\left(y_{t+1} \mid y_{t}\right) \hat{\phi}\left(z_{t+1} \mid z_{t}\right), \text { and } \hat{\phi}\left(z_{t+1} \mid z_{t}\right)=\frac{\phi\left(z_{t+1} \mid z_{t}\right) \lambda\left(z_{t+1}\right)^{1-\gamma}}{\sum_{z_{t+1}} \phi\left(z_{t+1} \mid z_{t}\right) \lambda\left(z_{t+1}\right)^{1-\gamma}}
$$

Furthermore, the growth-adjusted discount factor only depends on the aggregate state $z_{t}$ :

$$
\hat{\beta}\left(z_{t}\right)=\beta \sum_{z_{t+1}} \phi\left(z_{t+1} \mid z_{t}\right) \lambda\left(z_{t+1}\right)^{1-\gamma}
$$

We assume that $\max _{z_{t}} \hat{\beta}\left(z_{t}\right)<1$ in order to insure that lifetime utility remains finite. Evidently this jointly restricts the time discount factor $\beta$, the endowment growth process and the coefficient of relative risk aversion $\gamma$.

The first part of our analysis (section 5 included) also assumes that the aggregate shocks are independent over time:

Condition 4.2. Aggregate endowment growth is i.i.d.:

$$
\phi\left(z_{t+1} \mid z_{t}\right)=\phi\left(z_{t+1}\right) .
$$


In this case the growth rate of aggregate endowment is uncorrelated over time, so that the logarithm of the aggregate endowment follows a random walk with drift 19 As a result, the growthadjusted discount factor is a constant: $\hat{\beta}\left(z_{t}\right)=\hat{\beta}$, since $\hat{\phi}\left(z_{t+1} \mid z_{t}\right)=\hat{\phi}\left(z_{t+1}\right)$. There are two competing effects on the growth-adjusted discount rate: consumption growth itself makes agents more impatient, while the consumption risk makes them more patient 20

Finally, we rule out cyclicality in the labor income share:

Condition 4.3. The labor income share $(1-\alpha)$ is constant.

We will relax some of these assumption in section 6.

We start our analysis of the infinite horizon economy in section 4.1 by characterizing equilibria for the Bewley model, a stationary model with a constant aggregate endowment in which agents trade a single discount bond and a stock 21 This model merely serves as a device to compute equilibrium allocations and prices. In the infinite horizon economy, household consumption will still be proportional to aggregate consumption in that the consumption share does not depend on aggregate shocks, like in the two-period example, but now the consumption shares depend on the household's history of idiosyncratic shocks in potentially complicated ways. The Bewley economy's only purpose is to allow us to compute these consumption shares. Then we turn to the stochastically growing economy (with different market structures), the one whose asset pricing implications we are interested in, and we show that equilibrium consumption allocations from the Bewley model can be implemented as equilibrium allocations in the stochastically growing Arrow model in section 4.2 and the Bond model in section 4.3 .

\subsection{The Bewley Model}

In this model the aggregate endowment is constant and equal to 1. Households face idiosyncratic shocks $y$ that follow a Markov process with transition probabilities $\varphi\left(y^{\prime} \mid y\right)$. The household's preferences over consumption shares $\left\{\hat{c}\left(y^{t}\right)\right\}$ are defined in equation (7), with the constant time discount factor $\hat{\beta}$ as defined in equation (8) .

\footnotetext{
${ }^{19}$ In section 6 we show that most of our results survive the introduction of persistence in the growth rates if a complete set of contingent claims on aggregate shocks is traded.

${ }^{20}$ The growth-adjusted measure $\hat{\phi}$ is obviously connected to the risk-neutral measure commonly used in asset pricing (Harrison and Kreps, 1979). Under our hatted measure, agents can evaluate utils from consumption streams while abstracting from aggregate risk; under a risk-neutral measure, agents can price payoffs by simply discounting at the risk-free rate.

${ }^{21}$ One of the two assets will be redundant for the households, so that this model is a standard Bewley model, as studied by Bewley (1986), Huggett (1993) or Aiyagari (1994). The presence of both assets will make it easier to demonstrate our equivalence results with respect to the THL and Arrow model later on.
} 


\subsubsection{Market Structure}

Agents trade only a riskless one-period discount bond and shares in a Lucas tree that yields safe dividends of $\alpha$ in every period. The price of the Lucas tree at time $t$ is denoted by $v_{t} 22$ The riskless bond is in zero net supply. Each household is indexed by an initial condition $\left(\theta_{0}, y_{0}\right)$, where $\theta_{0}$ denotes its wealth (including period 0 labor income) at time 0.

The household chooses consumption $\left\{\hat{c}_{t}\left(\theta_{0}, y^{t}\right)\right\}$, bond positions $\left\{\hat{a}_{t}\left(\theta_{0}, y^{t}\right)\right\}$ and share holdings $\left\{\hat{\sigma}_{t}\left(\theta_{0}, y^{t}\right)\right\}$ to maximize its normalized expected lifetime utility $\hat{U}(\hat{c})\left(s^{0}\right)$, subject to a standard budget constraint:23

$$
\hat{c}_{t}\left(y^{t}\right)+\frac{\hat{a}_{t}\left(y^{t}\right)}{\hat{R}_{t}}+\hat{\sigma}_{t}\left(y^{t}\right) \hat{v}_{t}=(1-\alpha) \eta\left(y_{t}\right)+\hat{a}_{t-1}\left(y^{t-1}\right)+\hat{\sigma}_{t-1}\left(y^{t-1}\right)\left(\hat{v}_{t}+\alpha\right) .
$$

Finally, each household faces one of two types of borrowing constraints. The first one restricts household wealth at the end of the current period. The second one restricts household wealth at the beginning of the next period: 24

$$
\begin{aligned}
\frac{\hat{a}_{t}\left(y^{t}\right)}{\hat{R}_{t}}+\hat{\sigma}_{t}\left(y^{t}\right) \hat{v}_{t} & \geq \hat{K}_{t}\left(y^{t}\right) \text { for all } y^{t} . \\
\hat{a}_{t}\left(y^{t}\right)+\hat{\sigma}_{t}\left(y^{t}\right)\left(\hat{v}_{t+1}+\alpha\right) & \geq \hat{M}_{t}\left(y^{t}\right) \text { for all } y^{t} .
\end{aligned}
$$

\subsubsection{Equilibrium in the Bewley Model}

The definition of equilibrium in this model is standard.

Definition 4.1. For an initial distribution $\Theta_{0}$ over $\left(\theta_{0}, y_{0}\right)$, a competitive equilibrium for the Bewley model consists of trading strategies $\left\{\hat{c}_{t}\left(\theta_{0}, y^{t}\right), \hat{a}_{t}\left(\theta_{0}, y^{t}\right), \hat{\sigma}_{t}\left(\theta_{0}, y^{t}\right)\right\}$, and prices $\left\{\hat{R}_{t}, \hat{v}_{t}\right\}$ such that

1. Given prices, trading strategies solve the household maximization problem

\footnotetext{
${ }^{22}$ The price of the tree is nonstochastic due to the absence of aggregate risk.

${ }^{23}$ We suppress dependence on $\theta_{0}$ for simplicity whenever there is no room for confusion.

${ }^{24}$ This distinction is redundant in the Bewley model, but it will become meaningful in our models with aggregate risk.
} 
2. The goods markets and asset markets clear in all periods $t$

$$
\begin{aligned}
\int \sum_{y^{t}} \varphi\left(y^{t} \mid y_{0}\right) \hat{c}_{t}\left(\theta_{0}, y^{t}\right) d \Theta_{0} & =1 . \\
\int \sum_{y^{t}} \varphi\left(y^{t} \mid y_{0}\right) \hat{a}_{t}\left(\theta_{0}, y^{t}\right) d \Theta_{0} & =0 . \\
\int \sum_{y^{t}} \varphi\left(y^{t} \mid y_{0}\right) \hat{\sigma}_{t}\left(\theta_{0}, y^{t}\right) d \Theta_{0} & =1 .
\end{aligned}
$$

In the absence of aggregate risk, the bond and the stock are perfect substitutes for households, and no-arbitrage implies that the stock return equals the risk-free rate:

$$
\hat{R}_{t}=\frac{\hat{v}_{t+1}+\alpha}{\hat{v}_{t}} .
$$

In addition, at these equilibrium prices, household portfolios are indeterminate. Without loss of generality one can therefore focus on trading strategies in which households only trade the stock, but not the bond: $\hat{a}_{t}\left(\theta_{0}, y^{t}\right) \equiv 0.25$

A stationary equilibrium in the Bewley model consists of a constant interest rate $\hat{R}$, a share price $\hat{v}$, optimal household allocations and a time-invariant measure $\Phi$ over income shocks and financial wealth 26 In the stationary equilibrium, households move within the invariant wealth distribution, but the wealth distribution itself is constant over time.

\subsection{The Arrow Model}

We now turn to our main object of interest, the model with aggregate risk. We first consider the Arrow market structure in which households can trade shares of the stock and a complete menu of contingent claims on aggregate shocks. Idiosyncratic shocks are still uninsurable. We demonstrate in this section that the allocations and prices of a stationary Bewley equilibrium can be transformed into equilibrium allocations and prices in the Arrow model with aggregate risk.

\subsubsection{Trading}

Let $a_{t}\left(s^{t}, z_{t+1}\right)$ denote the quantity purchased of a security that pays off one unit of the consumption good if aggregate shock in the next period is $z_{t+1}$, irrespective of the idiosyncratic shock $y_{t+1}$. Its

\footnotetext{
${ }^{25}$ Alternatively, we could have agents simply trade in the bond and adjust the net supply of bonds to account for the positive capital income $\alpha$ in the aggregate. We only introduce both assets into the Bewley economy to make the mapping to allocations in the Arrow and THL models simpler.

${ }^{26}$ See Chapter 17 of Ljungqvist and Sargent (2004) for the standard formal definition and the straightforward algorithm to compute such a stationary equilibrium.
} 
price today is given by $q_{t}\left(z^{t}, z_{t+1}\right)$. In addition, households trade shares in the Lucas tree. We use $\sigma_{t}\left(s^{t}\right)$ to denote the number of shares a household with history $s^{t}=\left(y^{t}, z^{t}\right)$ purchases today and we let $v_{t}\left(z^{t}\right)$ denote the price of one share.

An agent starting period $t$ with initial wealth $\theta_{t}\left(s^{t}\right)$ buys consumption commodities in the spot market and trades securities subject to the usual budget constraint:

$$
c_{t}\left(s^{t}\right)+\sum_{z_{t+1}} a_{t}\left(s^{t}, z_{t+1}\right) q_{t}\left(z^{t}, z_{t+1}\right)+\sigma_{t}\left(s^{t}\right) v_{t}\left(z^{t}\right) \leq \theta_{t}\left(s^{t}\right)
$$

If next period's state is $s^{t+1}=\left(s^{t}, y_{t+1}, z_{t+1}\right)$, her wealth is given by her labor income, the payoff from the contingent claim purchased in the previous period as well as the value of her position on the stock, including dividends:

$$
\theta_{t+1}\left(s^{t+1}\right)=(1-\alpha) \eta\left(y_{t+1}, z_{t+1}\right) e_{t+1}\left(z_{t+1}\right)+a_{t}\left(s^{t}, z_{t+1}\right)+\sigma_{t}\left(s^{t}\right)\left[v_{t+1}\left(z^{t+1}\right)+\alpha e_{t+1}\left(z_{t+1}\right) .\right]
$$

In addition to the budget constraints, the households' trading strategies are subject to solvency constraints of one of two types. The first type of constraint imposes a lower bound on the value of the asset portfolio at the end of the period today,

$$
\sum_{z_{t+1}} a_{t}\left(s^{t}, z_{t+1}\right) q_{t}\left(z^{t}, z_{t+1}\right)+\sigma_{t}\left(s^{t}\right) v_{t}\left(z^{t}\right) \geq K_{t}\left(s^{t}\right)
$$

while the second type imposes state-by-state lower bounds on net wealth tomorrow,

$$
a_{t}\left(s^{t}, z_{t+1}\right)+\sigma_{t}\left(s^{t}\right)\left[v_{t+1}\left(z^{t+1}\right)+\alpha e_{t+1}\left(z_{t+1}\right)\right] \geq M_{t}\left(s^{t}, z_{t+1}\right) \text { for all } z_{t+1} \text {. }
$$

We assume these solvency constraints are at least tight enough to prevent Ponzi schemes. In addition, we impose restrictions on the solvency constraints that make them proportional to the aggregate endowment in the economy:

Condition 4.4. We assume that the borrowing constraints only depend on the aggregate history through the level of the aggregate endowment. That is, we assume that:

$$
K_{t}\left(y^{t}, z^{t}\right)=\hat{K}_{t}\left(y^{t}\right) e_{t}\left(z^{t}\right)
$$

and

$$
M_{t}\left(y^{t}, z^{t}, z_{t+1}\right)=\hat{M}_{t}\left(y^{t}\right) e_{t+1}\left(z^{t+1}\right) .
$$

If the constraints did not have this feature in a stochastically growing economy, the constraints 
would become more or less binding as the economy grows, clearly not a desirable feature27. The definition of an equilibrium is completely standard (see section A.1 of the Appendix).

Instead of working with the model with aggregate risk, we transform the Arrow model into a stationary model. As we are about to show, the equilibrium allocations and prices in the de-trended model are the same as the allocations and prices in a stationary Bewley equilibrium.

\subsubsection{Equilibrium in the De-trended Arrow Model}

We use hatted variables to denote the variables in the stationary model. Households rank consumption shares $\left\{\hat{c}_{t}\right\}$ in exactly the same way as original consumption streams $\left\{c_{t}\right\}$. Dividing the budget constraint (11) by $e_{t}\left(z^{t}\right)$ and using equation (12) yields the deflated budget constraint:

$$
\begin{aligned}
& \hat{c}_{t}\left(s^{t}\right)+\sum_{z_{t+1}} \hat{a}_{t}\left(s^{t}, z_{t+1}\right) \hat{q}_{t}\left(z^{t}, z_{t+1}\right)+\sigma_{t}\left(s^{t}\right) \hat{v}_{t}\left(z^{t}\right) \\
\leq & (1-\alpha) \eta\left(y_{t}\right)+\hat{a}_{t-1}\left(s^{t-1}, z_{t}\right)+\sigma_{t-1}\left(s^{t-1}\right)\left[\hat{v}_{t}\left(z^{t}\right)+\alpha\right],
\end{aligned}
$$

where we have defined the deflated Arrow positions as $\hat{a}_{t}\left(s^{t}, z_{t+1}\right)=\frac{a_{t}\left(s^{t}, z_{t+1}\right)}{e_{t+1}\left(z^{t+1}\right)}$ and prices as $\hat{q}_{t}\left(z^{t}, z_{t+1}\right)=q_{t}\left(z^{t}, z_{t+1}\right) \lambda\left(z_{t+1}\right)$. The deflated stock price is given by $\hat{v}_{t}\left(z^{t}\right)=\frac{v_{t}\left(z^{t}\right)}{e_{t}\left(z^{t}\right)}$. Similarly, by deflating the solvency constraints (13) and (14), using condition (4.4), yields:

$$
\begin{aligned}
\sum_{z_{t+1}} \hat{a}_{t}\left(s^{t}, z_{t+1}\right) \hat{q}_{t}\left(z^{t}, z_{t+1}\right)+\sigma_{t}\left(s^{t}\right) \hat{v}_{t}\left(z^{t}\right) & \geq \hat{K}_{t}\left(y^{t}\right) \\
\hat{a}_{t}\left(s^{t}, z_{t+1}\right)+\sigma_{t}\left(s^{t}\right)\left[\hat{v}_{t+1}\left(z^{t+1}\right)+\alpha\right] & \geq \hat{M}_{t}\left(y^{t}\right) \text { for all } z_{t+1} .
\end{aligned}
$$

Finally, the goods market clearing condition is given by:

$$
\int \sum_{y^{t}} \phi\left(y^{t} \mid y_{0}\right) \hat{c}_{t}\left(\theta_{0}, s^{t}\right) d \Theta_{0}=1 .
$$

The conditional probabilities simplify due to condition (4.1). The asset market clearing conditions are exactly the same as before. In the stationary model, the household maximizes $\hat{U}(\hat{c})\left(s_{0}\right)$ by choosing consumption, Arrow securities and shares of the Lucas tree, subject to the budget constraint (15) and the solvency constraint (16) or (17) in each node $s^{t}$. The definition of a competitive equilibrium in the de-trended Arrow model is straightforward.

Definition 4.2. For initial aggregate state $z_{0}$ and distribution $\Theta_{0}$ over $\left(\theta_{0}, y_{0}\right)$, a competitive equilibrium for the de-trended Arrow model consists of trading strategies $\left\{\hat{a}_{t}\left(\theta_{0}, s^{t}, z_{t+1}\right)\right\},\left\{\hat{\sigma}_{t}\left(\theta_{0}, s^{t}\right)\right\}$,

\footnotetext{
${ }^{27}$ In the incomplete markets literature the borrowing constraints usually satisfy this condition (see e.g. Heaton and Lucas (1996)). It is easy to show that solvency constraints that are not too tight in the sense of Alvarez and Jermann (2000) also satisfy this condition.
} 
$\left\{\hat{c}_{t}\left(\theta_{0}, s^{t}\right)\right\}$ and prices $\left\{\hat{q}_{t}\left(z^{t}, z_{t+1}\right)\right\},\left\{\hat{v}_{t}\left(z^{t}\right)\right\}$ such that

1. Given prices, trading strategies solve the household maximization problem

2. The goods market clears, that is, equation (18) holds for all $z^{t}$.

3. The asset markets clear

$$
\begin{aligned}
\int \sum_{y^{t}} \varphi\left(y^{t} \mid y_{0}\right) \hat{\sigma}_{t}\left(\theta_{0}, s^{t}\right) d \Theta_{0} & =1 \\
\int \sum_{y^{t}} \varphi\left(y^{t} \mid y_{0}\right) \hat{a}_{t}\left(\theta_{0}, s^{t}, z_{t+1}\right) d \Theta_{0} & =0 \text { for all } z_{t+1} \in Z
\end{aligned}
$$

The first order conditions and complementary slackness conditions, together with the appropriate transversality condition, are listed in the appendix in section (A.1.1). These are necessary and sufficient conditions for optimality on the household side. Now we are ready to establish the equivalence between equilibria in the Bewley model and in the Arrow model.

\subsubsection{Equivalence Results}

The equilibria in the Bewley model can be mapped into equilibria of the stochastically growing Arrow model.

Theorem 4.1. An equilibrium of the Bewley model $\left\{\hat{c}_{t}\left(\theta_{0}, y^{t}\right), \hat{a}_{t}\left(\theta_{0}, y^{t}\right), \hat{\sigma}_{t}\left(\theta_{0}, y^{t}\right)\right\}$ and $\left\{\hat{R}_{t}, \hat{v}_{t}\right\}$ can be made into an equilibrium for the Arrow model with growth, $\left\{a_{t}\left(\theta_{0}, s^{t}, z_{t+1}\right)\right\},\left\{\sigma_{t}\left(\theta_{0}, s^{t}\right)\right\}$, $\left\{c_{t}\left(\theta_{0}, s^{t}\right)\right\}$ and $\left\{q_{t}\left(z^{t}, z_{t+1}\right)\right\},\left\{v_{t}\left(z^{t}\right)\right\}$, with

$$
\begin{aligned}
c_{t}\left(\theta_{0}, s^{t}\right) & =\hat{c}_{t}\left(\theta_{0}, y^{t}\right) e_{t}\left(z^{t}\right) \\
\sigma_{t}\left(\theta_{0}, s^{t}\right) & =\hat{\sigma}_{t}\left(\theta_{0}, y^{t}\right) \\
a_{t}\left(\theta_{0}, s^{t}, z_{t+1}\right) & =\hat{a}_{t}\left(\theta_{0}, y^{t}\right) e_{t+1}\left(z^{t+1}\right) \\
v_{t}\left(z^{t}\right) & =\hat{v}_{t} e_{t}\left(z^{t}\right) \\
q_{t}\left(z^{t}, z_{t+1}\right) & =\frac{1}{\hat{R}_{t}} * \frac{\hat{\phi}\left(z_{t+1}\right)}{\lambda\left(z_{t+1}\right)}=\frac{1}{\hat{R}_{t}} * \frac{\phi\left(z_{t+1}\right) \lambda\left(z_{t+1}\right)^{-\gamma}}{\sum_{z_{t+1}} \phi\left(z_{t+1}\right) \lambda\left(z_{t+1}\right)^{1-\gamma}}
\end{aligned}
$$

The proof is given in the appendix, but here we provide its main intuition. Conjecture that the equilibrium prices of Arrow securities in the de-trended Arrow model are given by:

$$
\hat{q}_{t}\left(z^{t}, z_{t+1}\right)=\frac{\hat{\phi}\left(z_{t+1}\right)}{\hat{R}_{t}} .
$$


An unconstrained household's Euler equation for the Arrow securities is given by (see section (A.1.1) in the appendix)

$$
1=\frac{\hat{\beta}\left(s_{t}\right)}{\hat{q}_{t}\left(z^{t}, z_{t+1}\right)} \sum_{s^{t+1} \mid s^{t}, z_{t+1}} \hat{\pi}\left(s_{t+1} \mid s_{t}\right) \frac{u^{\prime}\left(\hat{c}_{t+1}\left(s^{t}, s_{t+1}\right)\right)}{u^{\prime}\left(\hat{c}_{t}\left(s^{t}\right)\right)} .
$$

But, in light of conditions (4.1) and (4.2) and given our conjecture that consumption allocations in the de-trended Arrow model only depend on idiosyncratic shock histories $y^{t}$ and not on $s^{t}=\left(y^{t}, z^{t}\right)$, this Euler equation reduces to

$$
\begin{aligned}
1 & =\frac{\hat{\beta} \hat{\phi}\left(z_{t+1}\right)}{\hat{q}_{t}\left(z^{t}, z_{t+1}\right)} \sum_{y_{t+1}} \varphi\left(y_{t+1} \mid y_{t}\right) \frac{u^{\prime}\left(\hat{c}_{t+1}\left(y^{t}, y_{t+1}\right)\right)}{u^{\prime}\left(\hat{c}_{t}\left(y^{t}\right)\right)} \\
& =\hat{\beta} \hat{R}_{t} \sum_{y_{t+1}} \varphi\left(y_{t+1} \mid y_{t}\right) \frac{u^{\prime}\left(\hat{c}_{t+1}\left(y^{t}, y_{t+1}\right)\right)}{u^{\prime}\left(\hat{c}_{t}\left(y^{t}\right)\right)}
\end{aligned}
$$

where we used the conjectured form of prices in (20). This is exactly the Euler equation for bonds in the Bewley model. Since Bewley equilibrium consumption allocations satisfy this condition, they therefore satisfy the Euler equation in the de-trended Arrow model, if prices are of the form (20). The proof in the appendix shows that a similar argument applies for the Euler equation with respect to the stock (under the conjectured stock prices), and also shows that for agents whose solvency constraints binds the Lagrange multipliers on the constraints in the Bewley equilibrium are also valid Lagrange multipliers for the constraints in the de-trended Arrow model. This implies, in particular, that our results go through regardless of how tight the solvency constraints are. Once one has established that allocations and prices of a Bewley equilibrium are an equilibrium in the de-trended Arrow model, one simply needs to scale up allocation and prices by the appropriate growth factors to obtain the equilibrium prices and allocations in the stochastically growing Arrow model, as stated in the theorem.

It is straightforward to compute risk-free interest rates for the Arrow model. By summing over aggregate states tomorrow on both sides of equation (201), we find that the risk-free rate in the de-trended Arrow model coincides with that of the Bewley model:

$$
\hat{R}_{t}^{A}=\frac{1}{\sum_{z_{t+1}} \hat{q}_{t}\left(z^{t}, z_{t+1}\right)}=\hat{R}_{t}
$$

Once we have determined risk free interest rates for the de-trended model, $\hat{R}_{t}^{A}=\hat{R}_{t}$, we can back out the implied interest rate for the original growing Arrow model, using (69) in the previous theorem 28

\footnotetext{
${ }^{28}$ The dependence of $\hat{R}_{t}^{A}$ on time $t$ is not surprising since, for an arbitrary initial distribution of assets $\Theta_{0}$, we
} 
Corollary 4.1. If equilibrium risk-free interest rates in the de-trended Arrow model are given by (23), equilibrium risk-free interest rates in the Arrow model with aggregate risk are given by

$$
R_{t}^{A}=\frac{1}{\sum_{z_{t+1}} q_{t}\left(z^{t}, z_{t+1}\right)}=\hat{R}_{t} \frac{\sum_{z_{t+1}} \phi\left(z_{t+1}\right) \lambda\left(z_{t+1}\right)^{1-\gamma}}{\sum_{z_{t+1}} \phi\left(z_{t+1}\right) \lambda\left(z_{t+1}\right)^{-\gamma}} .
$$

The theorem implies that we can solve for an equilibrium in the Bewley model of section 4.1 (and, in particular, a stationary equilibrium), including risk free interest rates $\hat{R}_{t}$, and we can deduce the equilibrium allocations and prices for the Arrow model from those in the Bewley model, using the mapping described in theorem 4.1. The key to this result is that households in the Bewley model face exactly the same Euler equations as the households in the de-trended version of the Arrow model.

This theorem has several important implications. First, we will use this equivalence result to show below that asset prices in the Arrow model are identical to those in the representative agent model, except for a lower risk-free interest rate (and a higher price/dividend ratio for stocks) 29 Second, the existence proofs in the literature for stationary equilibria in the Bewley model directly carry over to the stochastically growing model 30 Third, the moments of the wealth distribution vary over time but proportionally to the aggregate endowment. If the initial wealth distribution in the de-trended model corresponds to an invariant distribution in the Bewley model, then for example the ratio of the mean to the standard deviation of the wealth distribution is constant in the Arrow model with aggregate risk as well. Finally, an important result of the previous theorem is that, in the Arrow equilibrium, the trade of Arrow securities is simply proportional to the aggregate endowment: $a_{t}\left(\theta_{0}, s^{t}, z_{t+1}\right)=\hat{a}_{t}\left(\theta_{0}, y^{t}\right) e_{t+1}\left(z^{t+1}\right)$, or, equivalently, in the de-trended Arrow model households choose not to make their contingent claims purchases contingent on next period's aggregate shock: $\hat{a}_{t}\left(\theta_{0}, s^{t}, z_{t+1}\right)=\hat{a}_{t}\left(\theta_{0}, y^{t}\right)$. Furthermore, since in the Bewley model without loss of generality $\hat{a}_{t}\left(\theta_{0}, y^{t}\right)=0$, we can focus on the situation where Arrow securities are not traded at all: $a_{t}\left(\theta_{0}, s^{t}, z_{t+1}\right)=0$. This no-trade result for contingent claims suggests that our equivalence result will carry over to environments with more limited asset structures. That is what we show in the next section.

cannot expect the equilibrium to be stationary. In the same way we expect that $\hat{v}_{t}\left(z^{t}\right)$ is only a function of $t$ as well, but not of $z^{t}$.

${ }^{29}$ The fact that the risk-free interest rate is lower comes directly from the fact that interest rates in the Bewley model are lower than in the corresponding representative agent model without aggregate risk.

${ }^{30}$ See e.g. Huggett (1993), Aiyagari (1994) or Miao (2002) for (elements of) existence proofs. Uniqueness of a stationary equilibrium is much harder to establish. Our equivalence result shows that for any stationary Bewley equilibrium there exists a corresponding Arrow equilibrium in the model with aggregate risk. Furthermore note that our result does not rule out other Arrow equilibria either. 


\subsection{The Bond Model}

We now turn our attention to the main model of interest, namely the model with a stock and a single one-period discount bond. This section establishes the equivalence of equilibria in the Bond model and the Bewley model by showing that the optimality conditions in the de-trended Arrow and the de-trended Bond model are identical. In addition, we show that in the benchmark case with i.i.d. aggregate endowment growth shocks, agents do not even trade bonds in equilibrium.

\subsubsection{Market Structure}

In the Bond model, agents only trade a one-period discount bond and a stock. An agent who starts period $t$ with initial wealth composed of his stock holdings, bond and stock payouts, and labor income, buys consumption commodities in the spot market and trades a one-period bond and the stock, subject to the budget constraint:

$$
c_{t}\left(s^{t}\right)+\frac{b_{t}\left(s^{t}\right)}{R_{t}\left(z^{t}\right)}+\sigma_{t}\left(s^{t}\right) v_{t}\left(z^{t}\right) \leq(1-\alpha) \eta\left(y_{t}\right) e_{t}\left(z_{t}\right)+b_{t-1}\left(s^{t-1}\right)+\sigma_{t-1}\left(s^{t-1}\right)\left[v_{t}\left(z^{t}\right)+\alpha e_{t}\left(z_{t}\right)\right] .
$$

Here, $b_{t}\left(s^{t}\right)$ denotes the amount of bonds purchased and $R_{t}\left(z^{t}\right)$ is the gross interest rate from period $t$ to $t+1$. As was the case in the Arrow model, short-sales of the bond and the stock are constrained by a lower bound on the value of the portfolio today,

$$
\frac{b_{t}\left(s^{t}\right)}{R_{t}\left(z^{t}\right)}+\sigma_{t}\left(s^{t}\right) v_{t}\left(z^{t}\right) \geq K_{t}\left(s^{t}\right)
$$

or a state-by-state constraint on the value of the portfolio tomorrow,

$$
b_{t}\left(s^{t}\right)+\sigma_{t}\left(s^{t}\right)\left[v_{t+1}\left(z^{t+1}\right)+\alpha e_{t+1}\left(z_{t+1}\right)\right] \geq M_{t}\left(s^{t}, z_{t+1}\right) \text { for all } z_{t+1} \text {. }
$$

Since $b_{t}\left(s^{t}\right)$ and $\sigma_{t}\left(s^{t}\right)$ are chosen before $z_{t+1}$ is realized, at most one of the constraints (27) will be binding at a given time. The definition of an equilibrium for the Bond model follows directly. (see section (A.2) in the appendix). We now show that the equilibria in the Arrow and the Bond model coincide. As a corollary, it follows that the asset pricing implications of both models are identical. In order to do so, we first transform the model with growth into a stationary, de-trended model. 


\subsubsection{Equilibrium in the De-trended Bond Model}

Dividing the budget constraint (25) by $e_{t}\left(z^{t}\right)$ we obtain

$$
\hat{c}_{t}\left(s^{t}\right)+\frac{\hat{b}_{t}\left(s^{t}\right)}{R_{t}\left(z^{t}\right)}+\sigma_{t}\left(s^{t}\right) \hat{v}_{t}\left(z^{t}\right) \leq(1-\alpha) \eta\left(y_{t}\right)+\frac{\hat{b}_{t-1}\left(s^{t-1}\right)}{\lambda\left(z_{t}\right)}+\sigma_{t-1}\left(s^{t-1}\right)\left[\hat{v}_{t}\left(z^{t}\right)+\alpha\right]
$$

where we define the deflated bond position as $\hat{b}_{t}\left(s^{t}\right)=\frac{b_{t}\left(s^{t}\right)}{e_{t}\left(z^{t}\right)}$. Using condition (4.4), the solvency constraints in the de-trended model are simply:

$$
\begin{aligned}
\frac{\hat{b}_{t}\left(s^{t}\right)}{R_{t}\left(z^{t}\right)}+\sigma_{t}\left(s^{t}\right) \hat{v}_{t}\left(z^{t}\right) & \geq \hat{K}_{t}\left(y^{t}\right), \text { or } \\
\frac{\hat{b}_{t}\left(s^{t}\right)}{\lambda\left(z_{t+1}\right)}+\sigma_{t}\left(s^{t}\right)\left[\hat{v}_{t+1}\left(z^{t+1}\right)+\alpha\right] & \geq \hat{M}_{t}\left(y^{t}\right) \text { for all } z_{t+1} .
\end{aligned}
$$

The definition of equilibrium in the de-trended Bond model is straightforward and hence omitted 31 We now show that equilibrium consumption allocations in the de-trended Bond model coincide with those of the Arrow model.

\subsubsection{Equivalence Results}

As for the Arrow model, we can show that the Bewley equilibrium allocations and prices constitute, after appropriate scaling by endowment (growth) factors, an equilibrium of the Bond model with growth.

Theorem 4.2. An equilibrium of a stationary Bewley model, given by trading strategies $\left\{\hat{c}_{t}\left(\theta_{0}, y^{t}\right), \hat{a}_{t}\left(\theta_{0}, y^{t}\right)\right.$, $\left.\hat{\sigma}_{t}\left(\theta_{0}, y^{t}\right)\right\}$ and prices $\left\{\hat{R}_{t}, \hat{v}_{t}\right\}$, can be made into an equilibrium for the Bond model with growth, $\left\{b_{t}\left(\theta_{0}, s^{t}\right)\right\},\left\{c_{t}\left(\theta_{0}, s^{t}\right)\right\},\left\{\sigma_{t}^{B}\left(\theta_{0}, s^{t}\right)\right\}$ and $\left\{R_{t}\left(z^{t}\right)\right\}$ and $\left\{v_{t}\left(z^{t}\right)\right\}$ where

$$
\begin{aligned}
c_{t}\left(\theta_{0}, s^{t}\right) & =\hat{c}_{t}\left(\theta_{0}, y^{t}\right) e_{t}\left(z^{t}\right) \\
\sigma_{t}^{B}\left(\theta_{0}, s^{t}\right) & =\frac{\hat{a}_{t}\left(\theta_{0}, y^{t}\right)}{\left[\hat{v}_{t+1}+\alpha\right]}+\hat{\sigma}_{t}\left(\theta_{0}, y^{t}\right) \\
v_{t}\left(z^{t}\right) & =\hat{v}_{t} e_{t}\left(z^{t}\right) \\
R_{t}\left(z^{t}\right) & =\hat{R}_{t} * \frac{\sum_{z_{t+1}} \phi\left(z_{t+1}\right) \lambda\left(z_{t+1}\right)^{1-\gamma}}{\sum_{z_{t+1}} \phi\left(z_{t+1}\right) \lambda\left(z_{t+1}\right)^{-\gamma}}
\end{aligned}
$$

and bond holdings given by $b_{t}\left(\theta_{0}, s^{t}\right)=0$.

The crucial step of the proof, given in the appendix, shows that Bewley allocations, given

\footnotetext{
${ }^{31}$ We list the first order conditions for household optimality and the transversality conditions in section (A.2) of the appendix.
} 
the prices proposed in the theorem, satisfy the necessary and sufficient conditions for household optimality and all market clearing conditions in the de-trended Bond model.

This theorem again has several important consequences. First, equilibrium risk-free rates in the Arrow and in the Bond model coincide, despite the fact that the set of assets agents can trade to insure consumption risk differs in the two models. Second, in equilibrium of the Bond model, the bond market is inoperative: $b_{t-1}\left(s^{t-1}\right)=\hat{b}_{t-1}\left(s^{t-1}\right)=0$ for all $s^{t-1}$. Therefore all consumption smoothing is done by trading stocks, and agents keep their net wealth proportional to the level of the aggregate endowment 32 From the deflated budget constraint in (28):

$$
\hat{c}_{t}\left(y^{t}\right)+\frac{\hat{b}_{t}\left(y^{t}\right)}{R_{t}}+\sigma_{t}\left(y^{t}\right) \hat{v}_{t} \leq(1-\alpha) \eta\left(y_{t}\right)+\frac{\hat{b}_{t-1}\left(y^{t-1}\right)}{\lambda\left(z_{t}\right)}+\sigma_{t-1}\left(y^{t-1}\right)\left[\hat{v}_{t}+\alpha\right]
$$

it is clear that bond holdings $b_{t}\left(y^{t-1}\right)=0$ need to be zero for all $y^{t-1}$, if all the consumption, portfolio choices and prices, are independent of the aggregate history $z^{t}$, simply because the bond return in the deflated economy depends on the aggregate shock $z_{t}$ through $\lambda\left(z_{t}\right)$. This demonstrates the irrelevance of the history of idiosyncratic shocks $y^{t}$ for portfolio choice. There is no link between financial wealth and the share of this wealth being held in equity.

In summary, our results show that one can solve for equilibria in a standard Bewley model and then map this equilibrium into an equilibrium for both the Arrow model and the Bond model with aggregate risk. The risk-free interest rate and the price of the Lucas tree are the same in the stochastic Arrow and Bond models. Finally, without loss of generality, we can restrict attention to equilibria in which bonds are not traded; consequently transaction costs in the bond market would not change our results. Transaction costs in the stock market of course would (see section (6) ). In addition, this implies that our result is robust to the introduction of short-sale constraints imposed on stocks and bonds separately, because agents choose not to trade bonds in equilibrium, as long as these short-sale constraints are not tighter than the solvency constraints.

Finally, we briefly show that the endowment economy we considered is isomorphic to a production economy with a single input.

\footnotetext{
${ }^{32}$ There is a subtle difference between this result and the corresponding result for the Arrow model. In the Arrow model we demonstrated that contingent claims positions were in fact uncontingent: $\hat{a}_{t}\left(\theta_{0}, s^{t}, z_{t+1}\right)=\hat{a}_{t}\left(\theta_{0}, y^{t}\right)$ and equal to the Bond position in the Bewley equilibrium, but not necessarily equal to zero. In the Bond model bond positions have to be zero. But since bonds in the Bewley equilibrium are a redundant asset, one can restrict attention to the situation where $\hat{a}_{t}\left(\theta_{0}, y^{t}\right)=0$, although this is not necessary for our results.
} 


\subsection{Production Model}

We consider a production economy 33 in which output is produced using labor $L$ as the only input in production:

$$
Y_{t}\left(z^{t}\right)=e_{t}\left(z_{t}\right) L_{t}\left(z^{t}\right)^{1-\alpha}
$$

where $e_{t}\left(z^{t}\right)$ now denotes Total Factor Productivity, but evolves stochastically as before. Total labor input is given by

$$
L_{t}\left(z^{t}\right)=\int \sum_{s^{t}} \pi_{t}\left(s^{t} \mid s_{0}\right) \eta\left(y_{t}\right) l_{t}\left(\theta_{0}, s^{t}\right) d \Phi_{0}
$$

where $\eta\left(y_{t}\right)$ is the idiosyncratic labor productivity shock; so far this was the idiosyncratic income shock. Firms hire efficiency units of labor in a competitive labor market at a wage

$$
w_{t}\left(z^{t}\right)=(1-\alpha) Y_{t}\left(z^{t}\right) / L_{t}\left(z^{t}\right)
$$

Dividends that accrue to the holder of the shares in the company are given by:

$$
d_{t}\left(z^{t}\right)=(1-\alpha) Y_{t}\left(z^{t}\right)
$$

and the labor income share is $(1-\alpha)$ as before. Household labor income is given by:

$$
w_{t}\left(z^{t}\right) \eta\left(y_{t}\right) l_{t}\left(s^{t}\right)
$$

otherwise the household budget constraint remains unchanged. We assume that the period utility function is given by:

$$
u(c, l)=\frac{\left[c_{t}\left(s^{t}\right)^{\gamma}\left(1-l_{t}\left(s^{t}\right)\right)^{1-\gamma}\right]^{1-\sigma}}{1-\sigma}
$$

so that the intratemporal optimality condition becomes

$$
\frac{c_{t}\left(s^{t}\right)}{1-l_{t}\left(s^{t}\right)}=\frac{\gamma}{1-\gamma} w_{t}\left(z^{t}\right) \eta\left(y_{t}\right)
$$

This suggests that the entire aggregate shock will be absorbed by consumption, and labor supply is only affected by the idiosyncratic shock. We can apply the same detrending procedure as before, and then solve the Bewley model with labor productivity shocks and endogenous labor supply. Denote the resulting allocation in the Bewley model by a hat. The corresponding equilibrium allocations in the growing economy satisfy: $l_{t}\left(s^{t}\right)=\hat{l}_{t}\left(y^{t}\right)$, and thus $L_{t}\left(z^{t}\right)=\hat{L}_{t}$, where $\hat{L}_{t}$ is the nonstochastic aggregate labor supply in the Bewley model. In addition, consumption and wages

\footnotetext{
${ }^{33}$ We thank $\mathrm{xxx}$ for useful discussions leading to this subsection.
} 
in the growing economy can be obtained as:

$$
\begin{aligned}
c_{t}\left(s^{t}\right) & =e_{t}\left(z_{t}\right) \hat{c}_{t}\left(y^{t}\right) \\
w_{t}\left(s^{t}\right) & =e_{t}\left(z_{t}\right) \hat{w}_{t}
\end{aligned}
$$

and the mapping of assets between the Bewley model and the stochastically growing model is exactly the same as before. Note that these allocations satisfy the intratemporal optimality condition (31). The other optimality conditions remain unchanged from the case with exogenous labor supply.

Summary In both the Arrow and the Bond model, households do not have a motive for trading bonds, unless there are tighter short-sale constraints on stocks than on bonds. We do not deal with this case. In addition, the no-trade result depends critically on the i.i.d assumption for aggregate shocks, as we will show in section (66). If the aggregate shocks are not i.i.d, agents want to hedge against the implied shocks to interest rates. We will show in section (66) that these interest rate shocks look like taste shocks in the de-trended model. But, first, we compare the asset pricing implications of the equilibria just described in the Arrow and the Bond models to those emerging from the $B L$ (standard representative agent) model.

\section{$5 \quad$ Asset Pricing Implications}

This section shows that the multiplicative risk premium on a claim to aggregate consumption in the Bond model -and the Arrow model- equals the risk premium in the representative agent model. Uninsurable idiosyncratic income risk only lowers the risk-free rate, because the ratio of any two equilibrium state prices is the same as in the representative agent $B L$ economy, exactly as in the two-period example.

\subsection{Consumption-CAPM}

The benchmark model of consumption-based asset pricing is the representative agent $B L$ model. The representative agent owns a claim to the aggregate 'labor' income stream $\left\{(1-\alpha) e_{t}\left(z^{t}\right)\right\}$ and she can trade a stock (a claim to the dividends $\alpha e_{t}\left(z^{t}\right)$ of the Lucas tree), a bond and a complete set of Arrow securities 34

First, we show that the Breeden-Lucas Consumption-CAPM also prices excess returns on the stock in the Bond model and the Arrow model. Let $R^{s}$ denote the return on a claim to aggregate consumption. We have

\footnotetext{
${ }^{34}$ See separate appendix available on-line for a complete description.
} 
Lemma 5.1. The BL Consumption-CAPM prices excess returns in the Arrow model and the Bond model. In equilibrium in both models

$$
E_{t}\left[\left(R_{t+1}^{s}-R_{t}\right) \beta\left(\lambda_{t+1}\right)^{-\gamma}\right]=0 .
$$

The appendix shows that this result follows directly from subtracting the Euler equations for the bond from that for the stock in both models. This result has important implications for empirical work in asset pricing. First, and conditional on either the Arrow model or the Bond model being the correct model of the economy, despite the existence of market incompleteness and binding solvency constraints, an econometrician can estimate the coefficient of risk aversion (or the intertemporal elasticity of substitution) directly from aggregate consumption data and the excess return on stocks, as in Hansen and Singleton (1983). Second, the result provides a strong justification for explaining the cross-section of excess returns, when using the CCAPM, without trying to match the risk-free rate. The implications of the $B L$, the Arrow and the Bond model are the same with respect to excess returns, while not with respect to the risk-free rate.

\subsection{Risk Premia}

We now show that, perhaps not surprisingly in light of the previous result, the equilibrium risk premium in the Arrow and the Bond model is identical to the one in the representative agent model 35 While the risk-free rate is higher in the representative agent model than in the Arrow and Bond model, and consequently the price of the stock is correspondingly lower, the multiplicative risk premium is the same in all three models and it is constant across states of the world.

In order to demonstrate our main result we first show that the stochastic discount factors that price stochastic payoffs in the representative agent model and the Arrow (and thus the Bond) model only differ by a non-random multiplicative term, equal to the ratio of (growth-deflated) risk-free interest rates in the two models. In what follows we use the superscript $R E$ to denote equilibrium variables in the representative agent model.

Proposition 5.1. The equilibrium stochastic discount factor in the Arrow and the Bond model given by $m_{t+1}^{A}=m_{t+1}^{R E} \kappa_{t}$ where the non-random multiplicative term is given $\kappa_{t}=\frac{\hat{R}_{t}^{R E}}{\hat{R}_{t}} \geq 1$, and $m_{t+1}^{R E}$ is the stochastic discount factor in the representative agent model.

$\kappa_{t}$ is straightforward to compute, because it only involves the equilibrium risk-free interest rates from the stationary version of the representative agent model, $\hat{R}_{t}{ }^{R E}$, and the equilibrium interest rates from the Bewley model, $\hat{R}_{t}$. Luttmer (1991) and Cochrane and Hansen (1992) had already established a similar aggregation result for the case in which households face market wealth

\footnotetext{
${ }^{35}$ Note that this does not immediately follow from the result in Lemma 5.1
} 
constraints, but in a complete markets environment. We show that their result survives even if households trade only a stock and a bond.

The proof that risk premia are identical in the representative agent model and the Arrow as well as the Bond model follows directly from the previous decomposition of the stochastic discount factor 36 Let $R_{t, j}\left[\left\{d_{t+k}\right\}\right]$ denote the $j$-period holding return on a claim to the endowment stream $\left\{d_{t+k}\right\}_{k=0}^{\infty}$ at time $t$. Consequently $R_{t, 1}[1]$ is the gross risk-free rate and $R_{t, 1}\left[\alpha e_{t+k}\right]$ is the one-period holding return on a $k$-period strip of the aggregate endowment (a claim to $\alpha$ times the aggregate endowment $k$ periods from now). Thus $R_{t, 1}\left[\left\{\alpha e_{t+k}\right\}\right]$ is the one period holding return on an asset (such as a stock) that pays $\alpha$ times the aggregate endowment in all future periods. Finally, we define the multiplicative risk premium as the ratio of the expected return on stocks and the risk-free rate: $1+\nu_{t}=\frac{E_{t} R_{t, 1}\left[\left\{\alpha e_{t+k}\right\}\right]}{R_{t, 1}[1]}$. With this notation in place, we can state now our main result.

Theorem 5.1. The multiplicative risk premium in the Arrow model and Bond model equals that in the representative agent model $1+\nu_{t}^{A}=1+\nu_{t}^{\mathrm{B}}=1+\nu_{t}^{R E}$, and is constant across states of the world.

Thus, the extent to which households smooth idiosyncratic income shocks in the Arrow model or in the Bond model has absolutely no effect on the size of risk premia; it merely lowers the riskfree rate. Market incompleteness does not generate any dynamics in the conditional risk premia either: the conditional risk premium is constant.

\section{Extensions of the General Results}

In section 6.1, we investigate how robust our results are to the assumption that aggregate shocks are i.i.d over time, which implies that the growth rate of the aggregate endowment is i.i.d over time. In section 6.2, we show that our results go through in the case of permanent idiosyncratic shocks. These extensions are important, especially because the two-period model does not allow us to analyze these cases. Section (6.3) shows that the results we derived in the case of cyclical capital shares still hold in the infinite horizon economy.

The intuition that we built in the two-period example applies here too. In all of these cases, the irrelevance result goes through if households can manage to keep their consumption proportional to aggregate consumption (i.e. keep their consumption shares independent of aggregate shocks) by trading the limited menu of available securities.

\footnotetext{
${ }^{36}$ The proof strategy follows Alvarez and Jermann (2001) who derive a similar result in the context of a complete markets model populated by two agents that face endogenous solvency constraints.
} 


\subsection{Non-iid Aggregate Shocks}

Assume that the aggregate shock $z$ follows a first order Markov chain characterized by the transition matrix $\phi\left(z^{\prime} \mid z\right)>0$. So far we studied the special case in which $\phi\left(z^{\prime} \mid z\right)=\phi\left(z^{\prime}\right)$. Recall that the growth-adjusted Markov transition matrix and time discount factor are given by

$$
\hat{\phi}\left(z^{\prime} \mid z\right)=\frac{\phi\left(z^{\prime} \mid z\right) \lambda\left(z^{\prime}\right)^{1-\gamma}}{\sum_{z^{\prime}} \phi\left(z^{\prime} \mid z\right) \lambda\left(z^{\prime}\right)^{1-\gamma}} \text { and } \hat{\beta}(z)=\beta \sum_{z^{\prime}} \phi\left(z^{\prime} \mid z\right) \lambda\left(z^{\prime}\right)^{1-\gamma} \text {. }
$$

Thus if $\phi$ is serially correlated, $\hat{\phi}$ is too, and the discount factor $\hat{\beta}$ depends on the current aggregate state of the world. In the de-trended model, aggregate endowment shocks act as a common taste shock that renders all households more or less impatient. Since this shock affects all households in the same way, they will not able to insure against it. As a result, this shock affects the price/dividend ratio and the interest rate, but it leaves the risk premium unaltered. In contrast to our previous results, however, now there is trade in Arrow securities in equilibrium, so the equivalence between equilibria in the Arrow and the Bond model breaks down.

\subsubsection{Stationary Bewley Model}

We adhere to the same strategy, and we show that the equilibrium allocations and prices from a stationary version of the model, the Bewley model can be implemented, after appropriate scaling by the aggregate endowment, as equilibria in the stochastically growing model. Since the time discount factors are subject to aggregate shock, we first have to choose an appropriate nonstochastic time discount factor for this Bewley model. We choose a sequence of non-random time discount factors that assures that Bewley equilibrium allocations satisfy the time zero budget constraint in the model with aggregate shocks when the initial wealth distribution $\Theta_{0}$ in the two models coincide. Let

$$
\hat{\beta}_{0, \tau}\left(z^{\tau} \mid z_{0}\right)=\hat{\beta}\left(z_{0}\right) \hat{\beta}\left(z_{1}\right) \ldots \hat{\beta}\left(z_{\tau}\right)
$$

denote the time discount factor between period 0 and period $\tau+1$, given by the product of oneperiod time discount factors. We define the average (across aggregate shocks) time discount factor between period 0 and $t$ as:

$$
\widetilde{\beta}_{t}=\sum_{z^{t-1} \mid z_{0}} \widehat{\phi}\left(z^{t-1} \mid z_{0}\right) \hat{\beta}_{0, t-1}\left(z^{t-1} \mid z_{0}\right), t \geq 1
$$

where $\widehat{\phi}\left(z^{t-1} \mid z_{0}\right)$ is the probability distribution over $z^{t-1}$ induced by $\phi\left(z^{\prime} \mid z\right)$. If aggregate shocks are $i . i . d$, then we have that $\widetilde{\beta}_{t}=\hat{\beta}^{t}$, as before. Since $z_{0}$ is a fixed initial condition, we chose not to index $\widetilde{\beta}_{t}$ by $z_{0}$ to make sure it is understood that $\widetilde{\beta}_{t}$ is nonstochastic.

In order to construct equilibrium allocations in the stochastically growing model, we will show 
that equilibrium allocations and interest rates in the Bewley model with a sequence of non-random time discount factors $\left\{\widetilde{\beta}_{t}\right\}_{t=1}^{\infty}$ can be implemented as equilibrium allocations and interest rates for the actual Arrow model with stochastic discount factors. The crucial adjustment in this mapping is to rescale the risk-free interest rate in proportion to the taste shock $\hat{\beta}(z)$.

To understand the effect of these aggregate taste shocks on the time discount rate to be used in the Bewley model, we use a simple example

Example 6.1. Suppose that $\hat{\beta}(z)=e^{-\hat{\rho}(z)}$ is lognormal and i.i.d, where $\hat{\rho}(z)$ has mean $\hat{\rho}$ variance $\sigma^{2}$. Define the average t-period time discount rate $\widetilde{\rho}_{t}$ by $\widetilde{\beta}_{t}=e^{-\widetilde{\rho}_{t}}$. Then the average one-period discount rate used in the Bewley model is given by:

$$
\frac{\widetilde{\rho}_{t}}{t}=\widehat{\rho}-\frac{1}{2} \sigma^{2} \text { for any } t \geq 1
$$

Thus the presence of taste shocks $\left(\sigma^{2}>0\right)$ in the de-trended Arrow model induces a discount rate $\tilde{\rho}$ to be used in the Bewley model that is lower than the mean discount rate $\hat{\rho}$ because of the risk associated with the taste shocks.

This example suggests that these taste shocks lower the risk-free interest rates compared to those in model without taste shocks (which originate from aggregate endowment shocks in the stochastically growing model).

As before, we denote the Bewley equilibrium by $\left\{\hat{c}_{t}\left(\theta_{0}, y^{t}\right), \hat{a}_{t}\left(\theta_{0}, y^{t}\right), \hat{\sigma}_{t}\left(\theta_{0}, y^{t}\right)\right\}$ and $\left\{\hat{R}_{t}, \hat{v}_{t}\right\}$ Bewley equilibrium allocations and prices, for a given sequence of time discount factors $\left\{\widetilde{\beta}_{t}\right\}$. The risk-free rate has to equal the stock return in each period, to rule out arbitrage:

$$
\hat{R}_{t}=\frac{\hat{v}_{+1}+\alpha}{\hat{v}_{t}}
$$

Only the total wealth positions in the Bewley model are uniquely pinned down. Without loss of generality, we focus on the case where $\hat{a}_{t}\left(\theta_{0}, y^{t}\right)=0$ for all $y^{t}$. We now argue that the allocation $\left\{\hat{c}_{t}\left(\theta_{0}, y^{t}\right), \hat{\sigma}_{t}\left(\theta_{0}, y^{t}\right)\right\}$ can be made into an Arrow equilibrium, and in the process show why we need to choose the specific discount factor sequence in (32) for the Bewley model. We need some additional notation for state prices.

$$
\tilde{Q}_{t, \tau}=\prod_{j=0}^{\tau-t-1} \hat{R}_{t+j}^{-1}=\frac{1}{\hat{R}_{t, \tau}}
$$

denotes the Bewley equilibrium price of one unit of consumption to be delivered at time $\tau$, in terms of consumption at time $t$. By convention $\tilde{Q}_{\tau}=\tilde{Q}_{0, \tau}$ and $\tilde{Q}_{\tau, \tau}=1$ for all $\tau$. $\hat{R}_{t, \tau}$ is the gross risk-free interest rate between period $t$ and $\tau$ in the Bewley equilibrium. 


\subsubsection{Arrow Model}

In contrast to the Bewley model, the de-trended Arrow model features aggregate shocks to the time discount factor $\hat{\beta}$. These need to be reflected in prices. We therefore propose state-dependent equilibrium prices for the de-trended Arrow model, then we show that the Bewley equilibrium allocations, in turn, satisfy the Euler equations when evaluated at these prices, and they also satisfy the intertemporal budget constraint in the de-trended Arrow model. This implies that, absent binding solvency constraints, the Bewley equilibrium can be made into an equilibrium of the de-trended Arrow model, and thus, after the appropriate scaling, into an equilibrium of the original Arrow model. Finally, we discuss potentially binding solvency constraints and the Bond model.

We conjecture that the Arrow-Debreu prices in the deflated Arrow model are given by

$$
\hat{Q}_{t}\left(z^{t} \mid z_{0}\right)=\hat{\phi}\left(z^{t} \mid z_{0}\right) \tilde{Q}_{t} \frac{\hat{\beta}_{0, t-1}\left(z^{t-1} \mid z_{0}\right)}{\widetilde{\beta}_{t}}=\hat{\phi}\left(z^{t} \mid z_{0}\right) \frac{\hat{\beta}_{0, t-1}\left(z^{t-1} \mid z_{0}\right)}{\widetilde{\beta}_{t} \hat{R}_{0, t}}
$$

where $\tilde{Q}_{t}$ was defined above as the time 0 price of consumption in period $t$ in the Bewley model. The prices of the (one-period ahead) Arrow securities are then given by:

$$
\hat{q}_{t}\left(z^{t}, z_{t+1}\right)=\frac{\hat{Q}_{t+1}\left(z^{t+1} \mid z_{0}\right)}{\hat{Q}_{t}\left(z^{t} \mid z_{0}\right)}=\hat{\beta}\left(z_{t}\right) \hat{\phi}\left(z_{t+1} \mid z_{t}\right) \frac{1}{\hat{R}_{t}} \frac{\widetilde{\beta}_{t}}{\widetilde{\beta}_{t+1}}=\hat{q}_{t}\left(z_{t+1} \mid z_{t}\right)
$$

where we used the fact that $\frac{1}{\hat{R}_{t}}=\frac{\hat{R}_{0, t}}{\hat{R}_{0, t+1}}$. Arrow prices are Markovian in $z_{t}$, since $\hat{R}_{t}$ and $\left(\widetilde{\beta}_{t}, \widetilde{\beta}_{t+1}\right)$ are all deterministic. Equation (35) implies that interest rates in the de-trended Arrow model are given by

$$
\hat{R}_{t}^{A}\left(z_{t}\right) \equiv \sum_{z_{t+1}} \hat{q}_{t}\left(z_{t+1} \mid z_{t}\right)=\hat{R}_{t} \frac{\widetilde{\beta}_{t+1}}{\hat{\beta}\left(z_{t}\right) \widetilde{\beta}_{t}}
$$

Interest rates now depend on the current aggregate state of the world $z_{t}$. Finally, we also conjecture that the stock price in the de-trended Arrow model satisfies:

$$
\hat{v}_{t}\left(z^{t}\right)=\hat{v}_{t}\left(z_{t}\right)=\sum_{z_{t+1}} \hat{\phi}\left(z_{t+1} \mid z_{t}\right)\left(\frac{\hat{v}_{t+1}\left(z_{t+1}\right)+\alpha}{\hat{R}_{t}^{A}\left(z_{t}\right)}\right)
$$

Armed with these conjectured prices we can now prove the following result.

Lemma 6.1. Absent solvency constraints, the household Euler equations are satisfied in the Arrow model at the Bewley allocations $\left\{\hat{c}_{t+1}\left(y^{t}, y_{t+1}\right)\right\}$ and Arrow prices $\left\{\hat{q}_{t}\left(z_{t+1} \mid z_{t}\right)\right\}$ given by (35). 
Trading Next, we spell out which asset trades support the Bewley equilibrium consumption allocations in the de-trended Arrow model, and we show that the implied contingent claims positions clear the market for Arrow securities.

At any point in time and any node of the event tree, the position of Arrow securities at the beginning of the period, plus the value of the stock position cum dividends, has to finance the value of excess demand from today into the infinite future. Thus, the Arrow securities position implied by the Bewley equilibrium allocation $\left\{\hat{c}_{t}\left(\theta_{0}, y^{t}\right), \hat{\sigma}_{t}\left(\theta_{0}, y^{t}\right)\right\}$ is given by 37

$$
\begin{aligned}
\hat{a}_{t-1}\left(\theta_{0}, y^{t-1}, z^{t}\right)= & \hat{c}_{t}\left(\theta_{0}, y^{t}\right)-(1-\alpha) \eta\left(y_{t}\right)+\sum_{\tau=t+1}^{\infty} \sum_{z^{\tau}, y^{\tau}} \hat{Q}_{\tau}\left(z^{\tau} \mid z_{t}\right) \varphi\left(y^{\tau} \mid y^{t}\right)\left(\hat{c}_{\tau}\left(\theta_{0}, y^{\tau}\right)-(1-\alpha) \eta\left(y_{\tau}\right)\right) \\
& -\hat{\sigma}_{t-1}\left(\theta_{0}, y^{t-1}\right)\left[\hat{v}_{t}\left(z_{t}\right)+\alpha\right]
\end{aligned}
$$

Proposition 6.1. The contingent claims positions implied by the Bewley allocations in (38) clear the Arrow securities markets, that is

$$
\int \sum_{y^{t-1}} \varphi\left(y^{t-1} \mid y_{0}\right) \hat{a}_{t-1}\left(\theta_{0}, y^{t-1}, z^{t}\right) d \Theta_{0}=0 \text { for all } z^{t}
$$

Since the wealth from stock holdings at the beginning of the period

$$
\hat{\sigma}_{t-1}\left(\theta_{0}, y^{t-1}\right)\left[\hat{v}_{t}+\alpha\right]=\alpha \hat{\sigma}_{t-1}\left(\theta_{0}, y^{t-1}\right) \sum_{\tau=t}^{\infty} \widetilde{Q}_{t, \tau}
$$

has to finance future excess consumption demand in the Bewley equilibrium, we can state the contingent claims positions as:

$$
\begin{aligned}
\hat{a}_{t-1}\left(\theta_{0}, y^{t-1}, z_{t}\right)= & \sum_{\tau=t+1}^{\infty} \sum_{z^{\tau}}\left(\hat{Q}_{\tau}\left(z^{\tau} \mid z_{t}\right)-\widetilde{Q}_{t, \tau}\right) \sum_{y^{\tau}} \varphi\left(y^{\tau} \mid y^{t}\right)\left(\hat{c}_{\tau}\left(\theta_{0}, y^{\tau}\right)-(1-\alpha) \eta\left(y_{\tau}\right)\right) \\
& -\hat{\sigma}_{t-1}\left(\theta_{0}, y^{t-1}\right) \alpha \sum_{\tau=t+1}^{\infty} \sum_{z^{\tau}}\left(\hat{Q}_{\tau}\left(z^{\tau} \mid z_{t}\right)-\widetilde{Q}_{t, \tau}\right)
\end{aligned}
$$

The Arrow securities positions held by households are used to hedge against the interest rate shocks that govern the difference between the stochastic $\hat{Q}_{\tau}\left(z^{\tau} \mid z_{t}\right)$ and the deterministic $\widetilde{Q}_{t, \tau}$. If aggregate endowment growth is i.i.d, there are no taste shocks in the detrended Arrow model, and from (36) we see that the interest rates are deterministic. The gap between $\hat{Q}_{\tau}\left(z^{\tau} \mid z_{t}\right)$ and $\widetilde{Q}_{t, \tau}$ is zero and no Arrow securities are traded in equilibrium, confirming the results in section 4.2 ,

In order to close our argument, we need to show that no initial wealth transfers between individuals are required for this implementation. In other words, the initial Arrow securities

\footnotetext{
${ }^{37}$ We will verify below that the price of the stock in the de-trended Arrow model satisfies $\hat{v}_{t}\left(z^{t}\right)=\hat{v}_{t}\left(z_{t}\right)$.
} 
position $\hat{a}_{-1}\left(\theta_{0}, y^{-1}, z_{0}\right)$ implied by (38) at time 0 , is zero for all households 38

To do so we proceed in two steps. First, we show that the average time zero state prices in the Arrow model coincide with the state prices in the Bewley model. For this result to hold our particular choice of time discount factors $\left\{\widetilde{\beta}_{t}\right\}$ for the Bewley model is crucial.

Lemma 6.2. The conjectured prices for the Arrow model in (34) and the prices in the Bewley model defined in (33) satisfy

$$
\sum_{z^{\tau}} \hat{Q}_{\tau}\left(z^{\tau} \mid z_{0}\right)=\tilde{Q}_{\tau}
$$

Finally, using this result we can establish that no wealth transfers are necessary to implement the Bewley equilibrium as equilibrium in the de-trended Arrow model.

Lemma 6.3. The Arrow securities position at time 0 given in (38) is zero:

$$
\hat{a}_{-1}\left(\theta_{0}, y^{-1}, z_{0}\right)=0
$$

Having established that the Bewley equilibrium is an equilibrium for the de-trended Arrow model with the same initial wealth distribution $\Theta_{0}$, the following theorem obviously results.

Theorem 6.2. An equilibrium of the Bewley model $\left\{\hat{c}_{t}\left(\theta_{0}, y^{t}\right), \hat{\sigma}_{t}\left(\theta_{0}, y^{t}\right)\right\}$ and $\left\{\hat{R}_{t}, \hat{v}_{t}\right\}$ where households have a sequence of time discount factors $\left\{\widetilde{\beta}_{t}\right\}$ can be made into an equilibrium for the Arrow model with growth, $\left\{a_{t}\left(\theta_{0}, s^{t}, z_{t+1}\right)\right\},\left\{\sigma_{t}\left(\theta_{0}, s^{t}\right)\right\},\left\{c_{t}\left(\theta_{0}, s^{t}\right)\right\}$ and $\left\{q_{t}\left(z^{t}, z_{t+1}\right)\right\},\left\{v_{t}\left(z^{t}\right)\right\}$, with

$$
\begin{aligned}
c_{t}\left(\theta_{0}, s^{t}\right) & =\hat{c}_{t}\left(\theta_{0}, y^{t}\right) e_{t}\left(z^{t}\right) \\
\sigma_{t}\left(\theta_{0}, s^{t}\right) & =\hat{\sigma}_{t}\left(\theta_{0}, y^{t}\right) \\
a_{t}\left(\theta_{0}, s^{t}, z_{t+1}\right) & =\hat{a}_{t}\left(\theta_{0}, y^{t}, z_{t+1}\right) e_{t+1}\left(z^{t+1}\right) \text { with } \hat{a}_{t} \text { defined in (38) } \\
v_{t}\left(z_{t}\right) & =\sum_{z_{t+1}} \frac{\hat{\phi}\left(z_{t+1} \mid z_{t}\right)}{\lambda\left(z_{t+1}\right)}\left[\frac{v_{t+1}\left(z_{t+1}\right)+\alpha e_{t+1}\left(z_{t+1}\right)}{\hat{R}_{t}^{A}\left(z_{t}\right)}\right] \\
\hat{R}_{t}^{A}\left(z_{t}\right) & =\frac{\hat{R}_{t} \widetilde{\beta}_{t+1}}{\hat{\beta}\left(z_{t}\right) \widetilde{\beta}_{t}} \\
q_{t}\left(z^{t}, z_{t+1}\right) & =\frac{\hat{q}_{t}\left(z^{t}, z_{t+1}\right)}{\lambda\left(z_{t+1}\right)}=\frac{1}{\hat{R}_{t}^{A}\left(z_{t}\right)} * \frac{\phi\left(z_{t+1} \mid z_{t}\right) \lambda\left(z_{t+1}\right)^{-\gamma}}{\sum_{z_{t+1}} \phi\left(z_{t+1} \mid z_{t}\right) \lambda\left(z_{t+1}\right)^{1-\gamma}}
\end{aligned}
$$

Risk Premia Of course, this implies that our baseline irrelevance result for risk premia survives the introduction of non-i.i.d. aggregate shocks, provided that a complete menu of aggregate-

\footnotetext{
${ }^{38}$ Without this argument we merely would have shown that a Bewley equilibrium for initial condition $\Theta_{0}$ can be implemented as equilibrium of the de-trended Arrow model with initial conditions $z_{0}$ and some initial distribution of wealth, but not necessarily $\Theta_{0}$.
} 
state-contingent securities is traded 39 These aggregate taste shocks only affect interest rates and price/dividend ratios, not risk premia. When agents in the transformed model become more impatient, the interest rises and the price/dividend ratio decreases, but the conditional expected excess return is unchanged.

Solvency Constraints So far, we have abstracted from binding solvency constraints. Previously, we assumed that the solvency constraints satisfy $K_{t}\left(s^{t}\right)=\hat{K}_{t}\left(y^{t}\right) e_{t}\left(z^{t}\right)$ and $M_{t+1}\left(s^{t+1}\right)=$ $\hat{M}_{t}\left(y^{t}\right) e_{t}\left(z^{t+1}\right)$. The allocations computed in the stationary model using $\hat{K}_{t}\left(y^{t}\right)$ and $\hat{M}_{t}\left(y^{t}\right)$ as solvency constraints, satisfy a modified version of the solvency constraints $K_{t}\left(s^{t}\right)$ and $M_{t+1}\left(s^{t+1}\right)$.

Proposition 6.2. The allocations from theorem C.1 satisfy the modified solvency constraints:

$$
\begin{aligned}
K_{t}^{*}\left(s^{t}\right) & =K_{t}\left(s^{t}\right)+\sum_{z_{t+1}} q_{t}\left(z^{t}, z_{t+1}\right) a_{t}\left(\theta_{0}, s^{t}, z_{t+1}\right)+\sigma_{t}\left(\theta_{0}, s^{t}\right)\left[v_{t}\left(z_{t}\right)-\hat{v}_{t} e_{t}\left(z^{t}\right)\right] \\
M_{t+1}^{*}\left(s^{t+1}\right) & =M_{t+1}\left(s^{t+1}\right)+a_{t}\left(\theta_{0}, s^{t}, z_{t+1}\right)+\sigma_{t}\left(\theta_{0}, s^{t}\right)\left[v_{t+1}\left(z_{t+1}\right)-\hat{v}_{t+1} e_{t+1}\left(z^{t+1}\right)\right]
\end{aligned}
$$

where $\hat{v}_{t}$ is the (deterministic) Bewley equilibrium stock price.

If the allocations satisfy the constraints in the stationary Bewley model, they satisfy the modified solvency constraints in the actual Arrow model, but not the ones we originally specified, because of the nonzero state-contingent claims positions 40 Nevertheless, in principle, one could reverse-engineer a sequence of auxiliary solvency constraints such that in the actual equilibrium the modified version of the auxiliary constraints coincides with the actual constraints we want to impose, $K_{t}\left(s^{t}\right)$.

\subsubsection{Bond Model}

Finally, in the Bond model, our previous equivalence result no longer holds, since with predictability in aggregate consumption growth households trade state-contingent claims in the equilibrium of the Arrow model. Unless the aggregate shock can only take two values, the market structure of the Bond model prevents them from doing so, and thus our implementation and irrelevance results in this model are not robust to the introduction of non-i.i.d aggregate endowment growth.

\footnotetext{
${ }^{39}$ Note that

$$
\kappa_{t}\left(z_{t}\right)=\frac{\hat{R}_{t}^{R E}\left(z_{t}\right)}{\hat{R}_{t}^{A}\left(z_{t}\right)}=\frac{\widetilde{\beta}_{t}}{\hat{R}_{t} \widetilde{\beta}_{t+1}}=\kappa_{t}
$$

is still deterministic, and thus the proofs of section 5 go through unchanged.

${ }^{40}$ Note that these violations of the original constraints are completely due to the impact of interest rate shocks on the value of the asset portfolio.
} 


\subsection{Permanent Idiosyncratic Shocks}

Our results do not hinge on mean reversion in household income. In fact, we can also consider a version of our model with permanent idiosyncratic income shocks. In this economy, household income in logs follows a random walk:

$$
\log \eta_{t}=\log \eta_{t-1}+y_{t}
$$

where $y_{t} \sim N\left(-\frac{1}{2} \sigma_{y}^{2}, \sigma_{y}^{2}\right)$ is normally distributed and independent over time and across households. Also, we assume that $\eta_{-1}=1$ for all households. This implies that the level of household labor income at $t$ is given by:

$$
\eta_{t}\left(y^{t}\right)=\exp \left(\sum_{s=0}^{t} y_{s}\right) .
$$

and thus at any time $t$ we know that $E\left(\eta_{t}\left(y^{t}\right)\right)=1$, where $E$ is the expectation at time 0 for a single household. By the law of large numbers this expression is also equal to the cross-sectional expectation. As before, the stock pays a fraction $\alpha$ of the aggregate endowment $e_{t}\left(z^{t}\right)$ as dividends and the shares are in constant unit supply. In this environment, our aggregation and irrelevance result survives, under the same assumptions as in the paper. This follows because the implementation in the proof we provided above does not rely on mean reversion in labor income at all 41

In addition, one can show that in the case of permanent shocks as modeled above, an autarkic equilibrium in which agents do not trade and simply consume their labor income and dividends exists if and only if $\alpha=0$, that is, if all assets are in zero net supply. Therefore, even in the case of permanent shocks, equilibria in our environment need to feature trade in financial markets, unless $\alpha=0$. How does this result relate to the autarchy equilibrium in CD? To generate such an equilibrium with $\alpha>0$ they reverse-engineer the aggregate dividend process and the household labor income process. The resulting labor income process depends on the aggregate dividend process and it is not consistent with the standard random walk specification in equation (41) 42

Finally, we conclude by describing the extension of our irrelevance result to an environment with a counter-cyclical labor income share. It turns out that the results we derived in the two-period economy carry over.

\footnotetext{
${ }^{41}$ Of course, in the case of permanent shocks the existence of (stationary) equilibrium in the Bewley model becomes an issue. This problem can be circumvented by assuming that households die at an exponential rate, as in Yaari (1965).

${ }^{42}$ As explained by CD, their specification of the household labor income process is not empirically motivated (see bottom of page 228); the sole focus is tractability. Their household income process in logs features some mean reversion whose magnitude depends on the size of aggregate dividend payments.
} 


\subsection{Counter-cyclical aggregate labor income share}

The relevant question is whether households can keep their own consumption in line with the aggregate endowment in spite of the cyclical variation in the aggregate labor and capital income share by taking positions in the contingent bond markets. If they can do so, then the variation in the aggregate labor income share will have no bearing on allocations and prices. The intuition that we derived in the two-period economy extends to the infinite horizon economy: In the standard multiplicative case $(\eta(y, z)=\eta(y)(1-\alpha(z)))$, the Bewley equilibrium that we have derived cannot be implemented in the de-trended Arrow economy, because the required contingent bond payoff depends on the idiosyncratic shock realization $y_{t+1}$ at $t+1$ :

$$
a_{t}\left(\theta_{0}, s^{t}, y_{t+1}, z_{t+1}\right)=\hat{a}_{t}\left(\theta_{0}, y^{t}\right) e_{t+1}\left(z^{t+1}\right)-\left(\alpha-\alpha\left(z_{t+1}\right)\right) \eta\left(y_{t+1}\right)+\hat{\sigma}_{t}\left(\theta_{0}, y^{t}\right)\left(\alpha-\alpha\left(z_{t+1}\right)\right) .
$$

Hence, the irrelevance result breaks down. To replicate the payoffs of a claim to aggregate consumption, households need to issue bonds with payoffs that are contingent on the idiosyncratic shocks. However, if we assume that the household's labor income as a share of the aggregate endowment is given by the standard component $\eta(y)$, which depends only on the realization of the idiosyncratic event $y$ and a second component which depends on the realization of the aggregate shock $z$ :

$$
\eta(y, z)=\alpha-\alpha(z)+(1-\alpha) \eta(y)
$$

then the required contingent bond payoff does not depend on the idiosyncratic shock $y_{t+1}$ at $t+1$ :

$$
a_{t}\left(\theta_{0}, s^{t}, z_{t+1}\right)=\hat{a}_{t}\left(\theta_{0}, y^{t}\right) e_{t+1}\left(z^{t+1}\right)-\left(\alpha-\alpha\left(z_{t+1}\right)\right)+\hat{\sigma}_{t}\left(\theta_{0}, y^{t}\right)\left(\alpha-\alpha\left(z_{t+1}\right)\right) .
$$

Households with more than average financial wealths short contingent consumption claims for expansions and go long in contingent consumption claims for expansions. Households with financial wealth below the average do the opposite. Section C.2 in the separate appendix spells out the details. This means that we have implemented the same Bewley equilibrium in the de-trended Arrow economy with stochastic capital shares. Of course, the implementation of the Bewley equilibrium now requires trade in the contingent claim markets. The irrelevance result breaks down in the Bond economy, except in the case with only two aggregate states. This is not surprising. In the standard multiplicative case, the cross sectional distribution of the (demeaned) household income shares is not independent of aggregate shocks, whereas in the additive case it is. And our results go through in the additive case, but not in the multiplicative case. Essentially, in the multiplicative case, a large labor share (small $\alpha\left(z_{t}\right)$ ) increases the variance of the idiosyncratic shocks, exactly like CCV. 


\section{Conclusion}

We have derived conditions under which the history of a household's idiosyncratic shocks has no effect on his portfolio choice, even in the presence of binding solvency constraints. This portfolio irrelevance result directly implies the risk premium irrelevance result. Since all households bear the same amount of aggregate risk in equilibrium, the history of aggregate shocks does not affect equilibrium prices and allocations. The equilibrium risk-free rate, the risk premium and the price/dividend ratio are all deterministic, at least in the benchmark model without predictability in aggregate consumption growth. However, only a weaker version of this irrelevance result survives in economies with a predictable component in aggregate consumption growth (see e.g. Bansal and Yaron (2004)), because this component creates heterogeneous hedging demands that do depend on the household's history of idiosyncratic shocks. This deserves to be explored further.

Other than predictability in aggregate consumption growth shocks, there are two main ways around our results. One approach is to concentrate aggregate risk by forcing some households out of the stock market altogether. This is the approach adopted in the literature on limited participation (see e.g. Guvenen (2003), Vissing-Jorgensen (2002), Gomes and Michaelides (2008), Chien, Cole, and Lustig (2009) and Attanasio, Banks, and Tanner (2002)). The second approach consists of concentrating labor income risk in recessions. Recently Krusell and Smith (1997) and Storesletten, Telmer, and Yaron (2007) have argued that models with idiosyncratic income shocks and incomplete markets can generate an equity premium that is substantially larger than the CCAPM if there is counter-cyclical cross-sectional variance (CCV) in labor income shocks. Storesletten, Telmer and Yaron (2004) argue that this condition is satisfied in the data, although it is not clear the CCV in the data is strong enough to explain equity risk premia at reasonable levels of risk aversion. Our paper demonstrates analytically that $\mathrm{CCV}$ in labor income or limited stock market participation is not only sufficient, but necessary to make uninsurable idiosyncratic income shocks potentially useful for explaining the equity premium, even in the presence of binding solvency constraints.

\section{References}

AiYAgari, S. R. (1994): "Uninsured Idiosyncratic Risk and Aggregate Saving," The Quarterly Journal of Economics, 109, 659-684.

Aiyagari, S. R., And M. Gertler (1991): "Asset Returns with Transaction Costs and Uninsured Individual Risk," Journal of Monetary Economics, 27, 311-331.

Alvarez, F., and U. Jermann (2000): "Efficiency, Equilibrium, and Asset Pricing with Risk of Default.," Econometrica, 68(4), 775-798. 
(2001): "Quantitative Asset Pricing Implications of Endogenous Solvency Constraints,," Review of Financial Studies, 14, 1117-1152.

Angeletos, G.-M., And L.-E. Calvet (2006): "Idiosyncratic production risk, growth and the business cycle," Journal of Monetary Economics, Volume 53(6), 1095-1115.

Attanasio, O., J. Banks, and S. Tanner (2002): "Asset Holding and Consumption Volatility," Journal of Political Economy, 110(4), 771-792.

Bansal, R., And A. Yaron (2004): "Risks for the Long-Run: A Potential Resolution of Asset Pricing Puzzles," Journal of Finance, 59(4), 1481-1509.

BEwLEY, T. (1986): "Stationary Monetary Equilibrium with a Continuum of Independently Fluctuating Consumers," in Contributions to Mathematical Economics in Honor of Gerard Debreu, ed. by W. Hildenbrand, and A. Mas-Collel. North-Holland, Amsterdam.

Breeden, D. T. (1979): "An Intertemporal Asset Pricing Model with Stochastic Consumption and Investment Opportunities," Journal of Financial Economics, 7, 265-296.

Campbell, J. Y. (2006): "Household Finance," Journal of Finance, LXI(4), 1553-1607.

Campbell, J. Y., and J. H. Cochrane (1999): "By Force of Habit: A Consumption-Based Explanation of Aggregate Stock Market Behavior," Journal of Political Economy, 107(2), 205251.

Chan, Y. L., and L. Kogan (2002): "Catching Up With the Joneses: Heterogeneous Preferences and the Dynamics of Asset Prices," Journal of Political Economy, 110, 1255-1285.

Chien, Y., H. Cole, And H. Lustig (2009): "A Multiplier Approach to Understanding the Macro Implications of Household Finance," Available at SSRN: http://ssrn.com/abstract=1023184.

Cochrane, J. H., And L. P. Hansen (1992): "Asset Pricing Explorations for Macroeconomics," NBER Macroeconomics Annual, pp. 115-164.

Constantinides, G. (1982): "Intertemporal Asset Pricing with Heterogeneous Consumers and Without Demand Aggregation," Journal of Business, 55(2), 253-67.

Constantinides, G. M., And D. Duffie (1996): "Asset Pricing with Heterogeneous Consumers," Journal of Political Economy, 104, 219-240. 
Cooley, T. F., and E. C. Prescott (1995): "Economic Growth and Business Cycles," in Frontiers of Business Cycle Research, ed. by T. Cooley. Princeton University Press, Princeton, N.J.

DenhaAn, W. J. (2001): "Understanding Equilibrium Models with a Small and a Large Number of Agents," Journal of Economic Dynamics and Control, 25, 721-746.

Dumas, B. (1989): "Two-Person Dynamic Equilibrium in the Capital Market," Review of Financial Studies, 2(2), 157-188.

Epstein, L. G., And S. Zin (1989): "Substitution, Risk Aversion and the Temporal Behavior of Consumption and Asset Returns: A Theoretical Framework," Econometrica, 57, 937-969.

Garleanu, N. B., and S. Panageas (2007): "Young, Old, Conservative, and Bold: The Implications of Heterogeneity and Finite Lives for Asset Pricing," mimeo Working Paper Haas School of Business.

Gomes, F., And A. Michaelides (2008): "Asset Pricing with Limited Risk Sharing and Heterogeneous Agents," Review of Financial Studies, 21(1), 415-448.

Grossman, S., and R. Shiller (1982): "Consumption Correlatedness and Risk Measurement in Economies with Non-Traded Assets and Heterogeneous Information," Journal of Financial Economics, 10, 195-210.

Guvenen, F. (2003): "A Parsimonious Macroeconomic Model for Asset Pricing: Habit Formation or Cross-Sectional Heterogeneity," Working Paper University of Rochester.

Hammond, P., And Y. Sun (2003): "Monte Carlo Simulation of Macroeconomic Risk with a Continuum of Agents: The Symmetric Case," Economic Theory, 21, 743-766.

Hansen, L. P., And K. J. Singleton (1983): "Stochastic Consumption, Risk Aversion, and the Temporal Behavior of Asset Returns," Journal of Political Economy, 91, 249-265.

Harrison, M. J., And D. M. Kreps (1979): "Martingales and Arbitrage in Multiperiod Securities Markets," Journal of Economic Theory, 20, 381-408.

Heaton, J., And D. LuCAS (1996): "Evaluating the Effects of Incomplete Markets on Risk Sharing and Asset Pricing," Journal of Political Economy, 104, 668-712.

Huggett, M. (1993): "The Risk-Free Rate in Heterogeneous Agent Incomplete Insurance Economies," Journal of Economic Dynamics and Control, 17, 953-969. 
Kocherlakota, N. (1996): "The Equity Premium: It's Still a Puzzle," Journal of Economic Literature, 34, 42-71.

KreBs, T. (2006): "Recursive Equilibrium in Endogenous Growth Models with Incomplete Markets," Economic Theory, 29, 505-523.

Krusell, P., and A. Smith (1997): "Income and Wealth Heterogeity, Portfolio Choice, and Equilibrium Asset Returns," Macroeconomic Dynamics, 1, 387-422.

(1998): "Income and Wealth Heterogeneity in the Macroeconomy," Journal of Political Economy, 6, 867-896.

Kubler, F., And K. Schmedders (2002): "Recursive Equilibria in Economies with Incomplete Markets," Macroeconomic Dynamics, 6, 284-306.

Levine, D., And W. Zame (2002): "Does Market Incompleteness Matter?," Econometrica, vol. $70(5), 1805-1839$.

Ljungqvist, L., And T. J. Sargent (2004): Recursive Macroeconomic Theory, Second Edition. MIT Press, Cambridge, Mass.

LucAs, D. (1994): "Asset Pricing with Unidiversifiable Income Risk and Short Sales Constraints: Deepening the Equity Premium Puzzle," Journal of Monetary Economics, 34, 325-341.

LucAs, R. (1978): “Asset Prices in an Exchange Economy," Econometrica, 46(6), 1429-54.

Luttmer, E. (1991): “Asset Pricing in Economies with Frictions," Ph.D. thesis.

Mankiw, G. N. (1986): "The Equity Premium and the Concentration of Aggregate Shocks," Journal of Financial Economics, 17, 211-219.

Marcet, A., And K. Singleton (1999): "Equilibrium Asset Prices and Savings of Heterogeneous Agents in the Presence of Incomplete Markets and Portfolio Constraints," Macroeconomic Dynamics, 3, 243-277.

Mehra, And E. Prescott (1985): "The Equity Premium: A Puzzle.," Journal of Monetary Economics, 15(2), 145-161.

MiAo, J. (2006): "Competitive Equilibria of Economies with a Continuum of Consumers and Aggregate Shocks," Journal of Economic Theory, 128, 274-298.

Negishi, T. (1960): "Welfare Economics and Existence of an Equilibrium for a Competitive Economy," Metroeconomica, 12, 92-97. 
Rubinstein, M. (1974): “An Aggregation Theorem for Security Markets," Journal of Financial Economics, 1, 225-244.

Schulhofer-Wohl, S. (2008): "Heterogeneity, Risk Sharing and the Welfare Costs of Idiosyncratic Risk,".

Storesletten, K., C. Telmer, and A. Yaron (2004): "Cyclical Dynamics in Idiosyncratic Labor-Market Risk," Journal of Political Economy, 112, 695-717.

(2007): "Asset pricing with idiosyncratic risk and overlapping generations," Review of Economic Dynamics, 10(4), 519-548.

Telmer, C. (1993): “Asset-Pricing Puzzles and Incomplete Markets," Journal of Finance, 48, $1803-1832$.

Vissing-Jorgensen, A. (2002): "Limited Asset market Participation and Elasticity of Intertemporal Substitution," The Journal of Political Economy, 110(4), 825-853.

Weil, P. (1989): "The Equity Premium Puzzle and the Risk-Free Rate Puzzle," Journal of Monetary Economics, 24, 401-424.

WeIL, P. (1992): "Equilibrium Asset Prices with Undiversifable Labor Income Risk," Journal of Economic Dynamics and Control, 16, 769-790.

Willen, P. (1999): "Welfare, Financial Innovation and Self-Insurance in Dynamic Incomplete Market Models," Working Paper.

Wilson, R. (1968): "The Theory of Syndicates," Econometrica, 36, 119-32.

YAARI, M. E. (1965): "Uncertain Lifetime, Life Insurance, and the Theory of the Consumer," Review of Economic Studies, 32(2), 137-150. 


\section{A Additional Definitions}

\section{A.1 Arrow Model}

The definition of an equilibrium in the Arrow model is standard. Each household is assigned a label that consists of its initial financial wealth $\theta_{0}$ and its initial state $s_{0}=\left(y_{0}, z_{0}\right)$. A household of type $\left(\theta_{0}, s_{0}\right)$ then chooses consumption allocations $\left\{c_{t}\left(\theta_{0}, s^{t}\right)\right\}$, trading strategies for Arrow securities $\left\{a_{t}\left(\theta_{0}, s^{t}, z_{t+1}\right)\right\}$ and shares $\left\{\sigma_{t}\left(\theta_{0}, s^{t}\right)\right\}$ to maximize her expected utility (11), subject to the budget constraints (11) and subject to solvency constraints (13) or (14).

Definition A.1. For initial aggregate state $z_{0}$ and distribution $\Theta_{0}$ over $\left(\theta_{0}, y_{0}\right)$, a competitive equilibrium for the Arrow model consists of household allocations $\left\{a_{t}\left(\theta_{0}, s^{t}, z_{t+1}\right)\right\},\left\{\sigma_{t}\left(\theta_{0}, s^{t}\right)\right\},\left\{c_{t}\left(\theta_{0}, s^{t}\right)\right\}$ and prices $\left\{q_{t}\left(z^{t}, z_{t+1}\right)\right\},\left\{v_{t}\left(z^{t}\right)\right\}$ such that

1. Given prices, household allocations solve the household maximization problem

2. The goods market clears for all $z^{t}$,

$$
\int \sum_{y^{t}} \frac{\pi\left(y^{t}, z^{t} \mid y_{0}, z_{0}\right)}{\pi\left(z^{t} \mid z_{0}\right)} c_{t}\left(\theta_{0}, s^{t}\right) d \Theta_{0}=e_{t}\left(z^{t}\right)
$$

3. The asset markets clear for all $z^{t}$

$$
\begin{aligned}
\int \sum_{y^{t}} \frac{\pi\left(y^{t}, z^{t} \mid y_{0}, z_{0}\right)}{\pi\left(z^{t} \mid z_{0}\right)} \sigma_{t}\left(\theta_{0}, s^{t}\right) d \Theta_{0} & =1 \\
\int \sum_{y^{t}} \frac{\pi\left(y^{t}, z^{t} \mid y_{0}, z_{0}\right)}{\pi\left(z^{t} \mid z_{0}\right)} a_{t}\left(\theta_{0}, s^{t}, z_{t+1}\right) d \Theta_{0} & =0 \text { for all } z_{t+1} \in Z
\end{aligned}
$$

\section{A.1.1 Optimality Conditions for De-trended Arrow Model}

Define the Lagrange multiplier

$$
\hat{\beta}\left(s^{t}\right) \hat{\pi}\left(s^{t} \mid s_{0}\right) u^{\prime}\left(\hat{c}_{t}\left(s^{t}\right)\right) \hat{\mu}\left(s^{t}\right) \geq 0
$$

for the constraint in (16) and

$$
\hat{\beta}\left(s^{t}\right) \hat{\pi}\left(s^{t} \mid s_{0}\right) u^{\prime}\left(\hat{c}_{t}\left(s^{t}\right)\right) \hat{\kappa}_{t}\left(s^{t}, z_{t+1}\right) \geq 0
$$

for the constraint in (17). The Euler equations of the de-trended Arrow model are given by:

$$
\begin{aligned}
1= & \frac{\hat{\beta}\left(s_{t}\right)}{\hat{q}_{t}\left(z^{t}, z_{t+1}\right)} \sum_{s^{t+1} \mid s^{t}, z_{t+1}} \hat{\pi}\left(s_{t+1} \mid s_{t}\right) \frac{u^{\prime}\left(\hat{c}_{t+1}\left(s^{t}, s_{t+1}\right)\right)}{u^{\prime}\left(\hat{c}_{t}\left(s^{t}\right)\right)} \\
& +\hat{\mu}_{t}\left(s^{t}\right)+\frac{\hat{\kappa}_{t}\left(s^{t}, z_{t+1}\right)}{\hat{q}_{t}\left(z^{t}, z_{t+1}\right)} \forall z_{t+1} . \\
1= & \hat{\beta}\left(s_{t}\right) \sum_{s^{t+1} \mid s^{t}} \hat{\pi}\left(s_{t+1} \mid s_{t}\right)\left[\frac{\hat{v}_{t+1}\left(z^{t+1}\right)+\alpha}{\hat{v}_{t}\left(z^{t}\right)}\right] \frac{u^{\prime}\left(\hat{c}_{t+1}\left(s^{t}, s_{t+1}\right)\right)}{u^{\prime}\left(\hat{c}_{t}\left(s^{t}\right)\right)} \\
& +\hat{\mu}_{t}\left(s^{t}\right)+\sum_{z_{t+1}} \hat{\kappa}_{t}\left(s^{t}, z_{t+1}\right)\left[\frac{\hat{v}_{t+1}\left(z^{t+1}\right)+\alpha}{\hat{v}_{t}\left(z^{t}\right)}\right] .
\end{aligned}
$$


Only one of the two Lagrange multipliers enters the equations, depending on which version of the solvency constraint we consider. The complementary slackness conditions for the Lagrange multipliers are given by

$$
\begin{aligned}
\hat{\mu}_{t}\left(s^{t}\right)\left[\sum_{z_{t+1}} \hat{a}_{t}\left(s^{t}, z_{t+1}\right) \hat{q}_{t}\left(z^{t}, z_{t+1}\right)+\hat{\sigma}_{t}\left(s^{t}\right) \hat{v}_{t}\left(z^{t}\right)-\hat{K}_{t}\left(y^{t}\right)\right] & =0 \\
\hat{\kappa}_{t}\left(s^{t}, z_{t+1}\right)\left[\hat{a}_{t}\left(s^{t}, z_{t+1}\right)+\hat{\sigma}_{t}\left(s^{t}\right)\left[\hat{v}_{t+1}\left(z^{t+1}\right)+\alpha\right]-\hat{M}_{t}\left(y^{t}\right)\right] & =0 .
\end{aligned}
$$

The appropriate transversality conditions read as

$$
\begin{aligned}
\lim _{t \rightarrow \infty} \sum_{s^{t}} \hat{\beta}\left(s^{t-1}\right) \hat{\pi}\left(s^{t} \mid s_{0}\right) u^{\prime}\left(\hat{c}_{t}\left(s^{t}\right)\right)\left[\hat{a}_{t-1}\left(s^{t-1}, z_{t}\right)-\hat{M}_{t-1}\left(y^{t-1}\right)\right] & =0 . \\
\lim _{t \rightarrow \infty} \sum_{s^{t}} \hat{\beta}\left(s^{t-1}\right) \hat{\pi}\left(s^{t} \mid s_{0}\right) u^{\prime}\left(\hat{c}_{t}\left(s^{t}\right)\right)\left[\hat{\sigma}_{t-1}\left(s^{t-1}\right)\left(\hat{v}_{t}\left(z^{t}\right)+\alpha\right)-\hat{M}_{t-1}\left(y^{t-1}\right)\right] & =0,
\end{aligned}
$$

and

$$
\begin{aligned}
\lim _{t \rightarrow \infty} \sum_{s^{t}} \hat{\beta}\left(s^{t-1}\right) \hat{\pi}\left(s^{t} \mid s_{0}\right) u^{\prime}\left(\hat{c}_{t}\left(s^{t}\right)\right)\left[\sum_{z_{t+1}} \hat{a}_{t}\left(s^{t}, z_{t+1}\right) \hat{q}_{t}\left(z^{t}, z_{t+1}\right)-\hat{K}_{t}\left(y^{t}\right)\right] & =0 . \\
\lim _{t \rightarrow \infty} \sum_{s^{t}} \hat{\beta}\left(s^{t-1}\right) \hat{\pi}\left(s^{t} \mid s_{0}\right) u^{\prime}\left(\hat{c}_{t}\left(s^{t}\right)\right)\left[\hat{\sigma}_{t}\left(s^{t}\right) \hat{v}_{t}\left(z^{t}\right)-\hat{K}_{t}\left(y^{t}\right)\right] & =0 .
\end{aligned}
$$

Since the household optimization has a concave objective function and a convex constraint set the first order conditions and complementary slackness conditions, together with the transversality condition, are necessary and sufficient conditions for optimality of household allocation choices.

\section{A.2 Bond Model}

Agents only trade a single bond a single stock. Wealth tomorrow in state $s^{t+1}=\left(s^{t}, y_{t+1}, z_{t+1}\right)$ is given by

$$
\theta_{t+1}\left(s^{t+1}\right)=(1-\alpha) \eta\left(y_{t+1}\right) e_{t+1}\left(z_{t+1}\right)+b_{t}\left(s^{t}\right)+\sigma_{t}\left(s^{t}\right)\left[v_{t+1}\left(z^{t+1}\right)+\alpha e_{t+1}\left(z_{t+1}\right)\right] .
$$

Definition A.2. For an initial aggregate state $z_{0}$ and distribution $\Theta_{0}$ over $\left(\theta_{0}, y_{0}\right)$, a competitive equilibrium for the Bond model consists of household allocations $\left\{b_{t}\left(\theta_{0}, s^{t}\right)\right\},\left\{c_{t}\left(\theta_{0}, s^{t}\right)\right\},\left\{\sigma_{t}\left(\theta_{0}, s^{t}\right)\right\}$, and interest rates $\left\{R_{t}\left(z^{t}\right)\right\}$ and share prices $\left\{v_{t}\left(z^{t}\right)\right\}$ such that

1. Given prices, allocations solve the household maximization problem.

2. The goods market clears for all $z^{t}$ :

$$
\int \sum_{y^{t}} \frac{\pi\left(y^{t}, z^{t} \mid y_{0}, z_{0}\right)}{\pi\left(z^{t} \mid z_{0}\right)} c_{t}\left(\theta_{0}, s^{t}\right) d \Theta_{0}=e_{t}\left(z^{t}\right) .
$$


3. The asset markets clear for all $z^{t}$ :

$$
\begin{aligned}
& \int \sum_{y^{t}} \frac{\pi\left(y^{t}, z^{t} \mid y_{0}, z_{0}\right)}{\pi\left(z^{t} \mid z_{0}\right)} \sigma_{t}\left(\theta_{0}, s^{t}\right) d \Theta_{0}=1 . \\
& \int \sum_{y^{t}} \frac{\pi\left(y^{t}, z^{t} \mid y_{0}, z_{0}\right)}{\pi\left(z^{t} \mid z_{0}\right)} b_{t}\left(\theta_{0}, s^{t}\right) d \Theta_{0}=0 .
\end{aligned}
$$

\section{A.2.1 Optimality Conditions for Bond Model}

Define the Lagrange multiplier

$$
\hat{\beta}\left(s^{t}\right) \hat{\pi}\left(s^{t} \mid s_{0}\right) u^{\prime}\left(\hat{c}_{t}\left(s^{t}\right)\right) \hat{\mu}\left(s^{t}\right) \geq 0
$$

for the constraint in (29) and

$$
\hat{\beta}\left(s^{t}\right) \hat{\pi}\left(s^{t} \mid s_{0}\right) u^{\prime}\left(\hat{c}_{t}\left(s^{t}\right)\right) \hat{\kappa}_{t}\left(s^{t}, z_{t+1}\right) \geq 0
$$

for the constraint in (30). In the detrended Bond model the Euler equations read as

$$
\begin{aligned}
1= & \hat{\beta}\left(s_{t}\right) \sum_{s^{t+1} \mid s^{t}} \hat{\pi}\left(s_{t+1} \mid s_{t}\right)\left[\frac{R_{t}\left(z^{t}\right)}{\lambda\left(z_{t+1}\right)}\right] \frac{u^{\prime}\left(\hat{c}_{t+1}\left(s^{t}, s_{t+1}\right)\right)}{u^{\prime}\left(\hat{c}_{t}\left(s^{t}\right)\right)} \\
& +\hat{\mu}_{t}\left(s^{t}\right)+\sum_{z_{t+1}} \hat{\kappa}_{t}\left(s^{t}, z_{t+1}\right)\left[\frac{R_{t}\left(z^{t}\right)}{\lambda\left(z_{t+1}\right)}\right] . \\
1= & \hat{\beta}\left(s_{t}\right) \sum_{s^{t+1} \mid s^{t}} \hat{\pi}\left(s_{t+1} \mid s_{t}\right)\left[\frac{\hat{v}_{t+1}\left(z^{t+1}\right)+\alpha}{\hat{v}_{t}\left(z^{t}\right)}\right] \frac{u^{\prime}\left(\hat{c}_{t+1}\left(s^{t}, s_{t+1}\right)\right)}{u^{\prime}\left(\hat{c}_{t}\left(s^{t}\right)\right)} . \\
& +\hat{\mu}_{t}\left(s^{t}\right)+\sum_{z_{t+1}} \hat{\kappa}_{t}\left(s^{t}, z_{t+1}\right)\left[\frac{\hat{v}_{t+1}\left(z^{t+1}\right)+\alpha}{\hat{v}_{t}\left(z^{t}\right)}\right]
\end{aligned}
$$

with complementary slackness conditions given by:

$$
\begin{aligned}
\hat{\mu}_{t}\left(s^{t}\right)\left[\frac{\hat{b}_{t}\left(s^{t}\right)}{R_{t}\left(z^{t}\right)}+\hat{\sigma}_{t}\left(s^{t}\right) \hat{v}_{t}\left(z^{t}\right)-\hat{K}_{t}\left(y^{t}\right)\right] & =0 \\
\hat{\kappa}_{t}\left(s^{t}, z_{t+1}\right)\left[\frac{\hat{b}_{t}\left(s^{t}\right)}{\lambda\left(z_{t+1}\right)}+\hat{\sigma}_{t}\left(s^{t}\right)\left[\hat{v}_{t+1}\left(z^{t+1}\right)+\alpha\right]-\hat{M}_{t}\left(y^{t}\right)\right] & =0 .
\end{aligned}
$$

The transversality conditions are given by

$$
\begin{array}{r}
\lim _{t \rightarrow \infty} \sum_{s^{t}} \hat{\beta}\left(s^{t-1}\right) \hat{\pi}\left(s^{t} \mid s_{0}\right) u^{\prime}\left(\hat{c}_{t}\left(s^{t}\right)\right)\left[\frac{\hat{b}_{t-1}\left(s^{t-1}\right)}{\lambda\left(z_{t}\right)}-\hat{M}_{t-1}\left(y^{t-1}\right)\right]=0 . \\
\lim _{t \rightarrow \infty} \sum_{s^{t}} \hat{\beta}\left(s^{t-1}\right) \hat{\pi}\left(s^{t} \mid s_{0}\right) u^{\prime}\left(\hat{c}_{t}\left(s^{t}\right)\right)\left[\hat{\sigma}_{t-1}\left(s^{t-1}\right)\left(\hat{v}_{t}\left(z^{t}\right)+\alpha\right)-\hat{M}_{t-1}\left(y^{t-1}\right)\right]=0
\end{array}
$$


and

$$
\begin{aligned}
\lim _{t \rightarrow \infty} \sum_{s^{t}} \hat{\beta}\left(s^{t-1}\right) \hat{\pi}\left(s^{t} \mid s_{0}\right) u^{\prime}\left(\hat{c}_{t}\left(s^{t}\right)\right)\left[\frac{\hat{b}_{t}\left(s^{t}\right)}{R_{t}\left(z^{t}\right)}-\hat{K}_{t}\left(y^{t}\right)\right] & =0 . \\
\lim _{t \rightarrow \infty} \sum_{s^{t}} \hat{\beta}\left(s^{t-1}\right) \hat{\pi}\left(s^{t} \mid s_{0}\right) u^{\prime}\left(\hat{c}_{t}\left(s^{t}\right)\right)\left[\hat{\sigma}_{t}\left(s^{t}\right) \hat{v}_{t}\left(z^{t}\right)-\hat{K}_{t}\left(y^{t}\right)\right] & =0 .
\end{aligned}
$$

\section{B Proofs}

- Proof of Proposition 3.1.

Proof. We briefly derive this result. We can construct an equilibrium in the two period-economy from the household's first order conditions. These are necessary and sufficient. We use $\lambda_{0}\left(s_{0}\right)$ and $\lambda_{1}\left(s^{1}\right)$ to denote the Lagrangian multipliers on the budget constraints at time 0 and time 1 . The first order conditions are given by the first order condition for consumption at time 0 , at time 1 , and for contingent bond purchases in each aggregate state of the world:

$$
\begin{aligned}
\lambda_{0}\left(s_{0}\right) & =u^{\prime}\left(c_{0}\left(s_{0}\right)\right) \\
\lambda_{1}\left(s^{1}\right) & =u^{\prime}\left(c_{1}\left(s^{1}\right)\right) \beta \pi\left(y_{1} \mid y_{0}\right) \phi\left(z_{1} \mid z_{0}\right) \\
q_{0}\left(z_{0}, z_{1}=z_{l}\right) \lambda_{0}\left(s_{0}\right) & =\sum_{y_{1}} \lambda_{1}\left(s_{0},\left(y_{1}, z_{1}=z_{l}\right)\right) \\
q_{0}\left(z_{0}, z_{1}=z_{h}\right) \lambda_{0}\left(s_{0}\right) & =\sum_{y_{1}} \lambda_{1}\left(s_{0},\left(y_{1}, z_{1}=z_{h}\right)\right) \\
\lambda_{0}\left(s_{0}\right) v_{0}\left(z_{0}\right) & =\sum_{z_{1}} \sum_{y_{1}} \lambda_{1}\left(s^{1}\right) \alpha e_{1}\left(z^{1}\right)
\end{aligned}
$$

By combining these conditions, we obtain the following expression for the contingent bond prices and for the stock price:

$$
\begin{aligned}
q_{0}\left(z_{0}, z_{1}=z_{l}\right) & =\phi\left(z_{1}=z_{l} \mid z_{0}\right) \sum_{y_{1}} \pi\left(y_{1} \mid z_{1}\right) m\left(c_{1}\left(s^{1}\right), c_{0}\left(s_{0}\right)\right) \\
q_{0}\left(z_{0}, z_{1}=z_{h}\right) & =\phi\left(z_{1}=z_{h} \mid z_{0}\right) \sum_{y_{1}} \pi\left(y_{1} \mid z_{1}\right) m\left(c_{1}\left(s^{1}\right), c_{0}\left(s_{0}\right)\right) \\
v_{0}\left(z_{0}\right) & =\sum_{z_{1}} \sum_{y_{1}} \pi\left(y_{1} \mid z_{1}\right) \phi\left(z_{1} \mid z_{0}\right) m\left(c_{1}\left(s^{1}\right), c_{0}\left(s_{0}\right)\right) \alpha\left(z_{1}\right) e_{1}\left(z^{1}\right),
\end{aligned}
$$

where $m$ denotes the households intertemporal marginal rate of substitution:

$$
m\left(c_{1}\left(s^{1}\right), c_{0}\left(s_{0}\right)\right)=\frac{u^{\prime}\left(c_{1}\left(s^{1}\right)\right)}{u^{\prime}\left(c_{1}\left(s^{1}\right)\right)}
$$

Finally, given that we have no initial heterogeneity, all households choose the same asset allocation in period zero, and so we get zero bond holdings, identical stock holdings, and each household consumes the aggregate endowment in period zero, while they consume the labor endowment plus 
the capital endowment in period 1:

$$
\begin{aligned}
\sigma_{0}\left(s_{0}\right) & =1 \\
a_{0}\left(s_{0}, z_{1}\right) & =0 \\
c_{0}\left(s_{0}\right) & =e_{0}\left(z_{0}\right) \\
c_{1}\left(s^{1}\right) & \equiv\left[\left(1-\alpha\left(z_{1}\right)\right) \eta\left(y_{1}, z_{1}\right)+\alpha\left(z_{1}\right)\right] e_{1}\left(z^{1}\right) .
\end{aligned}
$$

Inserting this into the asset prices for Arrow securities yields the following expression for the Arrow prices and for the stock price:

$$
\begin{aligned}
q_{0}\left(z_{0}, z_{1}\right)= & \phi\left(z_{1} \mid z_{0}\right) \sum_{y_{1}} \pi\left(y_{1} \mid z_{1}\right) m\left(\left[\left(1-\alpha\left(z_{1}\right)\right) \eta\left(y_{1}, z_{1}\right)+\alpha\left(z_{1}\right)\right] \lambda\left(z_{1}\right) e_{0}\left(z_{0}\right), e_{0}\left(z_{0}\right)\right) \\
v_{0}\left(z_{0}\right)= & \sum_{z_{1}} \sum_{y_{1}} \pi\left(y_{1} \mid z_{1}\right) \phi\left(z_{1} \mid z_{0}\right) \alpha\left(z_{1}\right) e_{1}\left(z^{1}\right) * \\
& m\left(\left[\left(1-\alpha\left(z_{1}\right)\right) \eta\left(y_{1}, z_{1}\right)+\alpha\left(z_{1}\right)\right] \lambda\left(z_{1}\right) e_{0}\left(z_{0}\right), e_{0}\left(z_{0}\right)\right)
\end{aligned}
$$

Hence, there is no equilibrium trade in securities markets in this simple two-period economy.

- Proof of Proposition 4.1.

We use $U(c)\left(s^{t}\right)$ to denote the continuation utility of an agent from consumption stream $c$, starting at history $s^{t}$. This continuation utility follows the simple recursion

$$
U(c)\left(s^{t}\right)=u\left(c_{t}\left(s^{t}\right)\right)+\beta \sum_{s_{t+1}} \pi\left(s_{t+1} \mid s_{t}\right) U(c)\left(s^{t}, s_{t+1}\right),
$$

where it is understood that $\left(s^{t}, s_{t+1}\right)=\left(z^{t}, z_{t+1}, y^{t}, y_{t+1}\right)$. Divide both sides by $e_{t}\left(s^{t}\right)^{1-\gamma}$ to obtain

$$
\frac{U(c)\left(s^{t}\right)}{e_{t}\left(z^{t}\right)^{1-\gamma}}=u\left(\hat{c}_{t}\left(s^{t}\right)\right)+\beta \sum_{s_{t+1}} \pi\left(s_{t+1} \mid s_{t}\right) \frac{e_{t+1}\left(z^{t+1}\right)^{1-\gamma}}{e_{t}\left(z^{t}\right)^{1-\gamma}} \frac{U(c)\left(s^{t}, s_{t+1}\right)}{e_{t+1}\left(z^{t+1}\right)^{1-\gamma}} .
$$

Define a new continuation utility index $\hat{U}(\cdot)$ as follows:

$$
\hat{U}(\hat{c})\left(s^{t}\right)=\frac{U(c)\left(s^{t}\right)}{e_{t}\left(z^{t}\right)^{1-\gamma}} .
$$

It follows that

$$
\begin{aligned}
\hat{U}(\hat{c})\left(s^{t}\right) & =u\left(\hat{c}_{t}\left(s^{t}\right)\right)+\beta \sum_{s_{t+1}} \pi\left(s_{t+1} \mid s_{t}\right) \lambda\left(z_{t+1}\right)^{1-\gamma} \hat{U}(\hat{c})\left(s^{t}, s_{t+1}\right) . \\
& =u\left(\hat{c}_{t}\left(s^{t}\right)\right)+\hat{\beta}\left(s_{t}\right) \sum_{s_{t+1}} \hat{\pi}\left(s_{t+1} \mid s_{t}\right) \hat{U}(\hat{c})\left(s^{t}, s_{t+1}\right) .
\end{aligned}
$$

Thus it follows, for two consumption streams $c$ and $c^{\prime}$, that

$$
U(c)\left(s^{t}\right) \geq U\left(c^{\prime}\right)\left(s^{t}\right) \text { if and only if } \hat{U}(\hat{c})\left(s^{t}\right) \geq \hat{U}\left(\hat{c}^{\prime}\right)\left(s^{t}\right),
$$

i.e., the household orders original and growth-deflated consumption streams in exactly the same way.

- Proof of Theorem 4.1. 
The proof consists of two parts. In a first step, we argue that the Bewley equilibrium allocations and prices can be transformed into an equilibrium for the de-trended Arrow model, and in a second step, we argue that by scaling the allocations and prices by the appropriate endowment (growth) factors, we obtain an equilibrium of the stochastically growing Arrow model.

Step 1: Take allocations and prices from a Bewley equilibrium, $\left\{\hat{c}_{t}\left(y^{t}\right), \hat{a}_{t}\left(y^{t}\right), \hat{\sigma}_{t}\left(y^{t}\right)\right\},\left\{\hat{R}_{t}, \hat{v}_{t}\right\}$ and let the associated Lagrange multipliers on the solvency constraints be given by

$$
\hat{\beta}^{t} \varphi\left(y^{t} \mid y_{0}\right) u^{\prime}\left(\hat{c}_{t}\left(y^{t}\right)\right) \hat{\mu}\left(y^{t}\right) \geq 0,
$$

for the constraint in (9) and

$$
\hat{\beta}^{t} \varphi\left(y^{t} \mid y_{0}\right) u^{\prime}\left(\hat{c}_{t}\left(y^{t}\right)\right) \hat{\kappa}_{t}\left(y^{t}\right) \geq 0,
$$

for the constraint in (10). The first order conditions (which are necessary and sufficient for household optimal choices together with the complementary slackness and transversality conditions) in the Bewley model, once combined to the Euler equations, are given by:

$$
\begin{aligned}
1 & =\hat{R}_{t} \hat{\beta} \sum_{y^{t+1} \mid y^{t}} \varphi\left(y_{t+1} \mid y_{t}\right) \frac{u^{\prime}\left(\hat{c}_{t+1}\left(y^{t}, y_{t+1}\right)\right)}{u^{\prime}\left(\hat{c}_{t}\left(y^{t}\right)\right)}+\hat{\mu}_{t}\left(y^{t}\right)+\hat{R}_{t} \hat{\kappa}_{t}\left(y^{t}\right) . \\
& =\hat{\beta}\left[\frac{\hat{v}_{t+1}+\alpha}{\hat{v}_{t}}\right] \sum_{y^{t+1} \mid y^{t}} \varphi\left(y_{t+1} \mid y_{t}\right) \frac{u^{\prime}\left(\hat{c}_{t+1}\left(y^{t}, y_{t+1}\right)\right)}{u^{\prime}\left(\hat{c}_{t}\left(y^{t}\right)\right)}+\hat{\mu}_{t}\left(y^{t}\right)+\left[\frac{\hat{v}_{t+1}+\alpha}{\hat{v}_{t}}\right] \hat{\kappa}_{t}\left(y^{t}\right) .
\end{aligned}
$$

The corresponding Euler equations for the de-trended Arrow model, evaluated at the Bewley equilibrium allocations and Lagrange multipliers $\hat{\mu}\left(y^{t}\right)$ and $\hat{\kappa}_{t}\left(y^{t}\right) \hat{\phi}\left(z_{t+1}\right)$, read as (see (42) and (43)):

$$
\begin{aligned}
1= & \frac{\hat{\beta}\left(s_{t}\right)}{\hat{q}_{t}\left(z^{t}, z_{t+1}\right)} \sum_{s^{t+1} \mid s^{t}, z_{t+1}} \hat{\pi}\left(s_{t+1} \mid s_{t}\right) \frac{u^{\prime}\left(\hat{c}_{t+1}\left(y^{t}, y_{t+1}\right)\right)}{u^{\prime}\left(\hat{c}_{t}\left(y^{t}\right)\right)} \\
& +\hat{\mu}_{t}\left(y^{t}\right)+\frac{\hat{\kappa}_{t}\left(y^{t}\right) \hat{\phi}\left(z_{t+1}\right)}{\hat{q}_{t}\left(z^{t}, z_{t+1}\right)} \forall z_{t+1} . \\
1= & \hat{\beta}\left(s_{t}\right) \sum_{s^{t+1} \mid s^{t}} \hat{\pi}\left(s_{t+1} \mid s_{t}\right)\left[\frac{\hat{v}_{t+1}\left(z^{t+1}\right)+\alpha}{\hat{v}_{t}\left(z^{t}\right)}\right] \frac{u^{\prime}\left(\hat{c}_{t+1}\left(y^{t}, y_{t+1}\right)\right)}{u^{\prime}\left(\hat{c}_{t}\left(y^{t}\right)\right)} \\
& +\hat{\mu}_{t}\left(y^{t}\right)+\hat{\kappa}_{t}\left(y^{t}\right) \sum_{z_{t+1}} \hat{\phi}\left(z_{t+1}\right)\left[\frac{\hat{v}_{t+1}\left(z^{t+1}\right)+\alpha}{\hat{v}_{t}\left(z^{t}\right)}\right] .
\end{aligned}
$$

Evaluated at the conjectured prices,

$$
\begin{aligned}
\hat{v}_{t}\left(z^{t}\right) & =\hat{v}_{t} \\
\hat{q}_{t}\left(z^{t}, z_{t+1}\right) & =\frac{\hat{\phi}\left(z_{t+1}\right)}{\hat{R}_{t}}
\end{aligned}
$$

and using the independence and i.i.d. assumptions, which imply

$$
\begin{aligned}
\hat{\pi}\left(s_{t+1} \mid s_{t}\right) & =\varphi\left(y_{t+1} \mid y_{t}\right) \hat{\phi}\left(z_{t+1}\right) \\
\hat{\beta}\left(s_{t}\right) & =\hat{\beta}
\end{aligned}
$$


these Euler equations can be restated as follows:

$$
\begin{aligned}
1= & \frac{\hat{\beta} \hat{R}_{t}}{\hat{\phi}\left(z_{t+1}\right)} \sum_{y^{t+1} \mid y^{t}} \varphi\left(y_{t+1} \mid y_{t}\right) \hat{\phi}\left(z_{t+1}\right) \frac{u^{\prime}\left(\hat{c}_{t+1}\left(y^{t}, y_{t+1}\right)\right)}{u^{\prime}\left(\hat{c}_{t}\left(y^{t}\right)\right)}+\hat{\mu}_{t}\left(y^{t}\right)+\hat{R}_{t} \hat{\kappa}_{t}\left(y^{t}\right) . \\
1= & \hat{\beta} \sum_{y^{t+1} \mid y^{t}} \varphi\left(y_{t+1} \mid y_{t}\right) \sum_{z_{t+1}} \hat{\phi}\left(z_{t+1}\right)\left[\frac{\hat{v}_{t+1}+\alpha}{\hat{v}_{t}}\right] \frac{u^{\prime}\left(\hat{c}_{t+1}\left(y^{t}, y_{t+1}\right)\right)}{u^{\prime}\left(\hat{c}_{t}\left(y^{t}\right)\right)} \\
& +\hat{\mu}_{t}\left(y^{t}\right)+\hat{\kappa}_{t}\left(y^{t}\right)\left[\frac{\hat{v}_{t+1}+\alpha}{\hat{v}_{t}}\right] \sum_{z_{t+1}} \hat{\phi}\left(z_{t+1}\right),
\end{aligned}
$$

which are, given that $\sum_{z_{t+1}} \hat{\phi}\left(z_{t+1}\right)=1$, exactly the Euler conditions (46)) and (47)) of the Bewley model and hence satisfied by the Bewley equilibrium allocations. A similar argument applies to the complementary slackness conditions, which for the Bewley model read as

$$
\begin{aligned}
\hat{\mu}_{t}\left(y^{t}\right)\left[\frac{\hat{a}_{t}\left(y^{t}\right)}{\hat{R}_{t}}+\hat{\sigma}_{t}\left(y^{t}\right) \hat{v}_{t}-\hat{K}_{t}\left(y^{t}\right)\right] & =0 . \\
\hat{\kappa}_{t}\left(y^{t}\right)\left[\hat{a}_{t}\left(y^{t}\right)+\hat{\sigma}_{t}\left(y^{t}\right)\left(\hat{v}_{t+1}+\alpha\right)-\hat{M}_{t}\left(y^{t}\right)\right] & =0,
\end{aligned}
$$

and for the de-trended Arrow model, evaluated at Bewley equilibrium allocations and conjectured prices, read as

$$
\begin{aligned}
\hat{\mu}_{t}\left(y^{t}\right)\left[\frac{\hat{a}_{t}\left(y^{t}\right)}{\hat{R}_{t}} \sum \hat{z}_{t+1}\left(z_{t+1}\right)+\hat{\sigma}_{t}\left(y^{t}\right)-\hat{K}_{t}\left(y^{t}\right)\right] & =0 . \\
\hat{\kappa}_{t}\left(y^{t}\right)\left[\hat{a}_{t}\left(y^{t}\right)+\hat{\sigma}_{t}\left(y^{t}\right)\left[\hat{v}_{t+1}+\alpha\right]-\hat{M}_{t}\left(y^{t}\right)\right] & =0 / \hat{\phi}\left(z_{t+1}\right) .
\end{aligned}
$$

Again, the Bewley equilibrium allocations satisfy the complementary slackness conditions in the detrended Arrow model. The argument is exactly identical for the transversality conditions. Finally, we have to check whether the Bewley equilibrium allocation satisfies the de-trended Arrow budget constraints. Plugging in the allocations yields:

$$
\hat{c}_{t}\left(s^{t}\right)+\frac{\hat{a}_{t}\left(y^{t}\right)}{\hat{R}_{t}} \sum_{z_{t+1}} \hat{\phi}\left(z_{t+1}\right)+\hat{\sigma}_{t}\left(y^{t}\right) \hat{v}_{t} \leq \eta\left(y_{t}\right)+\hat{a}_{t-1}\left(y^{t-1}\right)+\sigma_{t-1}\left(y^{t-1}\right)\left[\hat{v}_{t}+\alpha\right],
$$

which is exactly the budget constraint in the Bewley model. Thus, given the conjectured prices, the Bewley equilibrium allocations are optimal in the de-trended Arrow model.

Since the market clearing conditions for assets and consumption goods coincide in the two models, Bewley allocations satisfy the market clearing conditions in the de-trended Arrow model. Thus we conclude that the Bewley equilibrium allocations, together with prices (48) and (49) are an equilibrium in the de-trended Arrow model.

Step 2: Now, we need to show that an equilibrium of the de-trended Arrow model is, after appropriate scaling, an equilibrium in the stochastically growing model, but this was established in section 4.2.2, in which we showed that by with the transformations $\hat{c}_{t}\left(s^{t}\right)=\frac{c_{t}\left(s^{t}\right)}{e_{t}\left(z^{t}\right)}, \hat{a}_{t}\left(s^{t}, z_{t+1}\right)=\frac{a_{t}\left(s^{t}, z_{t+1}\right)}{e_{t+1}\left(z^{t+1}\right)}$, $\hat{\sigma}_{t}\left(s^{t}\right)=\sigma_{t}\left(s^{t}\right), \hat{q}_{t}\left(z^{t}, z_{t+1}\right)=q_{t}\left(z^{t}, z_{t+1}\right) \lambda\left(z_{t+1}\right), \hat{v}_{t}\left(z^{t}\right)=\frac{v_{t}\left(z^{t}\right)}{e_{t}\left(z^{t}\right)}$ household problems and market clearing conditions in the de-trended and the stochastically growing Arrow model coincide. 
- Proof of Theorem 4.2,

As in the Arrow model, the crucial part of the proof is to argue that Bewley equilibrium allocations and prices can be made into an equilibrium for the de-trended Bond model. The Euler equations of the Bewley model where given in (46) and (47).

The corresponding Euler equations for the de-trended Bond model, evaluated at the Bewley equilibrium allocations and Lagrange multipliers $\hat{\mu}\left(y^{t}\right)$ and $\hat{\kappa}_{t}\left(y^{t}\right) \hat{\phi}\left(z_{t+1}\right)$, read as (see (44) and (45))

$$
\begin{aligned}
1= & \hat{\beta}\left(s_{t}\right) \sum_{s^{t+1} \mid s^{t}} \hat{\pi}\left(s_{t+1} \mid s_{t}\right)\left[\frac{R_{t}\left(z^{t}\right)}{\lambda\left(z_{t+1}\right)}\right] \frac{u^{\prime}\left(\hat{c}_{t+1}\left(y^{t}, y_{t+1}\right)\right)}{u^{\prime}\left(\hat{c}_{t}\left(y^{t}\right)\right)} \\
& +\hat{\mu}\left(y^{t}\right)+\hat{\kappa}_{t}\left(y^{t}\right) \sum_{z_{t+1}} \hat{\phi}\left(z_{t+1}\right)\left[\frac{R_{t}\left(z^{t}\right)}{\lambda\left(z_{t+1}\right)}\right] . \\
1= & \hat{\beta}\left(s_{t}\right) \sum_{s^{t+1} \mid s^{t}} \hat{\pi}\left(s_{t+1} \mid s_{t}\right)\left[\frac{\hat{v}_{t+1}\left(z^{t+1}\right)+\alpha}{\hat{v}_{t}\left(z^{t}\right)}\right] \frac{u^{\prime}\left(\hat{c}_{t+1}\left(y^{t}, y_{t+1}\right)\right)}{u^{\prime}\left(\hat{c}_{t}\left(y^{t}\right)\right)} \\
& +\hat{\mu}\left(y^{t}\right)+\hat{\kappa}_{t}\left(y^{t}\right) \sum_{z_{t+1}} \hat{\phi}\left(z_{t+1}\right)\left[\frac{\hat{v}_{t+1}\left(z^{t+1}\right)+\alpha}{\hat{v}_{t}\left(z^{t}\right)}\right] .
\end{aligned}
$$

Using the conjectured prices, we note that

$$
\begin{aligned}
\hat{v}_{t}\left(z^{t}\right) & =\hat{v}_{t} . \\
R_{t}\left(z^{t}\right) & =\hat{R}_{t} * \frac{\sum_{z_{t+1}} \phi\left(z_{t+1}\right) \lambda\left(z_{t+1}\right)^{1-\gamma}}{\sum_{z_{t+1}} \phi\left(z_{t+1}\right) \lambda\left(z_{t+1}\right)^{-\gamma}} .
\end{aligned}
$$

Now we use the independence and i.i.d. assumptions, which imply

$$
\begin{aligned}
\hat{\pi}\left(s_{t+1} \mid s_{t}\right) & =\varphi\left(y_{t+1} \mid y_{t}\right) \hat{\phi}\left(z_{t+1}\right) \\
\hat{\beta}\left(s_{t}\right) & =\hat{\beta} .
\end{aligned}
$$

Furthermore by definition of $\hat{\phi}\left(z_{t+1}\right)$,

$$
R_{t}\left(z^{t}\right) \sum_{z_{t+1}} \frac{\hat{\phi}\left(z_{t+1}\right)}{\lambda\left(z_{t+1}\right)}=R_{t}\left(z^{t}\right) \frac{\sum_{z_{t+1}} \phi\left(z_{t+1}\right) \lambda\left(z_{t+1}\right)^{-\gamma}}{\sum_{z_{t+1}} \phi\left(z_{t+1}\right) \lambda\left(z_{t+1}\right)^{1-\gamma}}=\hat{R}_{t}
$$

and thus the Euler equations can be restated as:

$$
\begin{aligned}
1= & \hat{\beta} \hat{R}_{t} \sum_{y^{t+1} \mid y^{t}} \varphi\left(y_{t+1} \mid y_{t}\right) \frac{u^{\prime}\left(\hat{c}_{t+1}\left(y^{t}, y_{t+1}\right)\right)}{u^{\prime}\left(\hat{c}_{t}\left(y^{t}\right)\right)}+\hat{\mu}\left(y^{t}\right)+\hat{\kappa}_{t}\left(y^{t}\right) \hat{R}_{t} . \\
1= & \hat{\beta} \sum_{y^{t+1} \mid y^{t}} \varphi\left(y_{t+1} \mid y_{t}\right)\left[\frac{\hat{v}_{t+1}+\alpha}{\hat{v}_{t}}\right] \frac{u^{\prime}\left(\hat{c}_{t+1}\left(y^{t}, y_{t+1}\right)\right)}{u^{\prime}\left(\hat{c}_{t}\left(y^{t}\right)\right)} \sum_{z_{t+1}} \hat{\phi}\left(z_{t+1}\right) \\
& +\hat{\mu}\left(y^{t}\right)+\hat{\kappa}_{t}\left(y^{t}\right)\left[\frac{\hat{v}_{t+1}+\alpha}{\hat{v}_{t}}\right] \sum_{z_{t+1}} \hat{\phi}\left(z_{t+1}\right),
\end{aligned}
$$

which again are, given that $\sum_{z_{t+1}} \hat{\phi}\left(z_{t+1}\right)=1$, exactly the Euler conditions (46) and (47) of the Bewley model and hence satisfied by the Bewley equilibrium allocations. For the Bewley model, the complementary slackness conditions were given in (52) and (53), and for the de-trended Bond 
model, evaluated at the proposed allocations in the theorem (which had bond holdings equal to zero) these equations are given by:

$$
\begin{aligned}
\hat{\mu}_{t}\left(y^{t}\right)\left[\hat{\sigma}_{t}^{B}\left(y^{t}\right) \hat{v}_{t}-\hat{K}_{t}\left(y^{t}\right)\right] & =\hat{\mu}_{t}\left(y^{t}\right)\left[\left(\frac{\hat{a}_{t}\left(y^{t}\right)}{\left[\hat{v}_{t+1}+\alpha\right]}+\hat{\sigma}_{t}\left(y^{t}\right)\right) \hat{v}_{t}-\hat{K}_{t}\left(y^{t}\right)\right] \\
& =\hat{\mu}_{t}\left(y^{t}\right)\left[\frac{\hat{a}_{t}\left(y^{t}\right)}{\hat{R}_{t}}+\hat{\sigma}_{t}\left(y^{t}\right) \hat{v}_{t}-\hat{K}_{t}\left(y^{t}\right)\right]=0,
\end{aligned}
$$

and

$$
\begin{aligned}
\hat{\kappa}_{t}\left(y^{t}\right)\left[\hat{\sigma}_{t}^{B}\left(y^{t}\right)\left[\hat{v}_{t+1}+\alpha\right]-\hat{M}_{t}\left(y^{t}\right)\right] & =\hat{\kappa}_{t}\left(y^{t}\right)\left[\left(\frac{\hat{a}_{t}\left(y^{t}\right)}{\left[\hat{v}_{t+1}+\alpha\right]}+\hat{\sigma}_{t}\left(y^{t}\right)\right)\left[\hat{v}_{t+1}+\alpha\right]-\hat{M}_{t}\left(y^{t}\right)\right] \\
& =\hat{\kappa}_{t}\left(y^{t}\right)\left[\hat{a}_{t}\left(y^{t}\right)+\hat{\sigma}_{t}\left(y^{t}\right)\left[\hat{v}_{t+1}+\alpha\right]-\hat{M}_{t}\left(y^{t}\right)\right]=0 / \hat{\phi}\left(z_{t+1}\right),
\end{aligned}
$$

where we use the fact that the Bewley equilibrium prices and interest rates satisfy

$$
\hat{R}_{t}=\frac{\hat{v}_{t+1}+\alpha}{\hat{v}_{t}}
$$

These complementary slackness conditions are satisfied since the Bewley equilibrium allocations satisfy the complementary slackness conditions in the Bewley model. The argument is exactly identical for the transversality conditions. Finally, we have to check whether the allocations proposed in the theorem satisfy the de-trended Bond model budget constraints. Plugging these into the detrended Bond model budget constraint yields

$$
\begin{aligned}
\hat{c}_{t}\left(y^{t}\right)+\frac{\hat{b}_{t}\left(y^{t}\right)}{R_{t}}+\hat{\sigma}_{t}^{B}\left(y^{t}\right) \hat{v}_{t} & \leq(1-\alpha) \eta\left(y_{t}\right)+\frac{\hat{b}_{t-1}\left(y^{t-1}\right)}{\lambda\left(z_{t}\right)}+\hat{\sigma}_{t-1}^{B}\left(y^{t-1}\right)\left[\hat{v}_{t}+\alpha\right] \\
\hat{c}_{t}\left(y^{t}\right)+\left[\frac{\hat{a}_{t}\left(y^{t}\right)}{\left[\hat{v}_{t+1}+\alpha\right]}+\hat{\sigma}_{t}\left(y^{t}\right)\right] \hat{v}_{t} & \leq(1-\alpha) \eta\left(y_{t}\right)+\left[\frac{\hat{a}_{t-1}\left(y^{t-1}\right)}{\left[\hat{v}_{t}+\alpha\right]}+\hat{\sigma}_{t-1}\left(y^{t-1}\right)\right]\left[\hat{v}_{t}+\alpha\right] \\
\hat{c}_{t}\left(y^{t}\right)+\frac{\hat{a}_{t}\left(y^{t}\right)}{\hat{R}_{t}}+\hat{\sigma}_{t}\left(y^{t}\right) \hat{v}_{t} & \leq(1-\alpha) \eta\left(y_{t}\right)+\hat{a}_{t-1}\left(y^{t-1}\right)+\hat{\sigma}_{t-1}\left(y^{t-1}\right)\left[\hat{v}_{t}+\alpha\right],
\end{aligned}
$$

which is exactly the budget constraint in the Bewley model. Thus, given the conjectured prices the allocations proposed in the theorem are optimal household choices in the de-trended Bond model. Equation (57) shows why, in contrast to the Arrow model, in the Bond model bond positions have to be zero. Nothing in this equation depends in the aggregate shock $z_{t}$ except for the term $\frac{\hat{b}_{t-1}\left(y^{t-1}\right)}{\lambda\left(z_{t}\right)}$. Therefore the budget constraint can only be satisfied if $\hat{b}_{t-1}\left(y^{t-1}\right)=0$. In the model with growth, households want to keep wealth at the beginning of the period proportional to the aggregate endowment in the economy, but, since bond positions are chosen in the previous period, and thus cannot depend on the realization of the aggregate shock today, bond positions have to be zero to achieve proportionally of wealth and the aggregate endowment. The market clearing conditions for bonds in the de-trended Bond model is trivially satisfied because bond positions are identically equal to zero. The goods market clearing condition is identical to that of the Bewley model and thus satisfied by the Bewley equilibrium consumption allocations. It remains to be shown that the 
stock market clears. We know that:

$$
\begin{aligned}
& \int \sum_{y^{t}} \varphi\left(y^{t} \mid y_{0}\right) \hat{\sigma}_{t}^{B}\left(\theta_{0}, y^{t}\right) d \Theta_{0} \\
= & \int \sum_{y^{t}} \varphi\left(y^{t} \mid y_{0}\right)\left[\frac{\hat{a}_{t}\left(\theta_{0}, y^{t}\right)}{\left[\hat{v}_{t+1}+\alpha\right]}+\hat{\sigma}_{t}\left(\theta_{0}, y^{t}\right)\right] d \Theta_{0} \\
= & \frac{1}{\left[\hat{v}_{t+1}+\alpha\right]} \int \sum_{y^{t}} \varphi\left(y^{t} \mid y_{0}\right) \hat{a}_{t}\left(\theta_{0}, y^{t}\right) d \Theta_{0}+\int \sum_{y^{t}} \varphi\left(y^{t} \mid y_{0}\right) \hat{\sigma}_{t}\left(\theta_{0}, y^{t}\right) d \Theta_{0} \\
= & 0+1
\end{aligned}
$$

where the last line follows from the fact that the bond and stock market clears in the Bewley equilibrium. Thus, we conclude that the allocations and prices proposed in the theorem indeed are an equilibrium in the de-trended Bond model, and, after appropriate scaling, in the original Bond model.

\section{- Proof of Lemma 5.1;}

The stock return is defined as:

$$
R_{t+1}^{s}\left(z^{t+1}\right)=\frac{v_{t+1}\left(z^{t+1}\right)+\alpha e_{t+1}\left(z_{t+1}\right)}{v_{t}\left(z^{t}\right)} .
$$

Subtracting the two Euler equations (50)-(51) in the Arrow model and (55)-(56) in the Bond model yields, in both cases

$$
\hat{\beta} \sum_{z^{t+1} \mid z^{t}} \hat{\phi}\left(z_{t+1}\right)\left[\frac{\hat{v}_{t+1}\left(z^{t+1}\right)+\alpha}{\hat{v}_{t}\left(z^{t}\right)}-\hat{R}_{t}\left(z^{t}\right)\right]=0 .
$$

Using the fact that $\hat{v}_{t+1}\left(z^{t+1}\right)=v_{t+1}\left(z^{t+1}\right) / e_{t+1}\left(z_{t+1}\right)$ and the definition of $\hat{\phi}\left(z_{t+1}\right)$ and $\hat{\beta}$, as well as (23) yields

$$
\beta \sum_{z^{t+1} \mid z^{t}} \phi\left(z_{t+1}\right) \lambda\left(z_{t+1}\right)^{-\gamma}\left[R_{t+1}^{s}\left(z^{t+1}\right)-R_{t}\left(z^{t}\right)\right]=0
$$

or in short

$$
E_{t}\left\{\beta \lambda\left(z_{t+1}\right)^{-\gamma}\left[R_{t+1}^{s}-R_{t}\right]\right\}=0
$$

Thus the representative agent stochastic discount factor $\beta \lambda\left(z_{t+1}\right)^{-\gamma}$ prices the excess return of stocks over bonds in both the Arrow and the Bond model. Note that in the Arrow model (but not in the Bond model) this stochastic discount factor any excess return $R_{t+1}^{i}-R_{t}$ as long as the returns only depend on the aggregate state $z_{t+1}$.

- Proof of Proposition [5.1.

From theorem 4.1 we know that in the Arrow model equilibrium prices for Arrow securities are given by:

$$
q_{t}^{A}\left(z^{t}, z_{t+1}\right)=\frac{\hat{q}_{t}^{A}\left(z^{t}, z_{t+1}\right)}{\lambda\left(z_{t+1}\right)}=\frac{\hat{\phi}\left(z_{t+1}\right)}{\lambda\left(z_{t+1}\right) \hat{R}_{t}^{A}}
$$

whereas in the representative agent model equilibrium prices for Arrow securities are given by:

$$
q_{t}\left(z^{t}, z_{t+1}\right)=\frac{\hat{q}_{t}\left(z^{t}, z_{t+1}\right)}{\lambda\left(z_{t+1}\right)}=\hat{\beta} \frac{\hat{\phi}\left(z_{t+1}\right)}{\lambda\left(z_{t+1}\right)}
$$


so that

$$
\frac{q_{t}^{A}\left(z^{t}, z_{t+1}\right)}{q_{t}\left(z^{t}, z_{t+1}\right)}=\frac{1}{\hat{\beta} \hat{R}_{t}^{A}}=\frac{\hat{R}^{R E}}{\hat{R}_{t}^{A}}=\kappa_{t} \geq 1
$$

where

$$
\hat{R}_{t}^{R E}=\hat{R}^{R E}=\frac{1}{\sum_{z_{t+1}} \hat{q}_{t}\left(z^{t}, z_{t+1}\right)}=\frac{1}{\sum_{z_{t+1}} \hat{\beta} \hat{\phi}\left(z_{t+1}\right)}=\frac{1}{\hat{\beta}}
$$

is the risk-free interest rate in the de-trended representative agent model. Note that the multiplicative factor $\kappa_{t}$ may depend on time since $\hat{R}_{t}^{A}$ may, but is nonstochastic, since $\hat{R}_{t}^{A}=\hat{R}_{t}$ (the risk-free interest rate in the de-trended Arrow model equals that in the Bewley model, which is evidently nonstochastic). Since interest rates in the Bewley model are (weakly) smaller than in the representative agent model, $\kappa_{t} \geq 1$. Equation (58) implies that the stochastic discount factor in the Arrow model equals the SDF in the representative agent model, multiplied by $\kappa_{t}$ :

$$
m_{t+1}^{A}\left(z^{t+1}\right)=m_{t+1}^{R E}\left(z^{t+1}\right) \kappa_{t}
$$

Finally, since the stochastic discount factor for the Arrow model is also a valid stochastic discount factor in the Bond model (although not necessarily the unique valid stochastic discount factor), the previous result also applies to the Bond model.

- Proof of Theorem 5.1:

Remember that we defined the multiplicative risk premium in the main text as

$$
1+\nu_{t}=\frac{E_{t} R_{t, 1}\left[\left\{e_{t+k}\right\}\right]}{R_{t, 1}[1]}
$$

We use $m_{t, t+k}=m_{t+1} \cdot m_{t+2} \ldots \cdot m_{t+k}$ to denote the k-period ahead pricing kernel (with convention that $\left.m_{t, t}=1\right)$, such that $E_{t}\left(d_{t+k} m_{t, t+k}\right)$ denotes the price at time $t$ of a random payoff $d_{t+k}$. Note that whenever there is no room for confusion we suppress the dependence of variables on $z^{t}$.

First, note that the multiplicative risk premium on a claim to aggregate consumption can be stated as a weighted sum of risk premia on strips (as shown by Alvarez and Jermann (2001)). By definition of $R_{t, 1}\left[\left\{e_{t+k}\right\}\right]$ we have

$$
\begin{aligned}
R_{t, 1}\left[\left\{e_{t+k}\right\}\right] & =\frac{\sum_{k=1}^{\infty} E_{t+1} m_{t+1, t+k} \alpha e_{t+k}}{\sum_{k=1}^{\infty} E_{t} m_{t, t+k} \alpha e_{t+k}} \\
& =\frac{1}{\sum_{j=1}^{\infty} E_{t} m_{t, t+j} e_{t+j}} * \sum_{k=1}^{\infty} \frac{E_{t+1} m_{t+1, t+k} e_{t+k}}{E_{t} m_{t, t+k} e_{t+k}} * E_{t} m_{t, t+k} e_{t+k} \\
& =\sum_{k=1}^{\infty} \frac{E_{t+1} m_{t+1, t+k} e_{t+k}}{E_{t} m_{t, t+k} e_{t+k}} \frac{E_{t} m_{t, t+k} e_{t+k}}{\sum_{j=1}^{\infty} E_{t} m_{t, t+j} e_{t+j}} \\
& =\sum_{k=1}^{\infty} \omega_{k} R_{t, 1}\left[e_{t+k}\right]
\end{aligned}
$$

where the nonrandom weights $\omega_{k}$ are given by

$$
\omega_{k}=\frac{E_{t} m_{t, t+k} e_{t+k}}{\sum_{j=1}^{\infty} E_{t} m_{t, t+j} e_{t+j}}
$$


Thus

$$
1+\nu_{t}=\frac{E_{t} R_{t, 1}\left[\left\{e_{t+k}\right\}\right]}{R_{t, 1}[1]}=\sum_{k=1}^{\infty} \omega_{k} \frac{E_{t} R_{t, 1}\left[e_{t+k}\right]}{R_{t, 1}[1]}
$$

and it is sufficient to show that the multiplicative risk premium $E_{t} R_{t, 1}\left[e_{t+k}\right] / R_{t, 1}$ [1] on all $k$-period strips of aggregate consumption (a claim to the Lucas tree's dividend in period $k$ only, not the entire stream) is the same in the Arrow model as in the representative agent model. First, we show that the one-period ahead conditional strip risk premia are identical:

$$
\frac{E_{t} \frac{E_{t+1} e_{t+1}}{E_{t}\left[m_{t+1}^{A} e_{t+1}\right]}}{\frac{1}{E_{t}\left[m_{t+1}^{A}\right]}}=\frac{E_{t} \frac{E_{t+1} \lambda_{t+1}}{E_{t}\left[m_{t+1}^{A} \lambda_{t+1}\right]}}{\frac{1}{E_{t}\left[m_{t+1}^{A}\right]}}=\frac{E_{t} \frac{E_{t+1} \lambda_{t+1}}{E_{t}\left[m_{t+1}^{R E} \lambda_{t+1}\right]}}{\frac{1}{E_{t}\left[m_{t+1}^{R E}\right]}}
$$

The first equality follows from dividing through by $e_{t}$. The second equality follows from the expression for $m^{A}$ in Proposition [5.1; $m_{t+1}^{A}=m_{t+1}^{R E} \kappa_{t}$.

Next we repeat the argument for the risk premium of a $k$-period strip:

$$
\frac{E_{t} R_{t, 1}^{A}\left[e_{t+k}\right]}{E_{t} R_{t, 1}^{A}[1]}=\frac{E_{t} \frac{E_{t+1}\left[m_{t+1, t+k}^{A} e_{t+k}\right]}{E_{t}\left[m_{t, t+k}^{A} e_{t+k}\right]}}{\frac{1}{E_{t}\left[m_{t+1}^{A}\right]}}=\frac{E_{t} \frac{\kappa_{t+1} \cdot \ldots \cdot \kappa_{t+k-1}}{\kappa_{t} \cdot \kappa_{t+1} \cdot \ldots \cdot \kappa_{t+k-1}} \frac{E_{t+1}\left[m_{t+1, t+k}^{R E} e_{t+k}\right]}{E_{t}\left[m_{t, t+k}^{R E} e_{t+k}\right]}}{\frac{1}{\kappa_{t} E_{t}\left[m_{t+1}^{R E}\right]}}=\frac{E_{t} R_{t, 1}^{R E}\left[e_{t+k}\right]}{R_{t, 1}^{R E}[1]}
$$

and thus risk premia on all $k$-period consumption strips in the Arrow model coincide with those in the representative agent model. But then (62) implies that the multiplicative risk premium in the two models coincide as well.

- Proof of Lemma 6.1; Absent binding solvency constraints the Euler equation in the Bewley model read as

$$
\begin{aligned}
1 & =\frac{\tilde{\beta}_{t+1}}{\tilde{\beta}_{t}} \hat{R}_{t} \sum_{y^{t+1} \mid y^{t}} \varphi\left(y_{t+1} \mid y_{t}\right) \frac{u^{\prime}\left(\hat{c}_{t+1}\left(y^{t}, y_{t+1}\right)\right)}{u^{\prime}\left(\hat{c}_{t}\left(y^{t}\right)\right)} \\
& =\frac{\tilde{\beta}_{t+1}}{\tilde{\beta}_{t}} \frac{\hat{v}_{t+1}+\alpha}{\hat{v}_{t}} \sum_{y^{t+1} \mid y^{t}} \varphi\left(y_{t+1} \mid y_{t}\right) \frac{u^{\prime}\left(\hat{c}_{t+1}\left(y^{t}, y_{t+1}\right)\right)}{u^{\prime}\left(\hat{c}_{t}\left(y^{t}\right)\right)}
\end{aligned}
$$

while in the Arrow model the Euler equations for Arrow securities are given by

$$
1=\frac{\hat{\beta}\left(z_{t}\right) \hat{\phi}\left(z_{t+1} \mid z_{t}\right)}{\hat{q}_{t}\left(z^{t}, z_{t+1}\right)} \sum_{y^{t+1} \mid y^{t}} \varphi\left(y_{t+1} \mid y_{t}\right) \frac{u^{\prime}\left(\hat{c}_{t+1}\left(y^{t}, y_{t+1}\right)\right)}{u^{\prime}\left(\hat{c}_{t}\left(y^{t}\right)\right)} .
$$

With conjectured Arrow securities prices $\hat{q}_{t}\left(z^{t}, z_{t+1}\right)=\hat{\beta}\left(z_{t}\right) \hat{\phi}\left(z_{t+1} \mid z_{t}\right) \frac{1}{\hat{\hat{R}}_{t}} \frac{\widetilde{\beta}_{t}}{\widetilde{\beta}_{t+1}}$ these equations obviously coincide with the bond Euler equation in the Bewley model, and thus the Bewley equilibrium allocation satisfies the Euler equations for Arrow securities. A similar argument applies to the Euler 
equation for stocks:

$$
\begin{aligned}
1 & =\hat{\beta}\left(z_{t}\right) \sum_{z^{t+1} \mid z^{t}} \hat{\phi}\left(z_{t+1} \mid z_{t}\right)\left[\frac{\hat{v}_{t+1}\left(z^{t+1}\right)+\alpha}{\hat{v}_{t}\left(z^{t}\right)}\right] \sum_{y^{t+1} \mid y^{t}} \varphi\left(y_{t+1} \mid y_{t}\right) \frac{u^{\prime}\left(\hat{c}_{t+1}\left(y^{t}, y_{t+1}\right)\right)}{u^{\prime}\left(\hat{c}_{t}\left(y^{t}\right)\right)} \\
& =\frac{\tilde{\beta}_{t+1}}{\tilde{\beta}_{t}} \hat{R}_{t} \sum_{y^{t+1} \mid y^{t}} \varphi\left(y_{t+1} \mid y_{t}\right) \frac{u^{\prime}\left(\hat{c}_{t+1}\left(y^{t}, y_{t+1}\right)\right)}{u^{\prime}\left(\hat{c}_{t}\left(y^{t}\right)\right)}
\end{aligned}
$$

The state-contingent interest rate in this model is given by:

$$
\frac{1}{\hat{R}_{t}^{A}\left(z_{t}\right)}=\hat{\beta}\left(z_{t}\right) \frac{\widetilde{\beta}_{t}}{\hat{R}_{t} \widetilde{\beta}_{t+1}}
$$

which can easily be verified from equation (35).

- Proof of Proposition 6.1.

We need to check that Arrow securities positions defined in (38) satisfy the market clearing condition

$$
\int \sum_{y^{t-1}} \varphi\left(y^{t-1} \mid y_{0}\right) \hat{a}_{t-1}\left(\theta_{0}, y^{t-1}, z^{t}\right) d \Theta_{0}=0 \text { for all } z^{t}
$$

for each $z_{t}$. By the goods market clearing condition in the Bewley model we have, since total labor income makes up a fraction $1-\alpha$ of total income

$$
\begin{aligned}
& \int \sum_{y^{t-1}} \varphi\left(y^{t-1} \mid y_{0}\right)\left(\hat{c}_{t}\left(y^{t}, \theta_{0}\right)-(1-\alpha) \eta\left(y_{t}\right)\right) d \Theta_{0} \\
= & \int \sum_{y^{t-1}} \varphi\left(y^{t-1} \mid y_{0}\right) \sum_{y^{t} \mid y^{t-1}} \varphi\left(y^{t} \mid y^{t-1}\right)\left(\hat{c}_{t}\left(y^{t}, \theta_{0}\right)-(1-\alpha) \eta\left(y_{t}\right)\right) d \Theta_{0} \\
= & \sum_{y^{t}} \varphi\left(y^{t} \mid y_{0}\right)\left(\hat{c}_{t}\left(y^{t}, \theta_{0}\right)-(1-\alpha) \eta\left(y_{t}\right)\right) d \Theta_{0}=\alpha
\end{aligned}
$$

Similarly

$$
\int \sum_{y^{t-1}} \varphi\left(y^{t-1} \mid y_{0}\right) \sum_{y^{\tau}} \varphi\left(y^{\tau} \mid y^{t}\right)\left[\hat{c}_{\tau}\left(\theta_{0}, y^{\tau}\right)-(1-\alpha) \eta\left(y_{\tau}\right)\right] d \Theta_{0}=\alpha \text { for all } \tau>t
$$

Since the stock market clears in the Bewley model we have

$$
\int \sum_{y^{t-1}} \varphi\left(y^{t-1} \mid y_{0}\right) \hat{\sigma}_{t-1}\left(\theta_{0}, y^{t-1}\right) d \Theta_{0}=1 .
$$

Since the stock is a claim to $\alpha$ times the aggregate endowment in all future periods its (ex-dividend) price has to satisfy

$$
\hat{v}_{t}\left(z_{t}\right)=\alpha \sum_{\tau=t+1}^{\infty} \sum_{z^{\tau}} \hat{Q}_{\tau}\left(z^{\tau} \mid z_{t}\right)
$$


Combining these results implies that

$$
\begin{aligned}
& \int \sum_{y^{t}} \varphi\left(y^{t} \mid y_{0}\right) \hat{a}_{t-1}\left(\theta_{0}, y^{t-1}, z^{t}\right) d \Theta_{0} \\
= & \alpha+\alpha \sum_{\tau=t+1}^{\infty} \sum_{z^{\tau}} \hat{Q}_{\tau}\left(z^{\tau} \mid z_{t}\right)-1\left(\alpha+\alpha \sum_{\tau=t+1}^{\infty} \sum_{z^{\tau}} \hat{Q}_{\tau}\left(z^{\tau} \mid z_{t}\right)\right)=0
\end{aligned}
$$

for each $z_{t}$. Thus, each of the Arrow securities markets clears if households hold portfolios given by (38).

- Proof of Lemma 6.2.

By (34)

$$
\hat{Q}_{t}\left(z^{t} \mid z_{0}\right)=\hat{\phi}\left(z^{t} \mid z_{0}\right) \tilde{Q}_{t} \frac{\hat{\beta}_{0, t-1}\left(z^{t-1} \mid z_{0}\right)}{\widetilde{\beta}_{t}}
$$

and thus

$$
\begin{aligned}
\sum_{z^{t}} \hat{Q}_{t}\left(z^{t} \mid z_{0}\right) & =\frac{\tilde{Q}_{t}}{\widetilde{\beta}_{t}} \sum_{z^{t} \mid z_{0}} \hat{\phi}\left(z^{t} \mid z_{0}\right) \hat{\beta}_{0, t-1}\left(z^{t-1} \mid z_{0}\right) \\
& =\frac{\tilde{Q}_{t}}{\widetilde{\beta}_{t}} \sum_{z^{t} \mid z^{t-1}} \hat{\phi}\left(z^{t} \mid z^{t-1}\right) \sum_{z^{t-1} \mid z_{0}} \hat{\phi}\left(z^{t-1} \mid z_{0}\right) \hat{\beta}_{0, t-1}\left(z^{t-1} \mid z_{0}\right)=\tilde{Q}_{t}
\end{aligned}
$$

by definition of $\widetilde{\beta}_{t}$ in equation (321) and the fact that $\sum_{z^{t} \mid z^{t-1}} \hat{\phi}\left(z^{t} \mid z^{t-1}\right)=1$.

- Proof of Lemma 6.3.

The Arrow securities position at time zero needed to finance all future excess consumption mandated by the Bewley equilibrium is given by

$$
\begin{aligned}
\hat{a}_{-1}\left(\theta_{0}, y_{0}, z_{0}\right)= & \hat{c}_{0}\left(\theta_{0}, y_{0}\right)-(1-\alpha) \eta\left(y_{0}\right)+\sum_{\tau=1}^{\infty} \sum_{z^{\tau}, y^{\tau}} \hat{Q}_{\tau}\left(z^{\tau} \mid z_{0}\right)\left(\hat{c}_{\tau}\left(\theta_{0}, y^{\tau}\right)-(1-\alpha) \eta\left(y_{\tau}\right)\right) \\
& -\hat{\sigma}_{0}\left(\theta_{0}, y_{0}\right)\left[\hat{v}_{0}\left(z_{0}\right)+\alpha\right],
\end{aligned}
$$

where we substituted indexes -1 by 0 to denote initial conditions. In particular, $\hat{\sigma}_{0}\left(\theta_{0}, y_{0}\right)$ is the 
initial share position of an individual with wealth $\theta_{0}$. But

$$
\begin{aligned}
& \hat{a}_{-1}\left(\theta_{0}, y_{0}, z_{0}\right) . \\
= & \hat{c}_{0}\left(\theta_{0}, y_{0}\right)-(1-\alpha) \eta\left(y_{0}\right)+\sum_{\tau=1}^{\infty} \sum_{z^{\tau}, y^{\tau} \mid z_{0}, y_{0}} \hat{Q}_{\tau}\left(z^{\tau} \mid z_{0}\right) \varphi\left(y^{\tau} \mid y_{0}\right)\left(\hat{c}_{\tau}\left(\theta_{0}, y^{\tau}\right)-(1-\alpha) \eta\left(y_{\tau}\right)\right) \\
- & \hat{\sigma}_{0}\left(\theta_{0}, y_{0}\right)\left[\hat{v}_{0}\left(z_{0}\right)+\alpha\right] . \\
= & \hat{c}_{0}\left(\theta_{0}, y_{0}\right)-(1-\alpha) \eta\left(y_{0}\right)+\sum_{\tau=1}^{\infty} \sum_{y^{\tau} \mid y_{0}} \varphi\left(y^{\tau} \mid y_{0}\right)\left(\hat{c}_{\tau}\left(\theta_{0}, y^{\tau}\right)-(1-\alpha) \eta\left(y_{\tau}\right)\right) \sum_{z^{\tau} \mid z_{0}} \hat{Q}_{\tau}\left(z^{\tau} \mid z_{0}\right) \\
& -\hat{\sigma}_{0}\left(\theta_{0}, y_{0}\right) \alpha\left[1+\sum_{\tau=1}^{\infty} \sum_{z^{\tau} \mid z_{0}} \hat{Q}_{\tau}\left(z^{\tau} \mid z_{0}\right)\right] . \\
= & \hat{c}_{0}\left(\theta_{0}, y_{0}\right)-(1-\alpha) \eta\left(y_{0}\right)+\sum_{\tau=1}^{\infty} \widetilde{Q}_{\tau} \sum_{y^{\tau} \mid y_{0}} \varphi\left(y^{\tau} \mid y_{0}\right)\left(\hat{c}_{\tau}\left(\theta_{0}, y^{\tau}\right)-(1-\alpha) \eta\left(y_{\tau}\right)\right) \\
- & \hat{\sigma}_{0}\left(\theta_{0}, y_{0}\right) \alpha\left[\sum_{\tau=0}^{\infty} \widetilde{Q}_{\tau}\right] \\
= & 0,
\end{aligned}
$$

where the last equality comes from the intertemporal budget constraint in the standard incomplete markets Bewley model and the fact that the initial share position in that model is given by $\hat{\sigma}_{0}\left(\theta_{0}, y_{0}\right)$.

- Proof of Proposition 6.2.

The stationary Bewley allocation $\left\{\hat{a}_{t}^{B}\left(y^{t}\right)=0, \hat{\sigma}_{t}\left(y^{t}\right)\right\}$ satisfies the constraint

$$
\frac{\hat{a}_{t}^{B}\left(y^{t}\right)}{\hat{R}_{t}}+\hat{\sigma}_{t}\left(y^{t}\right) \hat{v}_{t} \geq \hat{K}_{t}\left(y^{t}\right)
$$

Using the fact that $\hat{a}_{t}^{B}\left(y^{t}\right)=0$ and adding

$$
\sum_{z_{t+1}} \hat{q}_{t}\left(z_{t+1} \mid z_{t}\right) \hat{a}_{t}\left(y^{t}, z_{t+1}\right)+\hat{\sigma}_{t}\left(y^{t}\right) \hat{v}_{t}\left(z_{t}\right)
$$

to both sides of (63) yields

$$
\begin{aligned}
& \sum_{z_{t+1}} \hat{q}_{t}\left(z_{t+1} \mid z_{t}\right) \hat{a}_{t}\left(y^{t}, z_{t+1}\right)+\hat{\sigma}_{t}\left(y^{t}\right) \hat{v}_{t}\left(z_{t}\right) \\
\geq & \hat{K}_{t}\left(y^{t}\right)+\sum_{z_{t+1}} \hat{q}_{t}\left(z_{t+1} \mid z_{t}\right) \hat{a}_{t}\left(y^{t}, z_{t+1}\right)+\hat{\sigma}_{t}\left(y^{t}\right)\left[\hat{v}_{t}\left(z_{t}\right)-\hat{v}_{t}\right] \\
\equiv & \hat{K}_{t}^{*}\left(y^{t}, z_{t}\right)
\end{aligned}
$$

where $\hat{K}_{t}^{*}\left(y^{t}\right)$ is the modified constraint for the de-trended Arrow model. Multiplying both sides by $e_{t}\left(z^{t}\right)$ gives the modified constraint for the Arrow model with growth stated in the main text. For the alternative constraint, we know that the Bewley equilibrium allocation satisfies

$$
\hat{a}_{t}^{B}\left(y^{t}\right)+\hat{\sigma}_{t}\left(y^{t}\right)\left[\hat{v}_{t+1}+\alpha\right] \geq \hat{M}_{t}\left(y^{t}\right) .
$$


Again using $\hat{a}_{t}^{B}\left(y^{t}\right)=0$ and adding

$$
\hat{a}_{t}\left(y^{t}, z_{t+1}\right)+\hat{\sigma}_{t}\left(y^{t}\right)\left[\hat{v}_{t+1}\left(z_{t+1}\right)+\alpha\right]
$$

to both sides of (63) yields

$$
\begin{aligned}
& \hat{a}_{t}\left(y^{t}, z_{t+1}\right)+\hat{\sigma}_{t}\left(y^{t}\right)\left[\hat{v}_{t+1}\left(z_{t+1}\right)+\alpha\right] \\
\geq & \hat{M}_{t}\left(y^{t}\right)+\hat{a}_{t}\left(y^{t}, z_{t+1}\right)+\hat{\sigma}_{t}\left(y^{t}\right)\left[\hat{v}_{t+1}\left(z_{t+1}\right)-\hat{v}_{t+1}\right] \\
\equiv & \hat{M}_{t}^{*}\left(y^{t}, z_{t+1}\right)
\end{aligned}
$$

Multiplying both sides by $e_{t+1}\left(z^{t+1}\right)$ again gives rise to the constraint stated in the main text. 